\title{
USO DO MELHOR PREDITOR LINEAR NÃO VIESADO (BLUP) EM ANÁLISES DIALÉLICAS E PREDIÇÃO DE HÍBRIDOS
}

\author{
MARIANA IEMMA
}

Dissertação apresentada à Escola Superior de Agricultura "Luiz de Queiroz", Universidade de São Paulo, para obtenção do título de Mestre em Agronomia, Área de Concentração: Estatística e Experimentação Agronômica.

PIRACICABA

Estado de São Paulo - Brasil

Janeiro - 2003 


\title{
USO DO MELHOR PREDITOR LINEAR NÃO VIESADO (BLUP) EM ANÁLISES DIALÉLICAS E PREDIÇÃO DE HÍBRIDOS
}

\author{
MARIANA IEMMA \\ Bacharel em Estatística
}

Orientador: Prof. Dr. ANTONIO AUGUSTO FRANCO GARCIA

Dissertação apresentada à Escola Superior de Agricultura "Luiz de Queiroz", Universidade de São Paulo, para obtenção do título de Mestre em Agronomia, Área de Concentração: Estatística e Experimentação Agronômica.

PIRACICABA

Estado de São Paulo - Brasil

Janeiro - 2003 


\section{Dados Internacionais de Catalogação na Publicação (CIP)} DIVISÃo DE BIBLIOTECA E DOCUMENTAÇÃO - ESALQ/USP

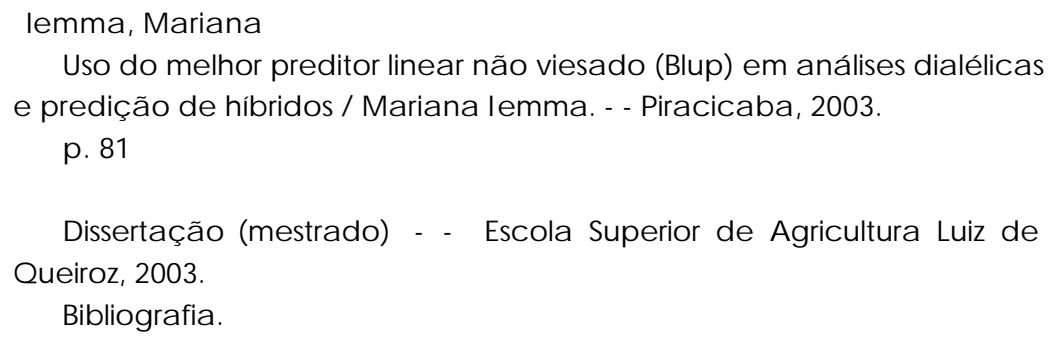

1. Cruza mento dia lélic o 2. Divergência genétic a 3. Genética estatística Linhagem vegetal 5. Milho híbrido 6. Modelos lineares I. Título

CDD 633.15

\section{"Permitida a cópia total ou parcial deste documento, desde que citada a fonte - $\mathrm{O}$ autor"}


Aos meus pais, Antonio e Ana,

às minhas irmãs, Luciana e Juliana

\section{OFEREÇO}

Ao meu marido João Ridinaldo

DEDICO 


\section{AGRADECIMENTOS}

Agradeço primeiramente a Deus pelo privilégio da vida.

Ao Prof. Dr. Antonio Augusto Franco Garcia, pela orientação, colaboração e, principalmente, pela confiança.

Aos Professores Doutores Cláudio Lopes de Souza Jr., Décio Barbin e Roseli Aparecida Leandro, pelas sugestões na elaboração da dissertação.

À Professora Anete Perreira de Souza e ao Professor Cláudio Lopes de Souza Jr., pela gentil cessão dos dados usados no trabalho.

À Luciana Aparecida Carlini Garcia, pela inestimável colaboração.

Ao meu marido João Ridinaldo e à minha irmã Juliana, por tanto apoio e dedicação em todos os momentos deste trabalho.

Aos meus pais, Antonio e Ana, à minha irmã Luciana e aos queridos Laerte e Neusa, pelo carinho e incentivo.

Aos amigos e colegas do curso de pós-graduação em Estatística e Experimentação Agronômica, pelos momentos de amizade e companheirismo.

Aos Professores e Funcionários do Departamento de Ciências Exatas da ESALQUSP, pelo carinho, respeito e amizade.

Aos funcionários da biblioteca da ESALQ, pela ajuda na elaboração da ficha catalográfica de dissertação.

À Escola Superior de Agricultura "Luiz de Queiroz", pela oportunidade de realização do meu mestrado.

À Coordenadoria de Aperfeiçoamento de Pesoal de Nível Superior - CAPES, pela concessão de bolsa de estudos.

A todos que de alguma forma contribuíram para a execução deste trabalho. 


\section{SUMÁRIO}

Página

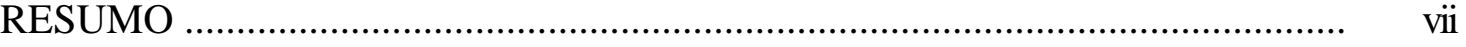

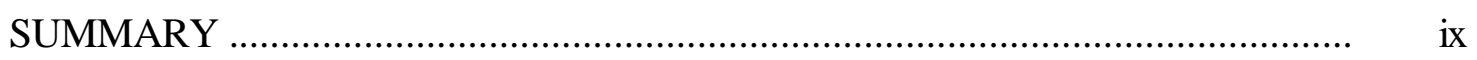

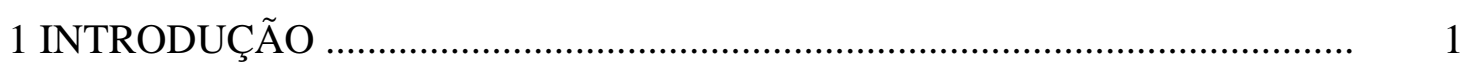

2 REVISÃO DE LITERATURA ...............................................................

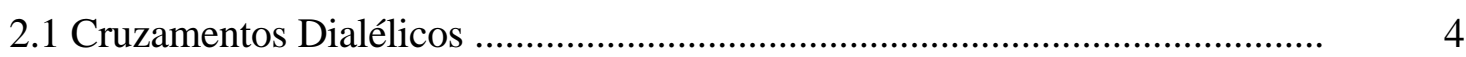

2.1.1 Dialelos Balenceados Completos …........................................................... 5

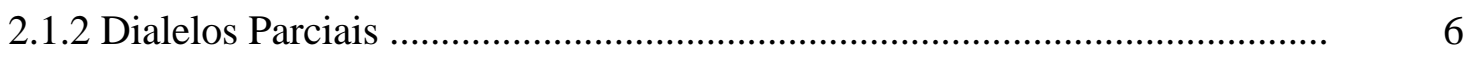

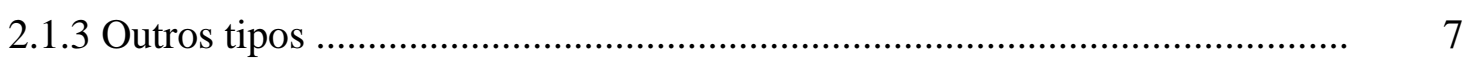

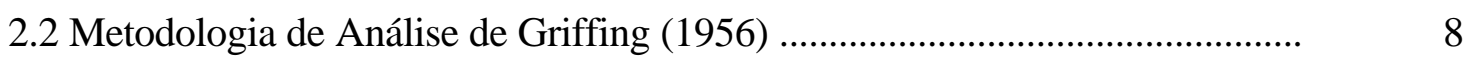

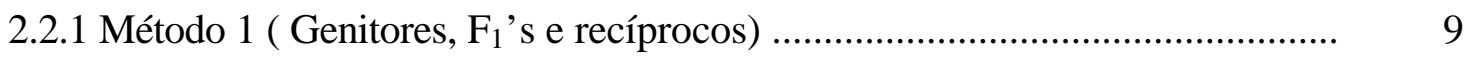

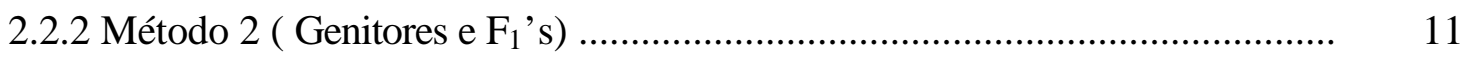

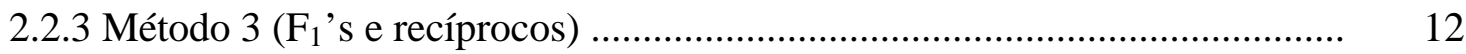

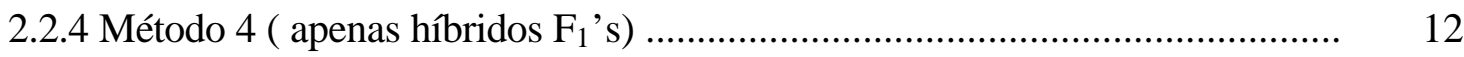

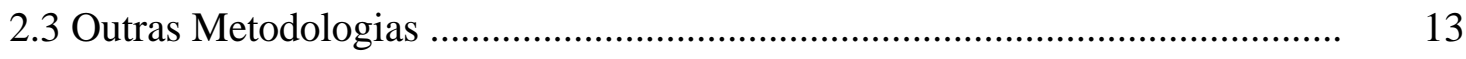

2.4 Análise pela Metodologia de Modelos Mistos ............................................... 13

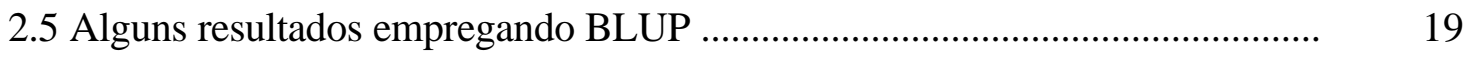

2.6 Marcadores moleculares e matrizes de similaridade genética ............................. 23

3 MATERIAL E MÉTODOS ….................................................................. 25

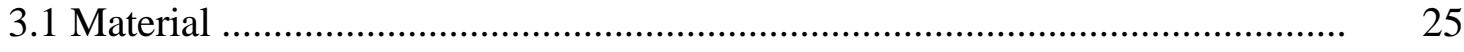

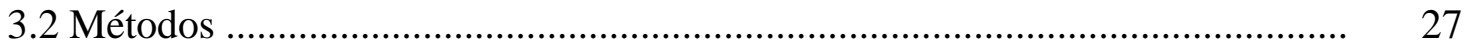

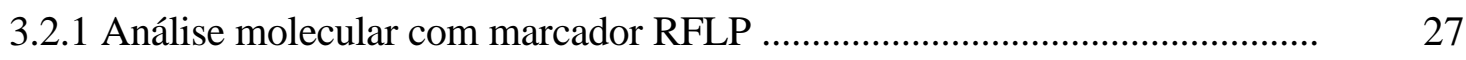

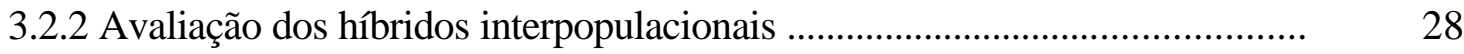


3.2.3 Análise dialélica ......................................................................................

3.2.4 Cálculo do coeficiente de parentesco ........................................................... 32

3.2.5 Construção do dendrograma (UPGMA) …………………………...............

3.2.6 Análise usando metodologia de modelos mistos ............................................. 35

3.2.6.1 Covariância genética entre os híbridos ...................................................... 35

3.2.6.2 Modelo linear misto .............................................................................. 36

3.2.6.3 Equações de modelo misto ..................................................................... 37

3.2.6.4 Estimativas de máxima verossimilhança restrita das variâncias e obtenção dos BLUP's ................................................................................... 38

3.2.7 Cálculo da produção das testemunhas usando o BLUP ....................................

3.2.8 Cálculo da produção dos híbridos usando o BLUP .......................................... 41

3.2.9 Comparações entre análise dialélica usando mínimos quadrados ordinários e metodologia de modelos mistos ........................................................................ 42

3.2.10 Predições de híbridos simples ...................................................................... 42

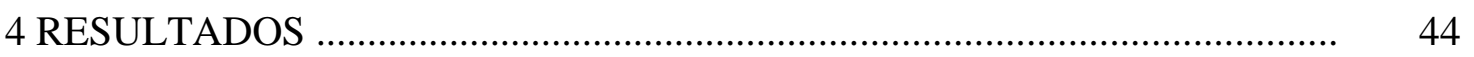

4.1 Avaliação dos híbridos interpopulacionais .....................................................

4.2 Análise dialélica .......................................................................................... 46

4.3 Coeficientes de parentesco .................................................................... 50

4.4 Estimativas das variâncias genéticas e populacionais ....................................... 54

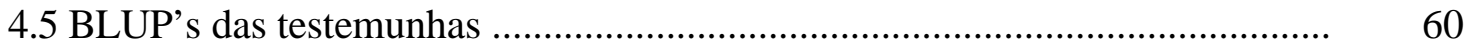

4.6 BLUP's dos efeitos das capacidades de combinação ........................................ 61

4.7 BLUP's das produções dos híbridos interpopulacionais ..................................... 67

4.8 Predição de híbridos não observados .................................................................. 69

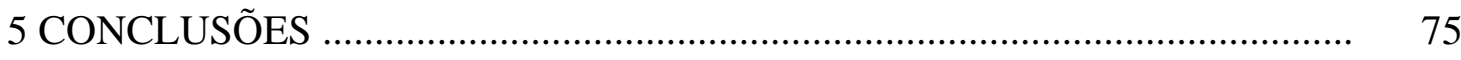

REFERÊNCIAS BIBLIOGRÁFICAS _............................................................... 


\section{USO DO MELHOR PREDITOR LINEAR NÃO VIESADO (BLUP) EM ANÁLISES DIALÉLICAS E PREDIÇÃO DE HÍBRIDOS}

Autora: MARIANA IEMMA

Orientador: Prof. Dr. ANTONIO AUGUSTO FRANCO GARCIA

\section{RESUMO}

A obtenção de híbridos de milho está relacionada com o aumento de produtividade dessa cultura. Para isso, normalmente são realizados cruzamentos entre linhagens de diferentes grupos heteróticos, que são determinados pelos melhoristas de forma que seja maximizada a divergência entre eles. A escolha dos genitores a serem cruzados pode ser facilitada pelo uso de cruzamentos dialélicos. Os modelos usados para a análise dos dialélicos permitem a estimação de parâmetros úteis para a seleção dos genitores e o estabelecimento de grupos heteróticos, sendo que os efeitos genéticos normalmente podem ser considerados como aleatórios. A forma tradicional de análise inclui tais efeitos na matriz de incidência dos efeitos fixos e emprega o método dos mínimos quadrados ordinários, o que impossibilita a análise usando a metodologia dos modelos mistos. Os objetivos deste trabalho foram comparar os resultados das análises dialélicas obtidas considerando o modelo fixo e o modelo misto e avaliar a eficiência do melhor preditor linear não viesado (BLUP) para predição de cruzamentos não realizados entre linhagens de milho, utilizando informações de marcadores moleculares RFLP para 
a estimação da matriz de parentesco. Foram considerados dados de 80 híbridos interpopulacionais e 20 testemunhas comerciais, avaliados em um látice 10 x 10 em três locais. Esses híbridos foram obtidos pelo cruzamento entre 8 linhagens do grupo heterótico BR-105 e 10 do grupo BR-106, as quais foram genotipadas com marcador RFLP. A análise dialélica foi realizada segundo a metodologia que considera o modelo genético como fixo e usa o método dos mínimos quadrados ordinários, e também usando a metodologia de modelos mistos, assumindo que a capacidade geral de combinação (CGC) dos dois grupos heteróticos e a capacidade específica de combinação (CEC) representam efeitos aleatórios. Além disso, foi avaliada a predição de híbridos simples não realizados, com base na matriz de covariâncias genéticas entre o híbrido não realizado e os híbridos preditores, usando as informações do marcador RFLP. Como todos os híbridos foram obtidos, foi simulada a retirada de cada um deles do conjunto, sendo sua performance predita a partir dos 79 restantes. Os resultados mostraram que, na comparação entre as análises dialélicas obtidas com as duas metodologias, embora os valores da CGC das linhagens da população BR-106 e da CEC tenham baixa correlação entre as duas metodologias ( $r=-0,11$ e $r=-0,06$, respectivamente), a classificação dos híbridos mais produtivos sofre poucas alterações $(r=0,99)$ e não causa dificuldades na seleção. A eficiência do BLUP para predição de cruzamentos não realizados entre linhagens de milho, utilizando informações de marcadores moleculares para a estimação da matriz de parentesco, mostrou a existência de moderada correlação entre os valores dos BLUP's da produção de grãos e os valores preditos a partir dos híbridos observados restantes $(\mathrm{r}=0,35)$, o que indica que essa metodologia tem capacidade em predizer a estimativa de valores não observados, porém com alguma imprecisão. Os mesmos resultados foram observados entre as capacidades específicas de combinação observadas e as preditas $(\mathrm{r}=0,30)$. Conclui-se que a metodologia de modelos mistos pode ser usada, desde que com ressalvas, dada as correlações moderadas. 


\section{USE OF BEST LINEAR UNBIASED PREDICTION IN DIALLEL ANALYSIS AND IN PREDICTION OF SINGLE CROSSES}

Author: MARIANA IEMMA

Adviser: Prof. Dr. ANTONIO AUGUSTO FRANCO GARCIA

\section{SUMMARY}

The obtainment of maize single crosses is related with increasing in productivity. To do so, inbred lines derived of different heterotic groups are crossed. These groups are established in such a way that the genetic divergences among them are maximized. Using diallel crosses can facilitate the choice of the inbred lines to be crossed. The models used to perform these analyses allow estimating genetic parameters that are useful in the selection of parental lines and in determining the heterotic groups. In these models, generally, the genetic effects are considered as random. However, these analyses are usually performed considering these effects in the matrix of fixed effects, and obtaining the parameter estimates according to the ordinary least squares method, making impossible using mixed linear models theory. The aims of this research were to compare the results of diallel analyses obtained by using fixed and mixed models, and evaluate the efficiency of the best linear unbiased predictor (BLUP) in predicting nonrealized single crosses. Eighty interpopulation hybrids and twenty commercial checks were evaluated in a $10 \times 10$ lattice design with two replications located in three 
environments. These single crosses were obtained by crossing eight and ten inbred lines from BR-105 and BR-106 heterotic groups, respectively. These eighteen lines were genotyped by using RFLP molecular markers and then the coefficient of parentage among them was estimated. The genetic parameters general (GCA) and specific (SCA) combining abilities were estimated through diallel analyses, considering the linear model as fixed and using the ordinary least squares as the estimation method. Besides, GCA and SCA were predicted using BLUP and assuming the genetic effects as random. Besides, the prediction of non-realized single crosses was evaluated. To do so, each one of the 80 realized hybrids was predicted based on information of the others 79 single crosses and using the genetic variance-covariance matrix estimated using RFLP information. According to the results, it was found poor correlation between estimatives and predictions obtained considering the model as fixed or mixed, for GCA within BR106 population $(\mathrm{r}=-0.11)$ and for SCA $(\mathrm{r}=-0.06)$. However, the ranking of the single crosses for productivity did not change $(\mathrm{r}=0.99)$ and did not make selection process more difficult. The efficiency of BLUP in predicting unrealized single crosses was moderated since the correlation between observed and predicted values was $\mathrm{r}=0.35$, indicating some imprecision in these predictions. Similar results were obtained when comparing observed and predicted SCAs $(\mathrm{r}=0.30)$. It was possible to conclude that BLUP can be useful in diallel analyses and in prediction of single crosses, but some caution have to be account since the correlations presented moderate values. 


\section{INTRODUÇÃO}

A obtenção de híbridos de milho está diretamente relacionada com o aumento de produtividade dessa cultura. Para isso, normalmente são realizados cruzamentos entre linhagens de diferentes grupos heteróticos, que são determinados pelos melhoristas de forma que seja maximizada a divergência entre eles. Os cruzamentos são então realizados somente entre as linhagens de grupos heteróticos distintos. Existem várias maneiras para determinação desses grupos, sendo que as mais comuns baseiam-se em informações das genealogias e, mais recentemente, no uso de marcadores moleculares.

Como dentro de cada grupo tem-se normalmente um número elevado de linhagens (ou genitores), mesmo com essa classificação torna-se economicamente inviável realizar e avaliar todos os possíveis cruzamentos (híbridos). Por exemplo, não haveria recursos financeiros e condições experimentais para testar adequadamente 2500 possíveis cruzamentos entre linhagens de dois grupos heteróticos com 50 linhagens cada. Vale ressaltar que, em stuações reais, este número de grupos e linhagens pode ser bem maior. Dessa forma, percebe-se que a identificação de forma eficiente de pares de linhagens que forneçam combinações híbridas superiores é crucial para o aumento da produção de milho nos programas de melhoramento genético (Bernardo, 1995).

Outro aspecto a ser abordado refere-se à escolha dos genitores a serem cruzados. A realização de cruzamentos dialélicos auxilia nessa escolha, principalmente por considerarem a capacidade de combinação das linhagens quando cruzadas, redundando em uma maior eficiência do programa de seleção (Vencovsky e Barriga,1992). Essa capacidade de combinação é que determina o potencial do cruzamento para a obtenção de híbridos superiores. 
Os modelos matemáticos usados para a análise desses cruzamentos dialélicos permitem a estimação de parâmetros que fornecem subsídios para a seleção dos genitores e o estabelecimento de grupos heteróticos. Em muitos casos, os efeitos genéticos podem ser considerados como aleatórios. No entanto, a forma tradicional de análise, incluem-nos na matriz de incidência dos efeitos fixos e empregam o método dos mínimos quadrados ordinários. Na prática, isso impossibilita a análise usando a medotologia dos modelos mistos (MMM). Assim, torna-se necessário empregar uma abordagem de análise usando as chamadas equações de modelo misto, desenvolvidas por Henderson (1949).

Nesse caso, os efeitos aleatórios são preditos usando o melhor preditor linear não viesado (BLUP), e os efeitos fixos são estimados usando o melhor estimador linear não viesado (BLUE).

Henderson (1974) cita algumas restrições ao emprego dos mínimos quadrados ordinários:

i) impossibilidade de estimar o valor genético de indivíduos não observados;

ii) apenas determinadas combinações lineares dos parâmetros são estimáveis.

O emprego da metodologia dos modelos lineares mistos, obtendo-se os melhores preditores lineares não viesados, é um método adequado para predição de valores genéticos, podendo inclusive ser utilizado para predição de cruzamentos não realizados (André, 1999; Bernardo, 1994, 1995, 1996a, 1996b, 1996c). No contexto de obtenção de híbridos de milho, pode ser mais uma ferramenta à disposição dos melhoristas, permitindo predizer os melhores cruzamentos antes mesmo de sua realização. Assim, seriam testados somente os cruzamentos mais promissores.

Henderson (1986) afirma que a principal restrição ao uso dessa metodologia é a grande demanda de recursos computacionais. Atualmente, com os avanços tecnológicos, isso deixa de ser um grande problema. Seu emprego, consiste basicamente em considerar os valores genéticos como sendo de efeito aleatório, corrigindo-os para os demais efeitos fixos contidos no modelo, sendo também apropriada para graus elevados de desbalanceamento. Isso permite, conforme já descrito, a obtenção do melhor preditor linear não viesado ("Best Linear Unbiased Predictor", BLUP) dos valores genéticos de 
cada indivíduo, além do melhor estimador linear não viesado ("Best Linear Unbiased Estimator”, BLUE) dos efeitos fixos (Henderson, 1974, 1975a).

A utilização do melhor preditor linear não viesado (BLUP) para predição de cruzamentos não realizados em milho tem mostrado eficiência considerável, conforme relatado por Bernardo em diversos artigos (1994, 1995, 1996a, 1996b). Contudo, a habilidade do melhor preditor linear não viesado (BLUP) para predizer os cruzamentos não realizados, de forma eficiente, depende do conhecimento do grau de parentesco dos genitores (Bernardo, 1995).

Recentemente, a determinação do grau de parentesco (ou divergência genética) entre possíveis genitores tem sido facilitada com o surgimento dos chamados marcadores moleculares. Diversos trabalhos, como por exemplo, os de Lanza et al. (1997) e Benchimol et al. (2000), mostram que esse parentesco pode ser determinado de forma eficiente. Esses marcadores provêm de técnicas que permitem identificaçõos de semelhanças diretamente no material genético (DNA) dos indivíduos, sendo disponíveis em número virtualmente ilimitado (Ferreira e Grattapaglia, 1996).

Nesse contexto, os objetivos deste trabalho foram: i) comparar os resultados das análises dialélicas obtidas considerando o modelo fixo e o modelo misto; ii) avaliar a eficiência do melhor preditor linear não viesado (BLUP) para predição de cruzamentos não realizados entre linhagens de milho, utilizando informações de marcadores moleculares para a estimação da matriz de parentesco. 


\section{REVISÃO DE LITERATURA}

\subsection{Cruzamentos Dialélicos}

Segundo Cruz e Regazzi (1994), o termo dialelo tem sido utilizado para expressar um conjunto de $p(p-1) / 2$ híbridos, resultante do acasalamento entre $p$ genitores (linhagens, variedades, clones etc.), podendo incluir, além dos respectivos pais, os híbridos recíprocos (usando o genitor macho como fêmea e vice-versa), outras gerações relacionadas, tais como $\mathrm{F}_{2}$ 's (segunda geração após o cruzamento inicial), retrocruzamentos (cruzamento de um indivíduo e seus genitores) etc. Esses cruzamentos podem ser realizados de diferentes maneiras, e são analisados, geralmente, empregando a teoria de modelos lineares fixos.

A análise dialélica tem por finalidade analisar o delineamento genético, provendo estimativas de parâmetros úteis na seleção de genitores para hibridação e no entendimento dos efeitos genéticos envolvidos na determinação dos caracteres quantitativos. Permitem, portanto, analisar o potencial genético dos genitores e dos cruzamentos.

Em muitas pesquisas de melhoramento genético, deseja-se conhecer a expressão média de um caráter (Vencovsky e Barriga, 1992). O valor médio pode ser específico de um dado genótipo ou, então, de uma população de genótipos. Em qualquer uma dessas situações, tratando-se de um caráter quantitativo, dispõe-se sempre de observações fenotípicas. Porém, ao reproduzir um genótipo por um grande número de indivíduos num dado ambiente, a média fenotípica aproximar-se-á do valor genotípico. Esse conceito é válido também para populações, pois se for avaliado um cultivar numa 
gama ampla de repetições, a média geral resultante refletirá, com segurança suficiente, o potencial genotípico desse cultivar (Vencovsky e Barriga, 1992).

Com base nesses conceitos, percebe-se que a definição de valor genotípico implica no uso de um número infinito de ambientes, o que evidentemente não é possível em situações práticas. Nota-se ainda que tais efeitos genéticos serão aleatórios em sua natureza. Henderson (1984) afirma que considerar os efeitos como fixos ou aleatórios depende dos objetivos do trabalho.

As metodologias de análise dialélica permitem estimar os efeitos genéticos, sendo que dentre as mais comumente utilizadas citam-se a proposta por Griffing (1956), pela qual são estimados os efeitos e as somas de quadrados dos efeitos da capacidade geral e específica de combinação; a metodologia proposta por Gardner e Eberhart (1966), na qual são avaliados os efeitos de variedades e heterose varietal; a proposta por Hayman (1954), que dá informações sobre o mecanismo básico de herança do caráter em estudo, dos valores genéticos dos genitores tilizados e do limite de seleção. Os tipos mais comuns de dialelos, quanto aos cruzamentos realizados, são apresentados a seguir. Detalhes podem ser encontrados em Vencovsky e Barriga (1992) e Cruz e Regazzi (1994).

\subsubsection{Dialelos Balanceados Completos}

São os dialelos que incluem os híbridos $\mathrm{F}_{1}$ 's (primeira geração após o cruzamento) entre todos os pares de combinações dos genitores, podendo adicionalmente incluir os genitores, seus híbridos recíprocos e, algumas vezes, outras gerações relacionadas, como $\mathrm{F}_{2}$ 's, retrocruzamentos etc. Uma ilustração de dialelos balanceados é apresentada na Tabela 1 . 
Tabela 1. Esquema representativo de dialelos balanceados completos envolvendo I genitores.

\begin{tabular}{|c|c|c|c|c|c|}
\hline \multirow[b]{2}{*}{ Genitores } & & & $i$ & & \\
\hline & 1 & 2 & 3 & $\ldots$ & $I$ \\
\hline \multirow{5}{*}{$j$} & $y_{11}^{a}$ & $y_{12}$ & $y_{13}$ & $\cdots$ & $y_{1 I}$ \\
\hline & $y_{21}$ & $y_{22}$ & $y_{23}$ & $\cdots$ & $y_{21}$ \\
\hline & $y_{31}$ & $y_{32}$ & $y_{33}$ & $\cdots$ & $y_{3 I}$ \\
\hline & $\vdots$ & $\vdots$ & $\vdots$ & $\ddots$ & $\vdots$ \\
\hline & $y_{I 1}$ & $y_{I 2}$ & $y_{13}$ & $\ldots$ & $y_{I I}$ \\
\hline
\end{tabular}

a) $y_{i j}$ : híbrido resultante do cruzamento entre os parentais $i$ e $j$.

Este esquema pode ser descrito, de forma geral, através de uma matriz quadrada de dimensão $i$, em que a diagonal principal, a matriz triangular superior, a matriz triangular inferior, representam, respectivamente, os genitores, os híbridos $\mathrm{F}_{1}$ 's e os cruzamentos recíprocos.

\subsubsection{Dialelos Parciais}

Este tipo envolve dois grupos diferentes de genitores e seus respectivos cruzamentos (Tabela 2). Sendo uma adaptação dos esquemas de Griffing (1956) e de Gardner e Eberhart (1966), tem possibilitado maximizar as informações sobre os grupos estudados com um número menor de cruzamentos do que o requerido no dialelo balanceado completo. 
Tabela 2. Esquema representativo de dialelos parciais entre dois grupos heteróticos $(i$ e $j$ ), com $I$ e $J$ genitores cada.

\begin{tabular}{ccccccc}
\hline & & & \multicolumn{3}{c}{ Grupo $j$} \\
\\
Genitores & 1 & 2 & 3 & $\ldots$ & $J$ \\
\hline \multirow{2}{*}{ Grupo $i$} & 1 & $y_{11}{ }^{\mathrm{a}}$ & $y_{12}$ & $y_{13}$ & $\ldots$ & $y_{i J}$ \\
& 2 & $y_{21}$ & $y_{22}$ & $y_{23}$ & $\ldots$ & $y_{2 J}$ \\
& 3 & $y_{31}$ & $y_{32}$ & $y_{33}$ & $\ldots$ & $y_{3 J}$ \\
& $\vdots$ & $\vdots$ & $\vdots$ & $\vdots$ & $\ddots$ & $\vdots$ \\
& $I$ & $y_{I 1}$ & $y_{I 2}$ & $y_{I 3}$ & $\ldots$ & $y_{I J}$
\end{tabular}

a) $y_{i j}$ : híbrido resultante do cruzamento entre os genitores $i$ e $j$ de dois grupos heteróticos distintos.

\subsubsection{Outros tipos}

a) Dialelos Circulantes

Nestes dialelos, os genitores são representados por um mesmo número de cruzamentos, porém sempre inferior a $p-1$, que ocorre nos dialelos balanceados. Em outras palavras, apenas parte dos cruzamentos possíveis de serem realizados com cada genitor são efetivamente obtidos. Permitem obter informações sobre os genitores com um número menor de cruzamentos, mas no entanto há perda de informações a respeito de certas combinações híbridas, que ficam ausentes.

b) Dialelos Incompletos

São dialelos em que os genitores são representados por um número variável de cruzamentos. Em geral, este tipo de delineamento ocorre como consequiência de perdas de tratamentos durante a condução dos ensaios ou ausência dos mesmos por problemas diversos, tais como insuficiência de sementes, incompatibilidade de cruzamentos etc.

c) Dialelos Desbalanceados 
São dialelos em que todas as combinações híbridas e também as demais gerações (genitores, recíprocos etc.) estão representadas, porém em freqüência variável, em virtude do número desigual de repetições por tratamento nos experimentos de avaliação dos cruzamentos.

\subsection{Metodologia de Análise de Griffing (1956)}

Vencovsky e Barriga (1992) e Cruz e Regazzi (1994), citam esta metodologia como uma das mais utilizadas em análise dialélica. Como ela foi utilizada no presente trabalho, terá seus modelos apresentados detalhadamente.

No esquema dialélico, os $p$ possíveis genitores podem ser reunidos em uma matriz $(p \times p)$ e divididos em três grupos: $p$ genitores; $p(p-1) / 2$ híbridos $\mathrm{F}_{1}$ 's; $p(p-1) / 2$ híbridos $\mathrm{F}_{1}$ 's recíprocos. De acordo com a inclusão, ou não, dos genitores e híbridos $\mathrm{F}_{1}$ 's recíprocos, esta metodologia pode ser classificada em quatro métodos de análise, a saber (Griffing, 1956):

a) Método 1: são incluídas todas as $p^{2}$ combinações;

b) Método 2: são incluídas $p(p+1) / 2$ combinações, excetuando os híbridos $\mathrm{F}_{1}$ 's recíprocos;

c) Método 3: são incluídas $p(p-1)$ combinações, excetuando os genitores;

d) Método 4: são incluídas $p(p-1) / 2$ combinações, excetuando os genitores e os híbridos $\mathrm{F}_{1}$ 's recíprocos.

Cada um destes métodos possui um modelo matemático específico para a análise. Tal modelo pode então ser analisado como fixo, aleatório ou misto, dependendo da natureza amostral dos genitores e dos objetivos do trabalho. Usualmente, os modelos são analisados como fixos, por simplificar a análise. Atualmente, contudo, em função da disponibilidade de recursos computacionais, é possível o emprego de metodologias mais sofisticadas, que permitem ainda incorporar informações de marcadores moleculares.

A seguir são apresentadas considerações teóricas e aplicações das várias metodologias descritas para análise da forma convencional, segundo Griffing (1956). 
Vale ressaltar que, inicialmente, os genótipos que compõem o dialelo são avaliados em experimentos, com repetições, seguindo delineamento experimental adequado, sendo os blocos incompletos os mais comuns. Realiza-se uma análise de variância da forma usual, e, então, efetua-se a análise dialélica, que basicamente consiste em decompor a soma de quadrados de tratamentos em somas de quadrados de interesse.

\subsubsection{Método 1 (Genitores, $\mathrm{F}_{1}$ 's e recíprocos)}

Considerando-se as médias das combinações genotípicas estimadas nos experimentos, tem-se o seguinte modelo matemático:

$$
y_{i j}=m+g_{i}+g_{j}+s_{i j}+r_{i j}+\bar{\varepsilon}_{i j} \text {, em que: }
$$

$y_{i j}$ : valor médio da combinação híbrida $(i \neq j)$ ou do progenitor $(i=j)$;

$m$ : constante;

$g_{i}, g_{j}$ : efeitos da capacidade geral de combinação do $i$-ésimo ou $j$-ésimo progenitor $(i, j=1,2, \ldots p)$;

$s_{i j}$ : efeito da capacidade específica de combinação para os cruzamentos entre os genitores de ordem $i$ e $j$;

$r_{i j}$ : efeito do recíproco, que mede as diferenças proporcionadas pelo progenitor $i$, ou $j$, quando utilizado como macho ou fêmea no cruzamento $i j$;

$\overline{\varepsilon_{i j}}$ : erro experimental médio associado à observação de ordem $i j$, estimado no experimento inicial de avaliação.

Neste modelo são considerados: $s_{i j}=s_{j i}, r_{i j}=-r_{j i}$ e $r_{i i}=0$.

Na forma matricial, tem-se:

$$
y=X \beta+\varepsilon, \text { em que }
$$

$n y_{1}$ : vetor dos valores observados;

${ }_{n} X_{p+1}$ : matriz de incidência dos efeitos genéticos (conhecida); 
${ }_{p+1} \beta_{1}$ : vetor dos efeitos da constante, das capacidades geral e específica de combinação, e dos efeitos dos recíprocos (desconhecido);

${ }_{n} \varepsilon_{1}$ : vetor do erro experimental associado aos elementos de $y$.

A estimação dos efeitos e das somas de quadrados dos efeitos é obtida a partir do modelo linear dado em (1), sendo que a matriz $X$ não é de posto coluna completo. Assim, as soluções do sistema de equações normais, são dadas por $\beta^{0}=\left(X^{\prime} X\right)^{G} X^{\prime} Y$, em que $\left(X^{\prime} X\right)^{G}$ é alguma inversa generalizada de $X X$, e variam conforme a escolha da inversa generalizada.

Na prática, para permitir a obtenção de solução única para as equações normais, bem como para tornar estimáveis individualmente os parâmetros de $\beta$, opta-se por completar o posto coluna de $X$, normalmente com acréscimo de linhas linearmente independentes, oriundas de funções paramétricas não-estimáveis. Em outros termos, o problema tem sido contornado obtendo-se soluções únicas do sistema por meio de cortes no espaço de soluções pela imposição de restrições convenientes. No contexto da genética e do melhoramento, as restrições, além de proporcionarem simplificação na análise, proporcionam estimadores cujo significado biológico tem sido de grande interesse, uma vez que há interesse em estimativas individuais dos efeitos genéticos, principalmente para fins de seleção. Ressalta-se o fato de as restrições nas soluções não interferirem no modelo.

Um outro atrativo para imposição de restrições, nos parâmetros ou nas soluções, é o fato de que a solução do sistema restrito ser também solução do sistema irrestrito. Assim, no sistema restrito, funções importantes como $g_{i}-g_{j}, s_{i j}-s_{j i}$, dentre outras, serão estimáveis, estando, portanto, à disposição do geneticista para a sua tarefa de identificação de genitores e híbridos superiores. Porém, os efeitos $g_{i}, s_{i j}$, etc, são agora estimáveis (sob a restrição empregada), o que é uma grande vantagem.

Usualmente, adotam-se restrições do tipo soma zero, ou seja, expressando cada efeito como um desvio em relação à média. As somas de quadrados para cada efeito do modelo, nessa situação ficam: 


$$
\begin{gathered}
S Q_{m}=R(m)=\hat{m} y_{. .}=\frac{y_{. .}^{2}}{p^{2}} \\
S Q_{g}=R(g \mid m)=\sum_{i} \hat{g}_{i}\left(y_{i .}+y_{. i}\right)=\frac{1}{2 p} \sum\left(y_{i .}+y_{. i}\right)^{2}-\frac{2}{p^{2}} y_{. .}^{2} \\
S Q_{s}=R(s \mid g, m)=\sum_{i<j} \hat{s}_{i j}\left(y_{i j}+y_{j i}\right)+\sum_{i} \hat{s}_{i i} y_{i i} \\
S Q_{r}=R(r \mid s, g, m)=\sum_{i<j} \hat{r}_{i j}\left(y_{i j}-y_{j i}\right)=\frac{1}{2} \sum_{i<j}\left(y_{i j}-y_{j i}\right)^{2}
\end{gathered}
$$

cujos significados de $g, s$ e $r$ são os mesmos que os já apresentados, exceto que $m$ é agora a média geral. No caso, $R(m), R(g \mid m), R(s \mid g, m)$ e $R(r \mid s, g, m)$ representam a redução na soma de quadrados do resíduo corrigido para $\mathrm{m}$; redução na soma de quadrados do resíduo após o ajuste do modelo para $g$, corrigido para $m$; redução na soma de quadrados do resíduo após o ajuste do modelo para $s$, corrigido para $g$ e $m$; redução na soma de quadrados do resíduo após o ajuste do modelo para $r$, corrigido para $s, g$, e $m$.

\subsubsection{Método 2 (Genitores e $\mathrm{F}_{1}$ ’s)}

Nesse caso, o modelo matemático é dado por:

$$
y_{i j}=m+g_{i}+g_{j}+s_{i j}+\bar{\varepsilon}_{i j} \text {, em que: }
$$

$y_{i j}$ : valor médio da combinação híbrida $(i \neq j)$ ou do progenitor $(i=j)$;

$m:$ constante;

$g_{i}, g_{j}$ : efeitos da capacidade geral de combinação do $i$-ésimo ou $j$-ésimo progenitor, respectivamente;

$s_{i j}$ : efeito da capacidade específica de combinação para os cruzamentos entre os genitores $i$ e $j$; 
$\overline{\varepsilon_{i j}}$ : erro experimental médio.

Neste modelo, considera-se $s_{i j}=s_{j i}$

De forma análoga ao que foi apresentado para o método 1, podem ser obtidos graus de liberdade, somas de quadrados e quadrados médios, usualmente após a imposição de restrições nas soluções ou nos parâmetros. Nota-se que o modelo agora não inclui $r_{i j}$.

\subsubsection{Método 3 ( $F_{1}$ 's e recíprocos)}

Nesse caso o modelo matemático é :

$$
y_{i j}=m+g_{i}+g_{j}+s_{i j}+r_{i j}+\overline{\boldsymbol{\varepsilon}}_{i j} \text {, em que: }
$$

$y_{i j}:$ valor médio dos híbridos $\mathrm{F}_{1}$ 's e recíprocos $(i, j=1,2, \ldots p)$;

$m:$ constante;

$g_{i}, g_{j}$ : efeitos da capacidade geral de combinação do $i$-ésimo ou $j$-ésimo progenitor, respectivamente;

$s_{i j}$ : efeito da capacidade específica de combinação para os cruzamentos entre os genitores de ordem $i$ e $j$;

$r_{i j}$ : efeito recíproco que mede as diferenças proporcionadas pelo progenitor $i$, ou $j$, quando utilizado como macho ou fêmea no cruzamento $i j$;

$\overline{\varepsilon_{i j}}$ : erro experimental médio.

Neste modelo, considera-se: $\quad s_{i j}=s_{j i}, r_{i j}=-r_{i j}$.

\subsubsection{Método 4 (apenas híbridos $\mathrm{F}_{1}$ ’s)}

O modelo matemático é dado por:

$$
y_{i j}=m+g_{i}+g_{j}+s_{i j}+\overline{\boldsymbol{\varepsilon}}_{i j} \text {, em que: }
$$


$y_{i j}:$ valor médio do híbrido $i j \quad(i, j=1,2, \ldots p, i<j)$;

$m:$ constante;

$g_{i}, g_{j}$ : efeitos da capacidade geral de combinação do $i$-ésimo ou $j$-ésimo progenitor, respectivamente;

$s_{i j}$ : efeito da capacidade específica de combinação para os cruzamentos entre os genitores de ordem $i$ e $j$;

$\overline{\varepsilon_{i j}}$ : erro experimental médio.

Considera-se $s_{i j}=s_{j i}$.

\subsection{Outras Metodologias}

A metodologia de análise dialélica desenvolvida por Gardner e Eberhart (1966) consiste em incluir, no mínimo, $p$ populações (ou variedades) e os $p(p-1) / 2$ híbridos $F_{1}$ 's. Ela se aplica a dialelos em que os genitores estão em equilíbrio de HardyWeinberg, e se caracteriza por prover informações detalhadas a respeito do potencial "per se" desses genitores e da heterose manifestada em seus híbridos.

Hayman (1954) propôs, ao contrário das metodologias citadas anteriormente, uma forma de análise que não se baseia em modelos matemáticos previamente estabelecidos, mas no conhecimento da natureza ambiental e genética de estatísticas, tais como médias, variâncias e covariâncias, obtidas a partir de uma tabela dialélica. Em função das pressuposições que assume, tem aplicação restrita.

\subsection{Análise pela Metodologia de Modelos Mistos}

Esta metodologia, proposta inicialmente por Henderson (1949), consiste na obtenção de predições dos valores genéticos, tratados como sendo de efeito aleatório, corrigidos para os demais efeitos fixos contidos no modelo. Foi denominada Metodologia dos Modelos Mistos (MMM), sendo que através dela pode-se obter o melhor preditor linear não viesado (BLUP) dos valores genéticos de cada indivíduo, 
além do melhor estimador linear não viesado (BLUE) dos efeitos fixos (Henderson, 1974, 1975a).

A forma usual de análise dialélica admite que os valores genéticos são fixos, o que pode induzir a distorções nas avaliações e influir na obtenção de estimativas dos valores genéticos (Henderson, 1974, 1975a e 1984). Martins (1995) e André (1999) argumentam que, se considerarmos a segregação alélica, em que cada genótipo é um veículo de alelos que segregam e se unem para formar novos genótipos, temos que os indivíduos tirados de cada cruzamento representam uma amostra dos possíveis descendentes. No caso de linhagens endogâmicas, isso não é verdadeiro, uma vez que elas não produzem gametas com alelos segregantes. No entanto, caso seja possível assumir que os efeitos genéticos são aleatórios, a metodologia dos modelos mistos poderia ser empregada com vantagens.

A seguir serão apresentadas algumas discussões teóricas a respeito da Metodologia de Modelos Mistos, de acordo com Henderson (1974, 1975a, 1984, 1986, 1959).

Um modelo misto pode ser expresso matricialmente da seguinte forma:

$$
y=X \beta+Z g+\varepsilon \text {,em que: }
$$

$y$ : vetor de observações;

$X$ : matriz de incidência dos efeitos fixos;

$Z$ : matriz de incidência dos efeitos genéticos, tomados como aleatórios;

$\beta$ : vetor de efeitos fixos a serem estimados;

$g:$ vetor de efeitos aleatórios a serem preditos;

$\varepsilon$ : vetor de erros aleatórios, associados a cada observação tal que $e \sim N\left(0, \sigma^{2}\right)$.

As dimensões dessas matrizes e vetores dependem do delineamento experimental empregado e do tipo de dialelo realizado.

Henderson et al. (1959) apresentam uma forma para a obtenção do melhor preditor linear não viesado (BLUP) dos efeitos aleatórios desse modelo misto, através da maximização da função densidade de probabilidade conjunta de $y$ e $g$, em relação aos efeitos fixos e valores genéticos. 
Tomando o modelo (2), assume-se que:

0 : vetor nulo;

$$
\left[\begin{array}{l}
y \\
g \\
\varepsilon
\end{array}\right] \sim N\left(\left[\begin{array}{c}
X \beta \\
0 \\
0
\end{array}\right],\left[\begin{array}{crc}
Z G Z^{\prime}+R & Z G & R \\
G Z^{\prime} & G & \phi \\
R & \phi & R
\end{array}\right]\right) ; \text { em que }
$$

$\phi$ : matriz nula;

$G=A \sigma_{g}^{2}$, em que $A$ é a matriz que indica o grau de associação genética entre os indivíduos (matriz de parentesco genético), cujo significado será detalhado oportunamente, $\sigma_{g}^{2}$ : variância genética;

$R$ : matriz de variâncias e covariâncias dos resíduos.

A obtenção das Equações de Modelos Mistos também pode ser feita pela minimização do quadrado médio do erro, além da já mencionada maximização da função densidade de probabilidade conjunta de $y$ e $g$ (Martins et al., 1995). A segunda forma, aqui apresentada, considera que a distribuição seja normal.

A função densidade de probabilidade conjunta de $y$ e $g$ pode ser escrita como o produto entre a função densidade condicional de $y$, dado $g$, e a função densidade de probabilidade de $g$ :

$f(y, g)=\frac{1}{(2 \pi)^{n / 2}|R|^{1 / 2}} \exp \left\{-\frac{1}{2}\left[(y-X \beta-Z g)^{\prime} R^{-1}(y-X \beta-Z g)\right]\right\} \frac{1}{(2 \pi)^{n / 2}|G|^{1 / 2}} \exp \left\{-\frac{1}{2}\left[(g-0)^{\prime} G^{-1}(g-0)\right]\right\}$

Para se proceder à maximização de $f(y, g)$, pode-se usar o artifício da transformação por logaritmo. Isso é possível, visto que, sendo $f(y, g)$ e $\log [f(y, g)]$ funções contínuas e crescentes no espaço $I R^{+}$, seus pontos de máximo são coincidentes dentro do espaço $\left[\begin{array}{ll}\beta^{\prime} & g^{\prime}\end{array}\right]$ e $Z G Z^{\prime}+R$. Assim, fazendo-se $L=\log [f(y, g)]$,tem-se: 


$$
\begin{aligned}
L= & \frac{1}{2} 2 n \log (2 \pi)-\frac{1}{2}(\log |R|+\log |G|)-\frac{1}{2}\left(y^{\prime} R^{-1} y-2 y^{\prime} R^{-1} X \beta-2 y^{\prime} R^{-1} Z g\right)+ \\
& +2 \beta^{\prime} X^{\prime} R^{-1} Z g+\beta^{\prime} X^{\prime} R^{-1} X \beta+g^{\prime} Z^{\prime} R^{-1} Z g+g^{\prime} G^{-1} g .
\end{aligned}
$$

Derivando-se $L$ em relação a $\beta$ e $g$, tem-se:

$$
\left[\begin{array}{l}
\frac{\partial L}{\partial \beta} \\
\frac{\partial L}{\partial g}
\end{array}\right]=\left[\begin{array}{c}
-X^{\prime} R^{-1} y+X^{\prime} R^{-1} X \beta+X^{\prime} R^{-1} Z g \\
-Z^{\prime} R^{-1} y+Z^{\prime} R^{-1} X \beta+Z^{\prime} R^{-1} Z g+G^{-1} g
\end{array}\right]
$$

Tomando-se tais derivadas identicamente nulas, obtém-se:

$$
\left[\begin{array}{c}
X^{\prime} R^{-1} X \beta^{0}+X^{\prime} R^{-1} Z \hat{g} \\
Z^{\prime} R^{-1} X \beta^{0}+Z^{\prime} R^{-1} Z \hat{g}+G^{-1} \hat{g}
\end{array}\right]=\left[\begin{array}{c}
X^{\prime} R^{-1} y \\
Z^{\prime} R^{-1} y
\end{array}\right]
$$

Dessa forma, a solução conjunta para os efeitos fixos e aleatórios, segundo Henderson (1984), é dada a partir do seguinte sistema de equações:

$$
\left[\begin{array}{cc}
X^{\prime} R^{-1} X & X^{\prime} R^{-1} Z \\
Z^{\prime} R^{-1} X & Z^{\prime} R^{-1} Z+G^{-1}
\end{array}\right]\left[\begin{array}{c}
\beta^{0} \\
\hat{g}
\end{array}\right]=\left[\begin{array}{c}
X^{\prime} R^{-1} y \\
Z^{\prime} R^{-1} y
\end{array}\right]
$$

Essas são as chamadas Equações de Modelos Mistos (EMM), que permitem obter o melhor estimador linear não viesado (BLUE) para os efeitos fixos $\left(\beta^{0}\right)$, bem como o melhor preditor linear não viesado (BLUP) para os efeitos aleatórios $(\hat{g})$. A solução do sistema será:

$$
\begin{gathered}
\beta^{0}=\left\{X^{\prime}\left[R^{-1}-R^{-1} Z\left(Z^{\prime} R^{-1} Z+G^{-1}\right)^{-1} Z^{\prime} R^{-1}\right] X\right\}^{G} \\
X^{\prime}\left[R^{-1}-R^{-1} Z\left(Z^{\prime} R^{-1} Z+G^{-1}\right)^{-1} Z^{\prime} R^{-1}\right] y \\
\hat{g}=\left(Z^{\prime} R^{-1} Z+G^{-1}\right)^{G} Z^{\prime} R^{-1}\left(y-X \beta^{0}\right)
\end{gathered}
$$

admitindo que $R$ e $G$ são não singulares.

Matricialmente, isso equivale a 


$$
\left[\begin{array}{c}
\beta^{0} \\
\hat{g}
\end{array}\right]=\left[\begin{array}{cc}
X^{\prime} R^{-1} X & X^{\prime} R^{-1} Z \\
Z^{\prime} R^{-1} X & Z^{\prime} R^{-1} Z+G^{-1}
\end{array}\right]^{G}\left[\begin{array}{c}
X^{\prime} R^{-1} y \\
Z^{\prime} R^{-1} y
\end{array}\right],
$$

em que $G$ representa qualquer inversa generalizada.

Algumas considerações podem ser feitas (Lopes et al.,1993):

a) $\beta^{0}$ é também solução de mínimos quadrados generalizados, pois:

$$
\begin{gathered}
\beta^{0}=\left(X^{\prime} V^{-1} X\right)^{G} X^{\prime} V^{-1} y, \text { em que: } \\
V^{-1}=R^{-1}-R^{-1} Z\left(Z^{\prime} R^{-1} Z+G^{-1}\right)^{-1} Z^{\prime} R^{-1}
\end{gathered}
$$

b) A variância de $\beta^{0}$ é :

$$
\operatorname{Var}\left(\beta^{0}\right)=\left[X^{\prime} R^{-1} X-X^{\prime} R^{-1} Z\left(Z^{\prime} R^{-1} Z+G^{-1}\right)^{-1} Z^{\prime} R^{-1} X\right]^{G}
$$

c) A variância de $\hat{g}$ é:

$$
\begin{aligned}
\operatorname{Var}(\hat{g})= & G Z^{\prime}\left\{R^{-1}-R^{-1} Z\left(Z^{\prime} R^{-1} Z+G^{-1}\right)^{-1} Z^{\prime} R^{-1}-\right. \\
& -\left[R^{-1}-R^{-1} Z\left(Z^{\prime} R^{-1} Z+G^{-1}\right)^{-1} Z^{\prime} R^{-1}\right] \\
& X\left\{X^{\prime}\left[R^{-1}-R^{-1} Z\left(Z^{\prime} R^{-1} Z+G^{-1}\right)^{-1} Z^{\prime} R^{-1}\right] X\right\}^{G} X^{\prime} \\
& {\left.\left[R^{-1}-R^{-1} Z\left(Z^{\prime} R^{-1} Z+G^{-1}\right)^{-1} Z^{\prime} R^{-1}\right]\right\} Z G^{\prime} . }
\end{aligned}
$$

Martins (1995) discute que essa forma de obtenção de $\beta^{0}$ e $\hat{g}$, de forma independente e sem considerar a notação matricial, reduz o esforço computacional reduzindo a dimensão das matrizes a serem invertidas, uma vez que as matrizes que necessitam inversão são de menor dimensão. Além disso, usualmente $R$ é matriz bloco diagonal, e muitas vezes tem estrutura do tipo $I \sigma^{2}$, o que simplifica a inversão.

As propriedades do melhor preditor linear não viesado (BLUP) foram descritas por Henderson (1984), e evidenciam a superioridade teórica dele como preditor de valores aleatórios. Esta superioridade tem sido confirmada principalmente através do uso 
de simulações, como por exemplo, em Sorensen e Kennedy (1984); Panter e Allen (1995a e 1995b); Jeyaruban et al. (1995), Bueno Filho (1997) e André (1999).

White e Hodge (1984) e André (1999) apresentam várias propriedades úteis do BLUP, referentes ao melhoramento genético vegetal, dentre as quais destacam-se:

a) estimação e predição não-viesadas num procedimento único;

b) pode-se levar em conta efeitos de seleção e de endogamia ao longo das gerações, desde que o grau de relacionamento genético (parentesco) entre os indivíduos avaliados seja conhecido;

c) a correlação entre os valores genéticos verdadeiros e os preditos é máxima dentre as classes de preditores lineares não viesados;

d) pode-se predizer o valor genético de indivíduos (observados ou não);

e) as variâncias e os erros do melhor preditor linear não viesado (BLUP) são menores em relação a outros métodos;

André (1999) menciona que o estimador de $\beta$ não ignora a presença dos efeitos genéticos, porque estes são tomados como aleatórios e considerados no modelo. Isso é visualizado observando-se $V^{-1}$, que inclui $G^{-1}$ em sua composição. Isso não ocorreria caso o modelo fosse tratado como fixo.

Contudo, conforme observa-se pelas equações de modelo misto, a predição dos valores genéticos requer o conhecimento prévio dos componentes de variância e covariâncias envolvidos ( $R$ e $G$ ). Assim, serão apresentados a seguir alguns dos métodos propostos para estimação desses componentes.

Dentre as diversas metodologias disponíveis, destacam-se os métodos I, II e III de Henderson (métodos da análise de variância ou dos momentos) (Henderson, 1953); o Método dos Estimadores Não Viesados de Mínima (MINQUE, Rao,1970; Rao, 1971a), o Método de Estimação Não Viesada de Mínima Variância Quadrática (MIVQUE, Rao, 1971b), o Método da Máxima Verossimilhança (ML, Hartley e Rao,1967), o Método da Máxima Verossimilhança Restrita (REML, Paterson e Thompson, 1971).

Durante a última década, o método REML tem-se tornado o método preferido para estimação de componentes de variância e covariâncias. Esta escolha deve-se, não 
apenas às propriedades estatísticas desejáveis que o método apresenta, mas também à grande evolução dos recursos computacionais disponíveis, ao desenvolvimento e adaptação de algoritmos especializados, explorando características específicas da estrutura dos dados ou do modelo de análise, e à utilização de uma variedade de técnicas numéricas (André, 1999).

\subsection{Alguns resultados empregando BLUP}

Sorensen e Kennedy (1984), usando simulação de populações com características semelhantes as de suínos, compararam a eficiência de dois métodos de seleção, um aplicando o método de mínimos quadrados ordinários e outro usando o modelo linear misto obtendo o melhor preditor linear não viesado (BLUP). Foram avaliados ganhos obtidos com a seleção em cada um dos métodos durante três gerações consecutivas. Os autores observaram que as estimativas de ganho obtidas com o melhor preditor linear não viesado (BLUP) foram sempre superiores às obtidas pelo método dos mínimos quadrados ordinários. Além disso, os ganhos estimados pelo melhor preditor linear não viesado (BLUP) foram mais próximos das estimativas de ganho quando a seleção era feita utilizando os verdadeiros valores genéticos.

Panter e Allen (1995a) estudaram a eficiência dos métodos de mínimos quadrados ordinários e do melhor preditor linear não viesado (BLUP), na identificação de linhagens superiores em cruzamentos de variedades de soja. Os autores simularam situações com igual número de dados em cada sub-classe (balanceamento dos dados), e também situações de desbalanceamento. Em todas as situações estudadas, o BLUP apresentou menor erro padrão, maiores valores de correlação entre os valores preditos e o desempenho dos cruzamentos avaliados em campo, bem como maior porcentagem de identificação de cruzamentos superiores dentre os realizados.

Uma das principais características do melhor preditor linear não viesado (BLUP) é a de utilizar informações de parentesco genético aditivo entre os pares de indivíduos. Os indivíduos mais aparentados têm uma proporção maior de alelos em comum, o que está relacionado ao grau de parentesco (por exemplo, o parentesco 
genético aditivo entre pai e filho é de 0,50 , entre meios irmãos 0,25 , e assim por diante). Este parentesco é levado em consideração na análise (André 1999), o que pode ser considerada uma vantagem desse método. $\mathrm{O}$ termo parentesco genético aditivo refere-se à proporção de alelos idênticos por descendência entre dois indivíduos, sendo equivalente ao dobro do valor do coeficiente de Malécot (Van Vleck, 1993b).

$\mathrm{O}$ melhor preditor linear não viesado (BLUP) possibilita, além da predição mais precisa do mérito genético, a inclusão do coeficiente de endogamia para todos os indivíduos avaliados, se toda informação de parentesco for conhecida (Henderson, 1974, 1984). Quando se dispõe de pouca ou nenhuma informação sobre o indivíduo, informações de parentes podem contribuir para a predição do seu valor genético. A magnitude dessa contribuição é determinada pelo grau de parentesco entre os indivíduos envolvidos na análise, sendo que, quanto maior for o grau de relacionamento genético, maior será esta contribuição (Wood et al.,1991; Van Vleck, 1993a; Panter e Allen, 1995a).

Bernardo (1994) comparou os resultados obtidos para o melhor preditor linear não viesado (BLUP) obtidos por meio de informações de parentesco de dois grupos de linhagens de milho. Para tanto, empregou genealogias e dados de marcadores moleculares do tipo RFLP ("restriction fragment length polymorphism"), sendo que o principal objetivo do trabalho consistiu em avaliar a eficiência do melhor preditor linear não viesado (BLUP) para predizer cruzamentos não realizados. Não foram verificadas alterações significativas nos resultados obtidos usando as genealogias ou os dados de marcadores moleculares. Desta forma, a utilização da informação de marcadores moleculares seria uma alternativa viável, desde que não se disponha de informações confiáveis da genealogia das linhagens avaliadas, o que normalmente ocorre na prática.

A utilização do melhor preditor linear não viesado (BLUP) no melhoramento genético vegetal, conforme citado por Bernardo (1994; 1995), consiste a predição do desempenho genético de híbridos que não estejam presentes ou que tenham sido perdidos. Assim, a partir de covariâncias genéticas entre as linhagens a serem cruzadas, pode-se predizer o desempenho genotípico de alguns dos seus cruzamentos, sem que eles tenham sido obtidos e avaliados. Dado o elevado número de híbridos possíveis de 
serem obtidos com poucas linhagens, esta técnica tem um grande potencial para fornecer auxílio ao melhoramento genético. Apesar da correlação entre o desempenho genotípico do cruzamento predito e o seu valor fenotípico ser baixa em muitos casos, essa abordagem apresenta vantagens (Bernardo, 1994). Este autor considera relevante o uso de técnicas preditivas como uma alternativa viável para diminuir os custos e também o tempo com a avaliação de híbridos em um programa de melhoramento de grande porte, onde são avaliadas milhares de combinações híbridas anualmente e apenas uma pequena quantidade é aproveitada como híbridos comerciais. A utilização do melhor preditor linear não viesado (BLUP), contudo, tem mostrado eficiência considerável para tal finalidade (Bernardo 1994, 1995, 1996a, 1996b).

A habilidade do melhor preditor linear não viesado (BLUP) para predição de cruzamentos não realizados, bem como o número de preditores (cruzamentos a serem realizados) necessários para obter predições suficientemente confiáveis, depende do grau de parentesco dos pais utilizados como preditores (Bernardo, 1995). Nesse contexto, o emprego de marcadores moleculares surge como alternativa para obtenção desse grau de parentesco com maior confiabilidade.

Bernardo (1994), usando a metodologia de modelos mistos, com estimativas de parentesco obtidas através de marcadores moleculares do tipo RFLP, para predizer o desempenho de alguns cruzamentos não realizados em um grupo de 54 híbridos de milho proveniente de dois grupos de linhagens avaliadas em um dialelo parcial, obteve estimativas de correlação entre o valor genotípico predito e o desempenho do cruzamento em campo para a produção de grãos, variando de 0,65 a 0,80. A eficiência na predição de cruzamentos não realizados aumentou à medida que se empregou um maior número de cruzamentos como preditores. Isso mostra a viabilidade da utilização desta metodologia como forma de identificação de cruzamentos promissores antes de sua realização.

Bernardo (1995) avaliou alguns modelos genéticos para realizar predições, considerando graus elevados de desbalanceamento do dialelo. Os valores de correlação entre o desempenho observado e predito para produção de grãos variaram entre $0,58 \mathrm{e}$ 0,75, quando foi utilizado um grupo de 67 híbridos. Os valores das estimativas de 
correlação foram considerados elevados, mesmo em situações em que o número de preditores utilizados era menor do que $20 \%$ do número de híbridos com desempenho a ser predito. Estes esultados sugerem que o melhor preditor linear não viesado (BLUP) pode ser eficiente na obtenção do valor genético de um número elevado de híbridos, avaliando-se um número bem menor de cruzamentos que o utilizado geralmente nos programas de melhoramento.

Bernardo (1996a; 1996b), utilizando um conjunto de 4099 híbridos de 16 combinações entre nove grupos hereróticos de milho avaliados em até 15 locais dos EUA, Canadá, Itália e França, encontrou estimativas de correlação entre o valor predito e o desempenho fenotípico para a produção de grãos de híbridos de milho variando entre 0,49 a 0,76, com uma tendência de estimativas mais elevadas para os grupos com maior número de híbridos avaliados. Segundo o autor, estes valores podem ser considerados moderadamente elevados e sugerem que o melhor preditor linear não viesado seja empregado de forma eficiente para identificação de cruzamentos não realizados com desempenho superior. Entretanto, sua utilização em larga escala, como método preditivo de cruzamentos não realizados, necessita ser melhor pesquisada, principalmente no tocante à quantidade e ao tipo de cruzamentos a serem utilizados como preditores, bem como aos modelos genéticos mais adequados.

Bueno Filho (1997) afirma que, para fins de seleção, a utilização do melhor preditor linear não viesado (BLUP) seria uma excelente estratégia, desde que estimativas dos componentes da variância estejam disponíveis. Entretanto, na prática do melhoramento genético vegetal, ainda é dada preferência a métodos de seleção fazendo uso de médias fenotípicas gerais, obtidas a partir de um modelo fixo.

Charcosset et al. (1998) analisaram diversos modelos para predição de híbridos $F_{1}$ de milho, encontrando como resultado a elevada eficiência de diversos modelos. Os autores afirmam que em situações práticas, a escolha do modelo depende do parentesco entre as linhagens.

André (1999), utilizando simulações e dados reais de um dialelo entre linhagens de feijão genotipadas com marcador RAPD ("random amplified polymorphic DNA"), concluiu que o melhor preditor linear não viesado é mais eficiente que o método 
dos mínimos quadrados ordinários para predição das capacidades de combinação e do efeito de cruzamento, principalmente quando existem informações sobre a similaridade genética entre os materiais a serem cruzados. O BLUP apresenta ainda a vantagem adicional de possibilitar a predição de cruzamentos não realizados, além de possibilitar precisão marcadamente superior em relação aos mínimos quadrados ordinários.

2.6 Marcadores moleculares e matrizes de similaridade genética

Uma vez que o BLUP permite a inclusão de matrizes de variância e covariância genética na análise, serão apresentados a seguir alguns conceitos de como essas matrizes podem ser obtidas com o uso de marcadores moleculares.

Atualmente, estão disponíveis diversas técnicas de biologia molecular para detecção de variabilidade genética diretamente no DNA (material genético dos seres vivos). As diferenças encontradas podem ser utilizadas para estudos detalhados de divergência entre indivíduos e substituem, com vantagens, medidas baseadas em genealogias.

Um marcador molecular de DNA é tipicamente uma pequena região do DNA mostrando polimorfismo (diferença) entre indivíduos (Liu, 1998). Tais diferenças podem ser detectadas por hibridação, em que uma pequena sequiência é marcada radioativamente e hibridizada com o DNA dos indivíduos, usando o princípio da complementariedade do DNA. Um exemplo de marcador que usa tal princípio é o marcador do tipo RFLP.

Outra técnica para detecção destas diferenças baseia-se na amplificação, que tem como princípio o emprego de reações para o aumento de seqüências específicas. Os principais marcadores moleculares deste tipo são o SSR (ou microssatélites), o RAPD e o AFLP (“amplified fragment length polymorphism”) (Liu, 1998).

Através de uma matriz de valores binários, em que as colunas dessa matriz representam os diferentes genótipos e as linhas representam as diferentes marcas a serem comparadas, podem-se representar os resultados obtidos com emprego dos marcadores em matrizes ${ }_{m} M_{g}$. Cada linha corresponde à identificação de uma marca numa região 
específica do DNA. A ausência ou presença dessa marca é identificada pelo número 0 ou 1 , respectivamente.

Por exemplo,

$$
{ }_{m} M_{g}=\left[\begin{array}{ccccc}
1 & 1 & 0 & \cdots & 1 \\
1 & 0 & 1 & \cdots & 0 \\
0 & 1 & 0 & \cdots & 0 \\
\vdots & \vdots & \vdots & \ddots & \vdots \\
0 & 0 & 1 & \cdots & 1
\end{array}\right], \text { em que }
$$

$m$ : número de marcas;

$g:$ o número de genótipos.

Para a comparação entre dois genótipos ocorrem as seguintes situações, para cada marca:

i) ambos possuem a mesma marca $(1,1)$;

ii) um genótipo possui a característica e outro não $(1,0$ ou 0,1$)$;

iii) ambos não possuem tal característica $(0,0)$.

Os coeficientes de similaridade são medidas que quantificam o quanto dois indivíduos são parecidos. Esses coeficientes podem ser divididos em duas categorias: medidas de similaridade e de dissimilaridade. Para a primeira, quanto maior o valor observado, mais parecidos são os indivíduos, para a segunda, quanto maior o valor observado, menos parecidos são os indivíduos (Meyer, 2002). Para cada tipo de variável (quantitativa, qualitativa, ordinais, qualitativas nominais e mistas) são definidos diferentes coeficientes de similaridade (Sneath \& Sokal, 1963; Johnson \& Wichern, 1988; Bussab et al., 1990). A partir dessas medidas são calculados os coeficientes de parentesco entre os indivíduos, permitindo posteriormente o emprego da metodologia de modelos mistos (Bernardo, 1993; Meyer, 2002). 


\section{MATERIAL E MÉTODOS}

\subsection{Material}

Para a realização do presente trabalho, foram utilizados resultados de um experimento para avaliação de um dialelo parcial (cruzamento entre linhagens de dois grupos heteróticos), realizado com 18 linhagens endogâmicas $\left(\mathrm{S}_{3}\right)$ de milho, provenientes das populações BR-105 e BR-106 (Tabela 3). Essas populações foram desenvolvidas no Centro Nacional de Milho e Sorgo (Embrapa Milho e Sorgo) e ambas apresentam ciclo precoce e baixa altura de planta (Pinto, 2000). Essas 18 linhagens e os 80 híbridos simples entre eles foram obtidos pelo Prof. Dr. Cláudio Lopes de Souza Jr., do Departamento de Genética, ESALQ/USP, que gentilmente cedeu os dados para realização do presente trabalho.

De cada população foram selecionadas 40 linhagens, as quais foram avaliadas e selecionadas pelas suas performances "per se" e uniformidade. No ano agrícola de 1991/92, no campo experimental da ESALQ/USP, município de Piracicaba/SP, oito linhagens da população BR-105 e as dez linhagens da BR-106 foram cruzadas em um sistema dialélico parcial produzindo 80 híbridos simples interpopulacionais, que originaram os dados considerados nesse trabalho.

Dessas 18 linhagens, oito foram oriundas da população BR-105 e dez da BR106, sendo que elas foram selecionadas a partir de cruzamentos entre as populações, com posterior seleção, isto é, a partir de cruzamentos entre linhagens da população BR105 x população BR-106, e vice-versa (Tabela 3). Basicamente, o critério para seleção das linhagens consistiu em escolher aqueles que produziram os melhores híbridos quando cruzados, avaliados em diversos experimentos com repetições. 
Tabela 3. Linhagens consideradas com código de uso e respectiva origem.

\begin{tabular}{ccc}
\hline Origem & Código de uso & Nome da linhagem \\
\hline & L9 (1) & $06-3$ \\
L10 (2) & $08-1$ \\
L11 (3) & $08-2$ \\
LR-106 (grupo1) & L13 (5) & $28-1$ \\
& L14 (6) & $03-5$ \\
& L15 (7) & $29-7$ \\
L16 (8) & $44-1$ \\
L17 (9) & $37-5$ \\
& L18 (10) & $14-4$ \\
& & \\
& L1 (1') & $05-2$ \\
& L2 (2') & $19-1$ \\
& L3 (3') & $17-1$ \\
& L4 (4') & $18-6$ \\
BR-105 (grupo2) & L5 (5') & $01-4$ \\
& L6 (6') & $23-2$ \\
& L7 (7') & $34-2$ \\
& L8 (8') & $33-5$ \\
\hline
\end{tabular}




\subsection{Métodos}

\subsubsection{Análise molecular com marcador RFLP}

Os dados referentes aos marcadores moleculares foram obtidos no Centro de Biologia Molecular e Engenharia Genética (CBMEG) da Universidade Estadual de Campinas (UNICAMP), sob coordenação da Profa. Dra. Anete Pereira de Souza, sendo os dados gentilmente cedidos para a realização do presente trabalho.

Brevemente, o DNA genômico foi isolado de um conjunto de tecidos foliares de 16 plantas de cada linhagem com cinco semanas de idade. $O$ material foi liofilizado, moído e o DNA genômico foi extraído usando o método CTAB. O DNA foi purificado por extração com fenol e depois foi separadamente cortado com quatro diferentes enzimas de restrição (Eco RI, Eco RV, Hind III e Bam HI) (Pinto, 2000).

Um total de 185 combinações de sonda e enzima foram analisadas, resultando num total de 973 bandas polimórficas, que foram avaliadas como zeros e uns (contagem binária). Todas as bandas de intensidade fraca foram ignoradas pois não foram reproduzidas em linhas repetidas e autoradiogramas (Benchimol et al.; 2000, Pinto, 2000). Estudos detalhados desse material mostram que os números de locos incluídos foram adequados para a finalidade do presente trabalho (Garcia et al., 2002).

Oitenta e oito sondas de DNA foram utilizadas para hibridação, fornecendo uma cobertura uniforme do genoma do milho. Os padrões de RFLP foram visualmente analisados nas autorradiografias para cada combinação sonda-enzima. Cada combinação foi considerada como um loco e os dados foram registrados somente para aquelas combinações que apresentaram uma boa intensidade de banda. Os dados foram tomados de acordo com a presença ou ausência ( 1 ou 0 , respectivamente) de cada banda em cada linhagem (Pinto, 2000). 
3.2.2 Avaliação dos híbridos interpopulacionais

Os 80 híbridos simples interpopulacionais foram avaliados em experimentos utilizando-se o delineamento experimental látice 10x10 (blocos incompletos), aos quais foram adicionados 20 híbridos comerciais, perfazendo um total de 100 tratamentos. Esses híbridos comerciais denominam-se: P3099, P3210, P3207, IG1xIG2, C808, C505, C701, C425, C805, ICI 8392, ICI 8447, ICI 791151, ICI 8452, ICI911, XL212, XL510, XL520, XL560, C505, C425.

Nesses experimentos, as parcelas foram constituídas por linhas de $4 \mathrm{~m}$ de comprimento, utilizando-se o espaçamento de 0,90m entre linhas e 0,20m entre plantas, sendo a área efetiva de $3,60 \mathrm{~m}^{2}$. Na semeadura foram colocadas 40 sementes por parcela e 15 dias após a germinação foi efetuado o desbaste, procurando-se manter o estande ideal de 20 plantas por parcela, resultando em uma densidade de aproximadamente 55.000 plantas/ha. As adubações de plantio e cobertura, além do controle de plantas daninhas, foram realizadas de acordo com o recomendado para a cultura do milho. Os experimentos foram realizados no ano agrícola de 1991/92, em três locais da região de Piracicaba/SP: Área Experimental do Departamento de Genética da ESALQ/USP, Fazenda Areão e Fazenda Caterpillar, com duas repetições por local. Cada um desses locais foi considerado um ambiente diferente para realização das análises. Foram tomados dados de parcelas individuais, que foram convertidos em $t . h a^{-1}$.

Para a realização da análise de variância conjunta foi adotado o seguinte modelo matemático:

$$
y_{m n p k}=\mu+t_{m}+r_{n(k)}+b_{p(n k)}+l_{k}+(t l)_{m k}+e_{m n p k} \text {, em que: }
$$

$y_{m n p k}$ :valor observado no tratamento $m$, repetição $n$, bloco $p$ e ambiente $k$;

$\mu:$ constante;

$t_{m}$ : efeito do tratamento $m$, em que $m=1,2, \ldots 100$, considerado aleatório;

$r_{n(k)}$ : efeito da repetição $n$ dentro do ambiente $k$, considerado fixo;

$b_{p(n k)}$ : efeito do bloco $p$ dentro da repetição $n$ no ambiente $k$, considerado fixo; 
$l_{k}$ : efeito do ambiente $k$, em que $k=1,2,3$, fixo;

$(t l)_{m k}$ : efeito da interação entre o tratamento $m$ e o ambiente $k$, aleatório;

$e_{\text {mnpk }}$ : erro intrabloco, associado ao tratamento $m$, repetição $n$, bloco $p$ e ambiente $k$, tal que $e_{m n p k} \sim N\left(0, \sigma^{2}\right)$.

Com base no modelo matemático considerado, foram determinadas as esperanças matemáticas dos quadrados médios, para correta realização dos testes de significância dos efeitos do modelo para as fontes de variação de interesse (Tabela 4). O efeito de tratamentos foi decomposto ortogonalmente em efeitos de híbridos, testemunhas e contrastes entre híbridos e testemunhas. Os efeitos $r_{n(k)}, b_{p(n k)}$ e $l_{k}$ foram considerados fixos para que a metodologia proposta por Henderson (1949) pudesse ser empregada. Todas as somas de quadrados obtidas foram ajustadas para todos os efeitos do modelo (tipo III), usando o pacote SAS (SAS, 1992). Para todos os tratamentos, foram obtidas as médias ajustadas ("LsMeans"), usando o referido pacote.

Tabela 4. Esquema da análise de variância com as esperanças matemáticas dos quadrados médios $(\mathrm{E}(\mathrm{QM}))$ e teste $\mathrm{F}$.

\begin{tabular}{lllll}
\hline F.V. & G.L. & Q.M. & E(QM) & F \\
\hline Ambientes(L) & $K-1$ & $Q_{1}$ & - & - \\
Repetições/L & $K(N-1)$ & $Q_{2}$ & - & - \\
Bloco/Repetições/L & $N K(P-1)$ & $Q_{3}$ & - & \\
Tratamento (T) & $M-1$ & $Q_{4}$ & $\sigma_{e}^{2}+10,909 \sigma_{t}^{2}+1,8182 \sigma_{t l}^{2}$ & $Q_{4} / Q_{5}$ \\
T x L & $(M-1)(K-1)$ & $Q_{5}$ & $\sigma_{e}^{2}+1,8182 \sigma_{t l}^{2}$ & $Q_{5} / Q_{6}$ \\
& $K(P-1)(N P-P-1)$ & $Q_{6}$ & $\sigma_{e}^{2}$ & - \\
Erro médio & & & \\
& & &
\end{tabular}




\subsubsection{Análise dialélica}

A análise dialélica foi realizada segundo a metodologia usualmente empregada, que considera o modelo genético como fixo e usa método dos mínimos quadrados ordinários (Vencovsky e Barriga, 1992; Cruz e Regazzi, 1994). As 20 testemunhas comerciais não foram consideradas nessa análise. Nesse caso, o efeito de tratamentos da análise de variância foi decomposto em efeitos genéticos, de acordo com o seguinte modelo matemático:

$$
\begin{gathered}
y_{i j^{\prime} k}=\mu+l_{k}+g_{i}+g_{j^{\prime}}+s_{i j^{\prime}}+(\lg )_{i k}+(\lg )_{j^{\prime} k}+(l s)_{i j^{\prime} k}+\overline{\boldsymbol{\varepsilon}}_{i j^{\prime} k}, \text { em que } \\
\sum_{k} l_{k}=\sum_{i} g_{i}=\sum_{j} g_{j^{\prime}}=\sum_{j} s_{i j^{\prime}}=\sum_{k} \lg { }_{i k}=\sum_{k} \lg { }_{j^{\prime} k}=\sum_{k} l s_{i j^{\prime} k}=0 ;(\text { restrições paramétricas); }
\end{gathered}
$$

$y_{i j ' k}$ : valor médio da combinação híbrida entre a $i$-ésima linhagem do grupo 1 (BR106) e a $j^{\prime}$-ésima linhagem do grupo 2 (BR-105) no $k$-ésimo ambiente;

$\mu$ : média dos híbridos considerando-se todos os ambientes;

$l_{k}$ : efeito do $k$-ésimo ambiente;

$g_{i}$ : efeito da capacidade geral de combinação da $i$-ésima linhagem do grupo 1;

$g_{j^{\prime}}$ : efeito da capacidade geral de combinação da $j^{\prime}$-ésima linhagem do grupo 2 ;

$s_{i j^{\prime}}$ : efeito da capacidade específica de combinação entre as linhagens $i$ e $j^{\prime}$, dos grupos 1 e 2 , respectivamente;

$(\lg )_{i k},(\lg )_{j^{\prime} k}$ : interação entre ambientes e os efeitos da capacidade geral de combinação de cada linhagem de cada grupo heterótico;

$(l s)_{i j^{\prime} k}$ :interação entre ambientes e os efeitos da capacidade específica de combinação entre a $i$-ésima linhagem do grupo 1 e $j^{\prime}$-ésima linhagem do grupo 2 ;

$\bar{\varepsilon}_{i j^{\prime} k}$ : erro experimental médio, tal que $\bar{\varepsilon}_{i j^{\prime} k} \sim N\left(0, \sigma^{2}\right)$.

No caso, cada híbrido $\left(y_{i j}{ }^{\prime} k\right)$ foi representado pela média ajustada das repetições de acordo com o modelo apresentado em 3.2.2. 
O esquema da análise é apresentado na Tabela 5 (Pinto, 2000). Os efeitos de ambiente e do resíduo foram tomados da análise de variância do experimento em látice, sendo divididos pelo número de locais e pelo número de repetições $\mathrm{x}$ locais, respectivamente.

Tabela 5. Esquema da análise dialélica dos 80 híbridos interpopulacionais (CGC: capacidade geral de combinação; CEC: capacidade específica de combinação).

\begin{tabular}{llll}
\hline F.V. & G.L. & Q.M. & F \\
\hline Ambientes(L) & $(K-1)$ & $Q M_{L}$ & - \\
C.G.C. 1 (BR-106) & $(p-1)$ & $Q M_{G 1}$ & $Q M_{G 1} / Q M_{G 1_{\times} L}$ \\
C.G.C. 2 (BR-105) & $(q-1)$ & $Q M_{G 2}$ & $Q M_{G 2} / Q M_{G 2_{\times} L}$ \\
C.E.C. & $(p-1)(q-1)$ & $Q M_{S}$ & $Q M_{S} / Q M_{S \times L}$ \\
C.G.C. 1 x L & $(K-1)(p-1)$ & $Q M_{G 1 \times L}$ & $Q M_{G 1_{\times} L} / Q M_{R}$ \\
C.G.C. 2 x L & $(K-1)(q-1)$ & $Q M_{G 2 \times L}$ & $Q M_{G 2_{\times} L} / Q M_{R}$ \\
C.E.C. x L & $(K-1)(p-1)(q-1)$ & $Q M_{S \times L}$ & $Q M_{S_{\times} L} / Q M_{R}$ \\
Erro combinado & $\sum_{k} g_{k}$ & $Q M_{R}$ & -
\end{tabular}

$p$ e $q$ : número de linhagens das populações BR-106 e BR-105, respectivamente. $K$ : número de ambientes.

$g_{k}:$ número de graus de liberdade do resíduo das análises de variância de cada local.

As estimativas de mínimos quadrados dos efeitos da capacidade geral de combinação e capacidade específica de combinação, na média dos ambientes, foram obtidas pelas seguintes expressões:

$$
\begin{aligned}
& \hat{m}=\frac{2}{p(p-1)} y_{. .} \\
& \hat{g}_{i}=\frac{1}{(p-2)}\left[y_{i .}-(p-1) \hat{m}\right]=\frac{1}{(p-2)}\left[y_{i .}-\frac{2}{p} y_{. .}\right]=\frac{1}{p(p-2)}\left[p y_{i .}-2 y_{. .}\right]
\end{aligned}
$$




$$
s_{i j^{\prime}}=y_{i j^{\prime}}-\left(\hat{m}+\hat{g}_{i}+\hat{g}_{j^{\prime}}\right)=y_{i j^{\prime}}-\frac{1}{(p-2)}\left(y_{i .}+y_{. j^{\prime}}\right)+\frac{2}{(p-1)(p-2)} y_{. .}
$$

\subsubsection{Cálculo do coeficiente de parentesco}

Calculou-se, com base em informação obtida no marcador RFLP, o parentesco entre as 18 linhagens. Tal procedimento justifica-se pelo fato de que marcadores moleculares têm sido usados para alocar linhagens em grupos heteróticos (Melchinger et al., 1991; Dudley et al., 1991; Pinto et al., 2001). Nesses trabalhos, dferentes medidas de similaridade são usadas, geralmente baseadas em proporções de bandas em comum apresentadas pelos genótipos.

Em função da proporção de bandas em comum superestimar o coeficiente de parentesco (Cox et al., 1985; Lynch, 1988), Bernardo (1993) propôs um método para estimar o coeficiente de parentesco sem esse viés, o qual foi empregado no presente trabalho e é apresentado a seguir.

A proporção de locos RFLP com bandas em comum entre as linhagens $i$ e $j^{\prime}$, denotada $S_{i j}$, tem a seguinte esperança matemática (Cox et al.,1985; Lynch,1988):

$$
E\left(S_{i j^{\prime}}\right)=f_{i j^{\prime}}^{\prime}+\left(1-f_{i j^{\prime}}^{\prime}\right) \delta_{i j^{\prime}}, \text { em que: }
$$

$S_{i j^{\prime}}$ : proporção de locos com bandas em comum;

$f_{i j^{\prime}}^{\prime}$ : probabilidade que as linhagens $i$ e $j^{\prime}$ carreguem alelos idênticos por descendência num dado loco (coeficiente de parentesco);

$\delta_{i j^{\prime}}$ : probabilidade média que uma banda de um loco na linhagem $i$ e dessa mesma banda na linhagem $j^{\prime}$ sejam idênticas em estado, dado que elas não são idênticas por descendência.

O segundo termo na equação representa o viés que ocorre se $S_{i j^{\prime}}$ for usado para estimar $f_{i j^{\prime}}^{\prime}$. Dessa forma, esse viés pode ser eliminado estimando-se $\delta_{i j^{\prime}}$ (Bernardo,1993): 


$$
\delta_{i j^{\prime}}=\frac{\delta_{i .}+\delta_{. j^{\prime}}}{2}, \text { em que }
$$

$\delta_{i .}, \delta_{. j^{\prime}}$ : proporção média de bandas em comum entre a linhagem $i\left(\right.$ ou $\left.j^{\prime}\right)$ e linhagens não aparentadas com ela (ou seja, proporção média de locos idênticos em estado).

No caso, em função das diferentes origens, considerou-se que as linhagens da população BR-105 não são aparentados com as linhagens da população BR-106, e viceversa (dois grupos heteróticos). Assim, calculou-se a proporção média de bandas em comum de cada linhagem de um grupo com todas as do outro grupo, obtendo-se $\delta_{i \text {. }}$ e $\delta_{j^{\prime}}$. Cada proporção foi calculada usando o coeficiente de Jaccard, que mede exatamente a proporção de bandas em comum (Meyer, 2002):

$$
J_{i j^{\prime}}=\frac{h_{i j^{\prime}}}{h_{i j^{\prime}}+b_{i j^{\prime}}+c_{i j^{\prime}}}, \text { em que: }
$$

$J_{i j}$ : coeficiente de Jaccard entre as linhagens $i$ e $j^{\prime}$;

$h_{i j}:$ número de bandas em comum entre as linhagens $i$ e $j^{\prime}$;

$b_{i j^{\prime}}$ : número de bandas que ocorrem na linhagem $i$ e não ocorrem na linhagem $j^{\prime}$;

$c_{i j}:$ número de bandas que ocorrem na linhagem $j^{\prime}$ e não ocorrem na linhagem $i$.

É importante ressaltar que, no caso de marcadores codominantes, como é o caso do RFLP, não é correto o emprego de coeficientes que consideram a ausência conjunta de bandas, uma vez que normalmente um loco pode ter vários alelos, causando a necessidade de completar a matriz com zeros simplesmente para que ela tenha dimensão adequada. Assim, esses zeros não indicam necessariamente ausências de banda e não foram considerados nos cálculos.

De posse dessas estimativas, calculou-se o coeficiente de parentesco, com base em marcadores moleculares e corrigido para o viés, usando (Bernardo, 1993): 


$$
f_{i j^{\prime}}^{M}=\frac{S_{i j^{\prime}}-\frac{1}{2}\left(\delta_{i .}+\delta_{j^{\prime} .}\right)}{1-\frac{1}{2}\left(\delta_{i .}+\delta_{j^{\prime}}\right)}, \text { em que: }
$$

$f_{i j^{\prime}}^{M}$ : coeficiente de parentesco entre as linhagens $i$ e $j^{\prime}$; baseado nos dados do marcador molecular RFLP.

\subsubsection{Construção do dendrograma (UPGMA)}

Para verificar se o coeficiente de parentesco calculado com base no marcador molecular alterou os agrupamentos formados com a análise usual, usando coeficientes de similaridade, um dendrograma foi construído segundo o método das médias aritméticas de grupos não ponderados (conhecido como UPGMA), que é uma técnica SAHN ("sequencial, agglomerative, hierarquic, nonoverlapping clustering methods") (Sneath \& Sokal, 1973).

Considerou-se inicialmente 18 linhagens, as quais foram agrupadas de forma sucessiva, baseando-se em sua proximidade. Foram formados assim pares de indivíduos mais próximos, sendo que a cada grupo formado foi necessário reconstruir a matriz de similaridade, definindo a distância entre o novo grupo com os indivíduos. Para tanto, calculou-se as médias entre as similaridades das linhagens de um dos grupos com as do outro. Esse processo se repetiu até a reunião de todas as linhagens em um único grupo.

Os agrupamentos foram então representados graficamente no chamado dendrograma, que é um diagrama de árvore no qual o eixo das abscissas representa o nível em que o indivíduo foi agrupado e o eixo das ordenadas representa os indivíduos. O dendrograma foi construído usando o programa computacional Statistica (1999), sendo que cada linhagem foi considerada um indivíduo. 
3.2.6 Análise dialélica usando metodologia de modelos mistos

\subsubsection{Covariância genética entre os híbridos}

Assumiu-se que $i$ e $j$ são linhagens do grupo heterótico 1, originado da população BR-106, enquanto $i^{\prime}$ e $j^{\prime}$ são linhagens do grupo heterótico 2, originado da população BR-105. Assim, assumindo ausência de epistase e ligação, a covariância genética entre os híbridos interpopulacionais $\left(i, i^{\prime}\right)$ e $\left(j, j^{\prime}\right)$ foi tomada como sendo (Souza Jr., 1989)

$$
\operatorname{Cov}\left[\left(i, i^{\prime}\right),\left(j, j^{\prime}\right)\right]=f_{i j} \sigma_{A_{12}}^{2}+f_{i^{\prime} j^{\prime}} \sigma_{A_{21}}^{2}+f_{i j} f_{i^{\prime} j^{\prime}} \sigma_{D_{(12)}}^{2}, \text { em que }
$$

$\operatorname{Cov}\left[\left(i, i^{\prime}\right),\left(j, j^{\prime}\right)\right]$ : covariância genética entre os híbridos $\left(i, i^{\prime}\right)$ e $\left(j, j^{\prime}\right)$, ou seja, entre híbridos interpopulacionais provenientes do cruzamento entre linhagens dos grupos 1 e 2

$f_{i j}, f_{i^{\prime} j^{\prime}}$ : coeficiente de parentesco entre as linhagens $i$ e $j$ (ou $i^{\prime}$ e $j^{\prime}$ ), ou seja, entre linhagens do mesmo grupo heterótico;

$\sigma_{A_{12}}^{2}$ : variância genética aditiva devida aos alelos da população 1 quando cruzada com a população 2 (no caso, BR-106 x BR-105);

$\sigma_{A_{21}}^{2}$ : variância genética aditiva devida aos alelos da população 2 quando cruzada com a população 1 (no caso, BR-105 x BR-106);

$\sigma_{D_{(12)}}^{2}$ : variância genética dominante resultante do cruzamento das populações 1 e 2.

Os valores de $f_{i j}$ e $f_{i^{\prime} j^{\prime}}$, foram estimados a partir dos dados do marcador molecular RFLP, ou seja, foram substituídos por $f_{i j}^{M}$ e $f_{i^{\prime} j^{\prime}}^{M}$, conforme já descrito. As variâncias genéticas aditivas e de dominância foram estimadas considerando o modelo linear misto apresentado a seguir. 


\subsubsection{Modelo linear misto}

Foi considerado o seguinte modelo linear:

$$
y=X \beta+Z_{0} c+Z_{1} a_{1}+Z_{2} a_{2}+Z d+e, \text { em que: }
$$

$y$ : vetor de observações (dados brutos);

$X$ : matriz de incidência dos efeitos fixos (parte da matriz referente ao delineamento experimental);

$\beta$ : vetor de parâmetros dos efeitos fixos, ou seja, da constante $\mu$, dos efeitos $r_{n(k)}$, $b_{p(n k)}$ e $h_{k}$, conforme descrito em 3.2.2;

$Z_{0}$ : matriz de incidência dos efeitos aleatórios das testemunhas;

$c$ : vetor de parâmetros aleatórios dos efeitos das testemunhas;

$Z_{1}$ : matriz de incidência dos efeitos da capacidade geral de combinação das linhagens do grupo heterótico 1 ;

$a_{1}$ : vetor dos efeitos aleatórios da capacidade geral de combinação das linhagens do grupo heterótico 1 ;

$Z_{2}$ : matriz de incidência dos efeitos da capacidade geral de combinação das linhagens do grupo heterótico 2 ;

$a_{2}$ : vetor dos efeitos aleatórios da capacidade geral de combinação das linhagens do grupo heterótico 2 ;

$Z$ : matriz de incidência dos efeitos da capacidade específica de combinação;

$d:$ vetor dos efeitos aleatórios da capacidade específica de combinação;

$e$ : vetor de resíduos.

Diferentemente do que foi feito na análise dialélica usual, assumiu-se que $c$, $a_{1}, a_{2}$ e $d$ representam efeitos aleatórios, seguinte recomendação de Bernardo (1994). Assim, a esperança matemática desses vetores é zero e as variâncias e covariâncias foram tomadas como sendo: 


$$
\operatorname{Var}=\left[\begin{array}{l}
c \\
a_{1} \\
a_{2} \\
d \\
e
\end{array}\right]=\left[\begin{array}{ccccc}
I \sigma_{c}^{2} & 0 & 0 & 0 & 0 \\
0 & A_{1} \sigma_{A_{12}}^{2} & 0 & 0 & 0 \\
0 & 0 & A_{2} \sigma_{A_{21}}^{2} & 0 & 0 \\
0 & 0 & 0 & D \sigma_{D_{(12)}}^{2} & 0 \\
0 & 0 & 0 & 0 & R \sigma_{e}^{2}
\end{array}\right] \text {, em que }
$$

$\sigma_{c}^{2}$ : variância entre as testemunhas;

$I$ : matriz identidade;

$A_{1}$ : matriz formada pelos elementos $f_{i j}$, ou seja, pelos valores dos coeficientes de parentesco entre as linhagens $i$ e $j$ do grupo 1;

$A_{2}$ : matriz formada pelos elementos $f_{i^{\prime} j^{\prime}}$, ou seja, pelos valores dos coeficientes de parentesco entre as linhagens $i^{\prime}$ e $j^{\prime}$ do grupo 2 ;

$D$ : matriz formada pelos elementos $f_{i j} f_{i j^{\prime}}$;

$R$ : matriz indicativa da estimativa de variâncias e covariâncias do resíduo, tomada como $R=I$

Os demais termos têm mesmo significado já apresentado. Assumiu-se que a matriz de parentesco entre as testemunhas é a identidade, uma vez que eles não foram analisados com o marcador RFLP. Nota-se que os coeficientes de $\sigma_{A_{12}}^{2}, \sigma_{A_{21}}^{2}$ e $\sigma_{D_{(12)}}^{2}$, resultam da expressão da covariância entre os híbridos.

\subsubsection{Equações de modelo misto}

A partir dessas pressuposições e modelo linear, foram construídas as equações de modelo misto, que permitiram a obtenção de estimativas não-viesadas e de variância mínima para os efeitos fixos $\left(\beta^{0}\right)$ e predições não-viesadas e de variância mínima para os efeitos aleatórios $\left(\hat{c}, \hat{a}_{1}, \hat{a}_{2}\right.$ e $\left.\hat{d}\right)$ : 


$$
\left[\begin{array}{l}
\beta^{0} \\
\hat{c} \\
\hat{a}_{1} \\
\hat{a}_{2} \\
\hat{d}
\end{array}\right]=\left[\begin{array}{ccccc}
X^{\prime} X & X^{\prime} Z_{0} & X^{\prime} Z_{1} & X^{\prime} Z_{2} & X^{\prime} Z \\
Z_{0}^{\prime} X & Z_{0}^{\prime} Z_{0}+V_{0} & Z_{0}^{\prime} Z_{1} & Z_{0}^{\prime} Z_{2} & Z_{0}^{\prime} Z \\
Z_{1}^{\prime} X & Z_{1}^{\prime} Z_{0} & Z_{1}^{\prime} Z_{1}+V_{1} & Z_{1}^{\prime} Z_{2} & Z_{1}^{\prime} Z \\
Z_{2}^{\prime} X & Z_{2}^{\prime} Z_{0} & Z_{2}^{\prime} Z_{1} & Z_{2}^{\prime} Z_{2}+V_{2} & Z_{2}^{\prime} Z \\
Z X & Z^{\prime} Z_{0} & Z^{\prime} Z_{1} & Z^{\prime} Z_{2} & Z^{\prime} Z+V_{3}
\end{array}\right]^{G}\left[\begin{array}{c}
X^{\prime} y \\
Z_{0}^{\prime} y \\
Z_{1}^{\prime} y \\
Z_{2}^{\prime} y \\
Z^{\prime} y
\end{array}\right]
$$

em que,

$G$ : inversa generalizada de Moore-Penrose.

$V_{0}=\frac{I \sigma_{e}^{2}}{\sigma_{c}^{2}} ;$

$V_{1}=A_{1}^{-1} \frac{\sigma_{e}^{2}}{\sigma_{A_{12}}^{2}}$;

$V_{2}=A_{2}^{-1} \frac{\sigma_{e}^{2}}{\sigma_{A_{21}}^{2}}$;

$V_{3}=D^{-1} \frac{\sigma_{e}^{2}}{\sigma_{D_{(12)}}^{2}}$;

Numa notação simplificada, que será usada posteriormente, cada elemento da inversa generalizada foi identificado por:

$$
\left[\begin{array}{c}
\beta^{0} \\
\hat{c} \\
\hat{a}_{1} \\
\hat{a}_{2} \\
\hat{d}
\end{array}\right]=\left[\begin{array}{lllll}
C_{00} & C_{01} & C_{02} & C_{03} & C_{04} \\
C_{10} & C_{11} & C_{12} & C_{13} & C_{14} \\
C_{20} & C_{21} & C_{22} & C_{23} & C_{24} \\
C_{30} & C_{31} & C_{32} & C_{33} & C_{34} \\
C_{40} & C_{41} & C_{42} & C_{43} & C_{44}
\end{array}\right]\left[\begin{array}{l}
X^{\prime} y \\
Z_{0}^{\prime} y \\
Z_{1}^{\prime} y \\
Z_{2}^{\prime} y \\
Z^{\prime} y
\end{array}\right]
$$

3.2.6.4 Estimativas de máxima verossimilhança restrita das variâncias e obtenção dos BLUP's

A obtenção das soluções das equações de modelos mistos depende do conhecimento de $\sigma_{e}^{2}, \sigma_{c}^{2}, \sigma_{A_{12}}^{2}, \sigma_{A_{21}}^{2}$ e $\sigma_{D_{(12)}}^{2}$. Por esse motivo, alguns autores 
preferem denominar os BLUP's obtidos dessa forma como EBLUP's, em que E significa "empirical", indicando que os valores paramétricos das variáveis são substituídos por suas estimativas. Para tanto, foram usadas estimativas dessas variâncias pelo método da máxima verossimilhança restrita (REML), usando um processo iterativo baseado no algoritmo EM, ou de maximização da esperança (Henderson, 1984;1985). As estimativas das variâncias foram obtidas iterativamente em:

$$
\begin{aligned}
& \hat{\sigma}_{e}^{2}=\frac{y^{\prime} y-\left[\begin{array}{lllll}
\beta^{0} & \hat{c} & \hat{a}_{1} & \hat{a}_{2} & \hat{d}
\end{array}\right]\left[\begin{array}{lllll}
X^{\prime} y & Z_{0}^{\prime} y & Z_{1}^{\prime} y & Z_{2}^{\prime} y & Z^{\prime} y
\end{array}\right]^{\prime}}{n-r[X]} ; \\
& \hat{\boldsymbol{\sigma}}_{c}^{2}=\frac{c^{\prime} c+\hat{\sigma}_{e}^{2} T R\left[C_{11}\right]}{n_{c}} \\
& \hat{\sigma}_{A_{12}}^{2}=\frac{a_{1}^{\prime} A_{1}^{-1} a_{1}+\hat{\sigma}_{e}^{2} T R\left\lfloor A_{1}^{-1} C_{22}\right\rfloor}{n_{1}} \text {; } \\
& \hat{\sigma}_{A_{21}}^{2}=\frac{a_{2}^{\prime} A_{2}^{-1} a_{2}+\hat{\sigma}_{e}^{2} T R\left\lfloor A_{2}^{-1} C_{33}\right\rfloor}{n_{2}} \text {; } \\
& \hat{\sigma}_{D(12)}^{2}=\frac{d^{\prime} D^{-1} d+\hat{\sigma}_{e}^{2} T R\left\lfloor D^{-1} C_{44}\right\rfloor}{n_{12}} ; \text { em que }
\end{aligned}
$$

$n$ : número de observações;

$r[X]:$ posto da matriz $X$;

$T R[]:$. operador traço;

$n_{c}:$ número de testemunhas (20);

$n_{1}$ : número de linhagens do grupo heterótico 1 (10, BR-106);

$n_{2}$ : número de linhagens do grupo heterótico 2 (8, BR-105);

$n_{12}$ : número de híbridos interpopulacionais (80).

Os demais termos têm o mesmo significado já apresentado.

Os valores para o início do processo iterativo foram tomados a partir das esperanças dos quadrados médios da Tabela 4. Assim, o valor inicial para $\sigma_{e}^{2}$ 
correspondeu ao quadrado médio do resíduo. Para $\sigma_{c}^{2}, \sigma_{A 12}^{2}, \quad \sigma_{A 21}^{2}$ e $\sigma_{D(12)}^{2}$, considerou-se um valor arbitrário próximo à estimativa de $\sigma_{t}^{2}$ da Tabela 4 , também obtida a partir das esperanças matemáticas.

Nota-se que as soluções das equações de modelo misto dependem das estimativas dos componentes de variância, que por sua vez dependem das soluções. Por esse motivo, foram atribuídos os valores iniciais aos componentes de variância, calculando-se em seguida as soluções das equações (estimativas dos efeitos fixos e predições dos efeitos aleatórios). Com base nessas soluções, os componentes foram recalculados e os valores substituídos nas equações de modelo misto, procedendo-se assim sucessivamente, até que não fossem notadas alterações significativas nos valores das soluções e dos componentes de variância após cada iteração. Todos os cálculos foram realizados utilizando o procedimento IML ("Interative Matrix Language") do programa SAS (SAS,1989). Após a convergência, foram obtidos os BLUE's e BLUP's dos efeitos fixos e aleatórios, respectivamente, conforme será detalhado.

Em seguida, foi estimado o coeficiente de herdabilidade com base na média dos híbridos, usando:

$$
\hat{h}^{2}=\frac{\frac{1}{2} \hat{\sigma}_{A_{12}}^{2}+\frac{1}{2} \hat{\sigma}^{2}{ }_{A_{21}}+\hat{\sigma}^{2} D(12)}{\frac{1}{2} \hat{\sigma}^{2}{ }_{A_{12}}+\frac{1}{2} \hat{\sigma}_{A_{21}}^{2}+\hat{\sigma}_{D(12)}^{2}+\frac{\hat{\sigma}_{e}^{2}}{n k}}, \text { em que }
$$

$n:$ número de ambientes;

$k:$ número de repetições por ambiente.

3.2.7 Cálculo da produção das testemunhas usando o BLUP

$\mathrm{O}$ vetor $y_{c}$ contendo o BLUP da produção das 20 testemunhas foi obtido usando (Bernardo, 1995) 


$$
y_{c}=\left(Z^{\prime} Z\right)^{-1} Z^{\prime}(y-X \beta), \text { em que }
$$

$y_{c}$ : vetor com o BLUP da produção dos 20 testemunhas;

$y$ : vetor de observações;

$X$ : matriz de incidência dos efeitos fixos;

$Z$ : matriz de incidência dos efeitos genéticos;

$\beta$ : vetor de parâmetros de efeitos fixos;

Para facilitar as interpretações, somou-se a esses BLUP's o valor da média geral do experimento.

\subsubsection{Cálculo da produção dos híbridos usando o BLUP}

O vetor $y_{p}$ contendo o BLUP da produção dos 80 híbridos interpopulacionais foi obtido usando (Bernardo, 1995)

$$
y_{P}=\left(Z^{\prime} Z\right)^{-1} Z^{\prime}(y-X \beta), \text { em que }
$$

$y_{P}$ : vetor com o BLUP da produção dos 80 híbridos interpopulacionais;

$y$ : vetor de observações;

$X$ : matriz de incidência dos efeitos fixos;

$Z$ : matriz de incidência dos efeitos genéticos;

$\beta$ : vetor de parâmetros de efeitos fixos;

Para que esses vetores fossem mais facilmente comparados com as médias ajustadas obtidas considerando o modelo fixo, somou-se a eles o valor da média geral do experimento, uma vez que os BLUP's são expressos originalmente em valores positivos e negativos (pois têm esperança igual a zero). 
3.2.9 Comparações entre análise dialélica usando mínimos quadrados ordinários e metodologia de modelos mistos.

As estimativas dos efeitos da capacidade geral e específica de combinação, usando mínimos quadrados (item 3.2.3), foram comparadas com as predições desses efeitos usando a metodologia de modelos mistos (item 3.2.6.4), através do coeficiente de correlação linear de Pearson:

$$
\hat{r}_{\text {fixo,aleatório }}=\frac{\hat{C}_{o v_{\text {fixo,aleatorio }}}}{\hat{\boldsymbol{\sigma}}_{\text {fixo }} \cdot \hat{\mathbf{\sigma}}_{\text {aleatório }}}, \mathrm{em} \text { que }
$$

$\hat{r}_{\text {fixo,aleatorio }}:$ coeficiente de correlação entre os efeitos estimados usando mínimos

quadrados (modelo fixo) e metodologia de modelos mistos (modelo misto, efeitos

genéticos, tomados como aleatórios);

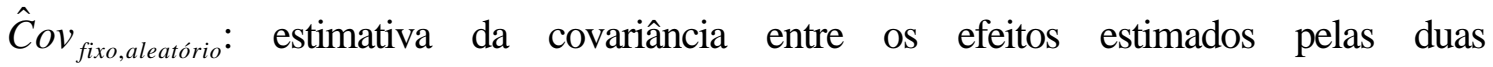
metodologias;

$\hat{\sigma}_{\text {fixo }}, \hat{\sigma}_{\text {aleatório }}$ :estimativa do desvio-padrão dos efeitos estimados em cada metodologia;

\subsubsection{Predições de híbridos simples}

Considerando o modelo linear misto adotado, a performance de um conjunto de $m$ híbridos não observados (perdidos ou não realizados) pode ser predita a partir de um conjunto de $p$ híbridos realizados (preditores) (Bernardo, 1995). No presente caso, como todos os 80 híbridos simples foram obtidos e avaliados, adotou-se o procedimento de validação cruzada ("cross validation") para determinar a eficiência dessa predição de híbridos não realizados (Bernardo, 1995; André, 1999).

Para tanto, foi retirado um dos híbridos do conjunto, sendo sua performance e capacidade específica de combinação predita a partir dos 79 híbridos restantes. Tal procedimento foi repetido para cada um dos em 80 híbridos, resultando assim 80 predições, as quais foram comparadas com os valores realmente obtidos, através do coeficiente de correlação de Pearson. É importante destacar que na prática o número de 
híbridos preditos é maior que o aqui realizado, que foi usado apenas como um ponto de referência.

A produção do híbrido retirado do conjunto foi predita usando:

$$
y_{M}=C_{M P} C_{P P}^{-1} y_{P} \text { em que, }
$$

$y_{M}:$ vetor com o valor predito do híbrido;

$C_{M P}$ : matriz de covariâncias genéticas entre o híbrido retirado e os híbridos preditores;

$C_{P P}$ : matriz de variâncias e covariâncias fenotípicas entre os híbridos preditores;

Os elementos de $C_{M P}$ e de $C_{P P}$ foram calculados a partir da expressão das covariâncias entre os híbridos (Souza Jr., 1989) (item 3.2.6.1), sendo as estimativas das variâncias obtidas pelo método da máxima verossimilhança restrita, já apresentado. Os elementos da diagonal de $C_{P P}$ foram acrescidos da quantidade $\hat{\sigma}_{e}^{2} / r$, sendo $r$ o número de observações do híbrido preditor. Isso foi feito porque $C_{P P}$ é uma matriz de variâncias e covariâncias fenotípicas.

De forma análoga, os valores da capacidade específica de combinação dos híbridos retirados foi obtida usando:

$$
d_{M}=S_{M P} C_{P P}^{-1} y_{P}, \text { em que }
$$

$d_{m}$ : vetor da capacidade específica de combinação predita para o híbrido retirado do conjunto;

$S_{M P}$ : matriz de variâncias e covariâncias dos efeitos da capacidade específica de combinação entre os híbridos preditores e os híbridos preditos;

$C_{P P}$ e $y_{P}$ : significado já apresentado.

A matriz $S_{M P}$ também foi calculada a partir das covariâncias de 3.2.6.1.

Nota-se que a predição de híbridos não observados dependem do conhecimento de $C_{M P}$ ou $S_{M P}$, o que só é possível com conhecimento de medidas de parentesco que, no caso, foram obtidas a partir do marcador RFLP. 


\section{RESULTADOS E DISCUSSÃO}

4.1 Avaliação dos híbridos interpopulacionais

Os resultados da análise de variância obtida usando o modelo matemático apresentado em 3.2.2, são apresentados na Tabela 6.

Tabela 6. Resultado da análise de variância conjunta, na avaliação dos híbridos interpopulacionais, segundo o delineamento látice 10 x 10 .

\begin{tabular}{lrrrrl}
\hline F.V. & G.L. & \multicolumn{1}{c}{ S.Q. } & \multicolumn{1}{c}{ QM } & F & Pr>F \\
\hline Ambientes(L) & 5 & 3057,5014 & 611,5502 & 670,81 & 0,0001 \\
Repetições/L & 6 & 23,2074 & 3,8678 & - & \\
Bloco/Repetições/L & 108 & 191,7726 & 1,7757 & - & \\
Tratamento (T) & 99 & 682,0466 & 6,8893 & 7,56 & 0,0001 \\
$\quad$ Híbridos & 79 & 478,1854 & 6,0529 & 6,64 & 0,0001 \\
Testemunha & 19 & 153,8477 & 8,0972 & 8,88 & 0,0001 \\
Híbridos vs testemunha & 1 & 46,7432 & 46,7432 & 51,28 & 0,0001 \\
T x L & 495 & 667,0717 & 1,3476 & 1,48 & 0,0001 \\
Erro médio & 486 & 443,0308 & 0,9115 & - & \\
\hline
\end{tabular}

CV\%:12,93

O coeficiente de variação (CV) obtido $(12,93 \%)$ é semelhante aos encontrados na literatura para a cultura do milho, e está dentro dos limites aceitáveis na experimentação agronômica.

O resultado da análise de variância conjunta mostrou que todas as fontes de variação apresentaram diferença significativa, o que indica a existência de diferença entre os híbridos, testemunhas e contraste entre esses grupos. A diferença entre os 
híbridos é importante para o presente trabalho, uma vez que essa fonte de variação foi decomposta nos efeitos de capacidade geral e específica de combinação.

Assim sendo, esses resultados evidenciam a existência de variação genética entre as linhagens, pois os híbridos se comportam de maneira diferenciada. A existência dessa variação é importante porque indica que determinadas combinações entre as linhagens são superiores às demais, e que as linhagens podem portanto ser separadas em grupos heteróticos distintos, conforme feito no presente caso (BR-105 e BR-106).

$\mathrm{Na}$ fonte de variação ambientes, a significância indica que existe diferença entre os ambientes, o que era esperado, uma vez que eles foram escolhidos com essa expectativa. A interação entre tratamentos e ambientes também foi significativa, indicando que os híbridos apresentam comportamento diferencial nos diversos ambientes. Isso é comumente encontrado nesse tipo de experimento.

Na Tabela 7 são apresentadas as médias, $t . h a^{-1}$ em ordem decrescente, dos 80 híbridos interpopulacionais. A média dos 80 híbridos foi 7,52 t.ha $a^{-1}$, variando de 3,56 t. $h a^{-1}$ a 9,23 t. $h a^{-1}$. Os cinco maiores valores encontrados foram para os híbridos $4 \times 2$ ' (L12 x L2); 2 x 6' (L10 x L6); 4 x 4' (L12 x L4); 3 x 8' (L11 x L8); e 10 x 7' (L18 x L7), o que não evidencia nenhuma tendência para os melhores classificados, ou seja, aparentemente, não há evidência da presença de alguma linhagem em particular que originou os melhores híbridos. Os menores valores foram para os cruzamentos 7 x 3' (L15 x L3); 7 x 2' (L15 x L2); 10 x 8' (L18 x L8); 7 x 7’ (L15 x L7) e 5 x 2' (L13 x L2), em que podemos observar a presença da linhagem 7 em três dos cinco piores classificados. 
Tabela 7. Valores das médias ajustadas dos híbridos interpopulacionais $t . h a^{-1}$ com os respectivos intervalos de confiança (99\% e 95\%). (LI e LS limite inferior e superior, respectivamente, dos intervalos de confiança).

\begin{tabular}{|c|c|c|c|c|c|c|c|c|c|c|c|}
\hline Híbrido & Iédia &. I. $95 \%$ & L.S. $95 \%$ & L.I.99\% & L.S. $99 \%$ & Híbrido & Média & L.I.95\% & L.S. $95 \%$ & L.I. $99 \%$ & L.S. $99 \%$ \\
\hline $4 \times 2{ }^{\prime}$ & م925 & 415 & 8180 & 4555 & 0 & 3, & 0 & 9923 & 8,1689 & 68064 & 8,3554 \\
\hline & & & & & ,6588 & & & & 473 & & \\
\hline $4 \times 4^{\prime}$ & 660 & 781 & ,4546 & 21 & 96 & & & & 86 & & 145 \\
\hline $3 \times 8$ & 8,7440 & & 30 & 05 & 39 & 6 & 7,5360 & 36 & 52 & 27 & 3111 \\
\hline $10 \times 7$ & 8,5860 & 7,9982 & 9,1748 & 7,8123 & 9,3607 & $9 \times 3{ }^{\prime}$ & 7,5320 & 41 & 206 & 81 & 3066 \\
\hline $3 \times 2{ }^{\prime}$ & 8,4750 & 7,8874 &, 0639 & 014 & ,2499 & $6 \times 4^{\prime}$ & 7,5300 & 17 & 182 & & 3042 \\
\hline $3 \times 6$, & 8,4660 & 78 & 43 & 18 & 03 & $x 5^{\prime}$ &, 5110 & & 02 & & 861 \\
\hline $6 \times 1$ & 8,3670 & 7,7796 & 8,9562 & & 1421 & $8 \times 3^{\prime}$ & 7,5000 & 21 & 887 & 61 & 2746 \\
\hline $6 \times 5^{\prime}$ & 10 & & & & & $9 \times 4^{\prime}$ & 20 & & 09 & & 569 \\
\hline $10 \times 4^{\prime}$ & 30 & 02 & 68 & & & x 8 & 80 & & 68 & & 128 \\
\hline $2 \times 2^{\prime}$ & 8,2970 & 7,7095 & 8,8860 & & 0720 & $5 \times 1$ & 7,4290 & 07 & 8,0173 & 48 & 2032 \\
\hline $10 \times 1$ & & & & & & $8 \times 11^{\prime}$ & & & & & 856 \\
\hline $4 \times 1{ }^{\prime}$ & 8,2260 & 7,6 & & & & $1 \times 2$ & 70 & & 53 & & 712 \\
\hline $5 \times 7$ & 8,2240 & & 25 & & & $3 \times 3$ & 7,3690 & & 580 & & 440 \\
\hline $10 \times 5$ & & & & & & $10 \times 2$ & & & & & 368 \\
\hline $2 \times 8$ & 8,1850 & 7,5 & 8,7736 & & & $2 \times 1{ }^{\prime}$ & 7,3580 & 06 & 171 & & 1331 \\
\hline $5 \times 4^{\prime}$ & 8,1040 & & 30 & & & $8 \times 8$ & 7,3140 & & 28 & & 888 \\
\hline $7 \times 1{ }^{\prime}$ & 40 & & & & & $9 \times 6^{\prime}$ & & & & & \\
\hline $9 \times 7$ & 8,0720 & 7,4843 & 08 & & 468 & $7 \times 5$ & 7,2290 & & 178 & 53 & 0038 \\
\hline $10 \times 6^{\prime}$ & 0130 & & & & & $3 \times 4^{\prime}$ & 7,1770 & & & & 513 \\
\hline $8 \times 5$ & 8,0030 & & & & & $3 \times 1$ & & & & & \\
\hline $2 \times 5$ & 0 & & 72 & & 31 & $4 \times 7$ & 90 & & & & 140 \\
\hline $4 \times 8^{\prime}$ & 7,8160 & & 52 & 7,0 & 11 & $8 \times 2{ }^{\prime}$ & 7,1030 & & 19 & & 779 \\
\hline $2 \times 7$ & & & & & & $4 \times 3{ }^{\prime}$ & & & & & \\
\hline $4 \times 5$ & 7,79 & & & & & $8 \times 4^{\prime}$ & & & & & 170 \\
\hline $4 \times 6^{\prime}$ & 7,7 & & & & & $9 \times 2{ }^{\prime}$ & & & & & 177 \\
\hline $5 \times 6^{\prime}$ & & & & & & $7 \times 4^{\prime}$ & & & & & 7,6955 \\
\hline $5 \times 8$ & 7,7340 & 7 , & 24 & 6 & 83 & $7 \times 6$, & 80 & & 64 & & 7,6624 \\
\hline $5 \times 5^{\prime}$ & & & & & 8,5 & $1 \times 7$ & & & & & 7,6546 \\
\hline $8 \times 7^{\prime}$ & & & & & & $1 \times 1^{\prime}$ & & & & & 765 \\
\hline $7 \times 8^{\prime}$ & 7,7110 & 7 , & 8 & 6,9 & 8 & $1 \times 4^{\prime}$ & 6,7100 & 32 & 98 & 5 , & 7,4758 \\
\hline & & & & & & $6 \times 8^{\prime}$ & & & & & 7,4485 \\
\hline $9 \times 1{ }^{\prime}$ & & & & & & $5 \times 3{ }^{\prime}$ & & & & & 7,4193 \\
\hline $6 \times 3{ }^{\prime}$ & 7,6520 & 7,0 & 104 & 6 & 63 & $1 \times 3^{\prime}$ & 6,6140 & 53 & 28 & 3 & 88 \\
\hline $6 \times 7$ & 7,6480 & & & & & $1 \times 5$ & 6,5630 & & 512 & 887 & 7,3372 \\
\hline $9 \times 5$ & 7,6180 & 7,0303 & 8,2068 & 6,8443 & 8,3928 & $5 \times 2$ & 6,2950 & & 6,8838 & 5,5213 & 7,0698 \\
\hline $1 \times 6^{\prime}$ & 7,6150 & 7,0276 & 8,2042 & 6,8416 & 8,3901 & $7 \times 7$ & 6,2830 & 5,6950 & 6,8716 & 5,5091 & 7,0576 \\
\hline $2 \times 4^{\prime}$ & 7,6070 & 7,0188 & 8,1954 & 6,8329 & 8,3813 & $10 \times 8$ & 5,9690 & 5,3811 & 6,5577 & 5,1951 & 6,7436 \\
\hline $1 \times 8$ & 7,6060 & 7,0185 & 8,1950 & 6,8325 & 8,3810 & $7 \times 2$ & 5,1080 & 4,5199 & 5,6965 & 4,3340 & 5,8824 \\
\hline $6 \times 2{ }^{\prime}$ & 7,5800 & 6,9924 & 8,1690 & 6,8065 & 8,3549 & $7 \times 3^{\prime}$ & 4,1510 & 3,5630 & 4,7395 & 3,3770 & 4,9255 \\
\hline
\end{tabular}

4.2 Análise dialélica

A Tabela 8 apresenta os resultados da análise dialélica, segundo modelo apresentado em (2.2.4). 
Tabela 8. Valores e significâncias dos quadrados médios das análises conjuntas de variâncias para capacidade geral de combinação (CGC) e capacidade específica de combinação (CEC) para produção de grãos.

\begin{tabular}{lrcccl}
\hline F.V. & G.L. & \multicolumn{1}{l}{ SQ } & Q.M. & F & Pr>F \\
\hline Ambientes (L) & 5 & 162,70 & 32,54 & 542,33 & 0,0001 \\
C.G.C. 1 (BR-106) & 9 & 13,95 & $1,55^{* *}$ & 9,12 & 0,0001 \\
C.G.C. 2 (BR-105) & 7 & 7,21 & $1,03^{* *}$ & 7,29 & 0,0001 \\
C.E.C. & 63 & 14,49 & $0,23^{* *}$ & 3,83 & 0,0001 \\
C.G.C.1 x L & 45 & 7,65 & $0,17^{* *}$ & 2,83 & 0,0001 \\
C.G.C.2 x L & 35 & 4,55 & $0,13^{* *}$ & 2,16 & 0,0001 \\
C.E.C. x L & 315 & 28,35 & $0,09^{* *}$ & 1,50 & 0,0001 \\
Erro médio & 486 & 29,16 & 0,06 & - & \\
\hline
\end{tabular}

$\mathrm{O}$ quadro da análise dialélica mostrou que existe diferença significativa na capacidade geral de combinação (CGC) entre as linhagens da população 1 (BR-106) e entre as linhagens da população 2 (BR-105). Ressalta-se que a capacidade geral de combinação está associada a presença de variância aditiva entre as linhagens.

A capacidade específica de combinação (CEC) mostrou diferença significativa, entre os híbridos, o que indica um comportamento diferenciado no cruzamento das linhagens. Associados aos resultados da Tabela 6, isso indica presença de variância dominante entre os 80 híbridos.

Na Tabela 9, são apresentadas as estimativas dos efeitos da capacidade geral de combinação das 18 linhagens, expressas como desvios em relação à média, em função da restrição paramétrica adotada (item 3.2.3). 
Tabela 9. Estimativas dos efeitos da capacidade geral de combinação $\left(\hat{g}_{i}\right)$ e desvio padrão (D.P.) do contraste entre duas linhagens para a variável produção de grãos (PG).

\begin{tabular}{|c|c|c|}
\hline Linhagens & & PG \\
\hline \multirow{10}{*}{ BR-106 } & L9 (1) & $-0,075^{*}$ \\
\hline & L10 (2) & $-0,173 * *$ \\
\hline & L11 (3) & $0,165 * *$ \\
\hline & L12 (4) & $0,105^{* *}$ \\
\hline & L13 (5) & $0,161 * *$ \\
\hline & L14 (6) & 0,031 \\
\hline & L15 (7) & $0,170 * *$ \\
\hline & L16 (8) & $-0,402 * *$ \\
\hline & L17 (9) & 0,010 \\
\hline & L18 (10) & 0,008 \\
\hline \multirow{8}{*}{ BR-105 } & L1 (1') & $-0,007$ \\
\hline & L2 (2') & $-0,039$ \\
\hline & L3 (3') & $-0,207 * *$ \\
\hline & L4 (4') & $-0,096 * *$ \\
\hline & L5 (5') & $0,155^{* *}$ \\
\hline & L6 (6') & $0,137 * *$ \\
\hline & L7 (7') & $0,135^{* *}$ \\
\hline & L8 (8') & $-0,079 * *$ \\
\hline D.P.1 $\left(\hat{g}_{{ }^{\prime} j}-\hat{g}_{{ }^{\prime} j^{\prime}}\right)$ & & 0,046 \\
\hline D.P.2 $\left(\hat{g}_{i}-\hat{g}_{i^{\prime}}\right)$ & & 0,052 \\
\hline
\end{tabular}

*,**) Significativamente diferente de zero a $5 \%$ e $1 \%$ de probabilidade, respectivamente, pelo teste $t$.

As estimativas dos efeitos da capacidade geral de combinação (CGC) (Tabela 9) nos permitiram concluir que, para a população BR-106, as linhagens L11 (3), L12 (4), L13 (5), L14 (6), L15 (7), L17 (9) e L18 (10), têm valores positivos, o que indica que elas são superiores as médias das linhagens envolvidas. Já as linhagens com valores negativos, L9 (1), L10 (2) e L16 (8), estão abaixo da média do conjunto, o que significa um desempenho inferior deles em cruzamentos. Para a população BR-105, tiveram valores positivos as seguintes linhagens: L5 (5'), L6 (6') e L7 (7') e valores negativos: L1 (1'), L2 (2'), L3 (3'), L4 (4') e L8 (8'). A interpretação é análoga. 
No conjunto, a linhagem superior foi a L15, seguida da L11, na população BR106. Na população BR-105, as linhagens L5 e L6 tiveram o melhor desempenho. A linhagem com pior desempenho foi L16 para a população BR-106 e L3, na população BR-105. O fato de apenas algumas significâncias terem sido positivas confirma as significâncias que foram observadas nas Tabelas 6 e 8, porém permitindo agora observar como as linhagens diferem entre si.

$\mathrm{Na}$ Tabela 10 são apresentadas as estimativas dos efeitos da capacidade específica de combinação, expressas como desvios em relação à média.

Tabela 10. Estimativas da capacidade específica de combinação (CEC) das populações

BR105 e BR-106.

\begin{tabular}{cccccccrr}
\hline BR106/BR105 & 1' (L1) & 2' (L2) & 3' (3) & 4' (L4) & \multicolumn{1}{c}{ 5' (L5) } & 6' (L6) & 7' (L7) & 8' (L8) \\
\hline 1 (L9) & 0,201 & 0,084 & 0,018 & $0,403^{*}$ & $-0,528^{* *}$ & 0,008 & 0,185 & $-0,372$ \\
2 (L10) & $-0,128$ & $-0,034$ & 0,044 & $-0,041$ & 0,003 & 0,074 & 0,037 & 0,045 \\
3 (L11) & $-0,026$ & $-0,207$ & 0,063 & $-0,012$ & $-0,003$ & 0,178 & $-0,047$ & 0,055 \\
4 (L12) & $-0,105$ & $-0,158$ & 0,022 & 0,092 & 0,054 & 0,107 & 0,166 & 0,005 \\
5 (L13) & 0,131 & $-0,124$ & $-0,034$ & 0,001 & $-0,072$ & $-0,033$ & 0,069 & 0,061 \\
6 (L14) & $-0,016$ & 0,149 & 0,190 & $-0,118$ & 0,105 & $-0,215$ & $-0,121$ & 0,026 \\
7 (L15) & $-0,110$ & 0,146 & $-0,112$ & 0,360 & 0,273 & $-0,202$ & $-0,160$ & $-0,194$ \\
8 (L16) & 0,217 & 0,077 & $-0,251$ & $-0,698^{* *}$ & $0,402^{*}$ & 0,154 & $-0,137$ & 0,236 \\
9 (L17) & $-0,038$ & $-0,049$ & 0,042 & 0,136 & $-0,060$ & $-0,128$ & 0,075 & 0,021 \\
10 (L18) & $-0,126$ & 0,116 & 0,017 & 0,061 & $-0,174$ & 0,056 & $-0,067$ & 0,117 \\
\hline
\end{tabular}

*, **) Significativo a $5 \%$ e $1 \%$ de probabilidade, respectivamente, pelo teste $\mathrm{t}$.

Os efeitos da capacidade específica de combinação (CEC), apresentados na Tabela 10, são medidas dos efeitos gênicos não aditivos (epistasia e dominância) e portanto, as estimativas da CEC foram nulas quando não houve dominância. No entanto, nota-se a presença de valores significativos, o que confirma o que foi observado na Tabela 10 para capacidade específica de combinação.

$\mathrm{Na}$ avaliação das linhagens em cruzamentos destacaram-se os híbridos 1 x 4'; 8 x 5’; 7 x 4'; 7 × 5’; 8 × 8', com valores positivos, e os híbridos 8 x 4’; 1 x 5’; 1 x 8’; 3 x 1'e 8 x 3'com valores negativos. No entanto, apenas dois valores positivos e dois negativos foram significativos (1 x 4' (L9 x L4) e 8 x 5' (L16 x L5), positivos; 8 x 4' (L16 x L4) e 1 x 5' (L9 x L5), negativos). 
Nota-se portanto que a análise dialélica usual, realizada considerando o modelo como fixo, permite classificar as linhagens quanto ao comportamento geral em cruzamentos (CGC), bem como a identificação de combinações híbridas superiores (CEC). No entanto, não foram incluídas covariâncias entre os híbridos, não usando a informação obtida com marcadores moleculares.

\subsection{Coeficientes de parentesco}

A Tabela 11 apresenta os valores do coeficiente de parentesco calculado entre as linhagens, usando os dados obtidos com o marcador molecular RFLP.

Tabela 11. Valores dos coeficientes de parentesco molecular entre 18 linhagens de milho das populações BR-105 (1 a 8) e BR-106 (9 a 18), calculados a partir de dados do marcador molecular RFLP. Parênteses: código para identificar as linhagens.

\begin{tabular}{|c|c|c|c|c|c|c|c|c|c|c|c|c|c|c|c|c|c|c|}
\hline & L1 (1') & L2 (2') & L3 (3') & L4 (4') & L5 (5') & L6 (6') & L7 (7') & L8 (8') & L9 (1) & L10 (2) & L11 (3) & L12 (4) & L13 (5) & L14 (6) & L15 (7) & L16 (8) & L17 (9) & L18 (10) \\
\hline L1 (1') & 1,0000 & & & & & & & & & & & & & & & & & \\
\hline L2 (2') & 0,2517 & 1,0000 & & & & & & & & & & & & & & & & \\
\hline L3 (3') & 0,0926 & 0,2174 & 1,0000 & & & & & & & & & & & & & & & \\
\hline L4 (4') & 0,0915 & 0,2981 & 0,2143 & 1,0000 & & & & & & & & & & & & & & \\
\hline L5 (5') & 0,1164 & 0,1392 & 0,0509 & 0,0856 & 1,0000 & & & & & & & & & & & & & \\
\hline L6 $\left(6^{\prime}\right)$ & 0,0725 & 0,1258 & 0,1327 & 0,1637 & 0,0793 & 1,0000 & & & & & & & & & & & & \\
\hline L7 (7') & 0,0366 & 0,1056 & 0,0463 & 0,0923 & 0,1283 & 0,2581 & 1,0000 & & & & & & & & & & & \\
\hline L8 (8') & 0,0694 & 0,1536 & 0,2407 & 0,0637 & 0,0826 & 0,1280 & 0,0962 & 1,0000 & & & & & & & & & & \\
\hline L9 (1) & 0,0000 & 0,0000 & 0,0000 & 0,0000 & 0,0000 & 0,0001 & 0,0115 & 0,0000 & 1,0000 & & & & & & & & & \\
\hline L10 (2) & 0,0076 & 0,0271 & 0,0218 & 0,0426 & 0,0000 & 0,0277 & 0,0052 & 0,0162 & 0,0969 & 1,0000 & & & & & & & & \\
\hline L11 (3) & 0,0000 & 0,0133 & 0,0145 & 0,0520 & 0,0000 & 0,0000 & 0,0118 & 0,0023 & 0,0151 & 0,0822 & 1,0000 & & & & & & & \\
\hline L12 (4) & 0,0000 & 0,0000 & 0,0023 & 0,0094 & 0,0291 & 0,0000 & 0,0219 & 0,0221 & 0,0141 & 0,0670 & 0,6107 & 1,0000 & & & & & & \\
\hline L13 (5) & 0,0437 & 0,0258 & 0,0185 & 0,0035 & 0,0000 & 0,0221 & 0,0000 & 0,0000 & 0,0340 & 0,0563 & 0,0424 & 0,0244 & 1,0000 & & & & & \\
\hline L14 (6) & 0,0000 & 0,0000 & 0,0052 & 0,0000 & 0,0296 & 0,0000 & 0,0264 & 0,0000 & 0,0889 & 0,0419 & 0,3400 & 0,2976 & 0,0351 & 1,0000 & & & & \\
\hline L15 (7) & 0,0119 & 0,0505 & 0,0018 & 0,0110 & 0,0000 & 0,0192 & 0,0000 & 0,0000 & 0,0096 & 0,0037 & 0,1065 & 0,0523 & 0,0377 & 0,1669 & 1,0000 & & & \\
\hline L16 (8) & 0,0188 & 0,0252 & 0,0000 & 0,0034 & 0,0000 & 0,0257 & 0,0055 & 0,0049 & 0,0080 & 0,0000 & 0,0000 & 0,0296 & 0,0000 & 0,0023 & 0,0779 & 1,0000 & & \\
\hline L17 (9) & 0,0000 & 0,0000 & 0,0000 & 0,0000 & 0,0000 & 0,0000 & 0,0287 & 0,0000 & 0,0241 & 0,0597 & 0,2553 & 0,2811 & 0,0047 & 0,2449 & 0,0570 & 0,0427 & 1,0000 & \\
\hline L18 (10) & 0,0000 & 0,0000 & 0,0000 & 0,0000 & 0,0000 & 0,0000 & 0,0196 & 0,0000 & 0,0109 & 0,0635 & 0,2519 & 0,2237 & 0,0000 & 0,2827 & 0,0898 & 0,0418 & 0,5826 & 1,0000 \\
\hline
\end{tabular}


De forma semelhante aquela apresentada por Bernardo (1993), os valores negativos foram substituídos por zero, pois $f_{i j^{\prime}}^{M}$ é uma probabilidade, de identidade por descendência e não deve apresentar valores negativos. Os valores substituídos foram muito próximos de zero (variando de $-0,052$ a $-0,0027$ ). Os maiores valores encontrados foram 0,6107 (L11 x L12), 0,5826 (L17 x L18); 0,3400 (L11 x L14); 0,2981 (L2 xL4) e 0,2976 (L12 x L14), sempre dentro de cada grupo heterótico, conforme esperado. Portanto, o intervalo de variação foi de 0 até 0,6107 (fora da diagonal principal). Dos 44 valores nulos encontrados, 40 estão entre os grupos heteróticos, o que já era esperado uma vez que as populações foram selecionadas para serem distintas, e apenas 4 valores nulos ocorreram entre as linhagens da população BR-106. A média da Tabela 11, exceto a diagonal, foi igual a 0,0534, mostrando que de forma geral os valores são baixos, indicando assim que as linhagens tendem a não serem aparentadas.

O parentesco médio entre as linhagens dentro de cada população foi 0,1078 para BR-106 e 0,1297 para BR-105. Já entre essas populações, o valor médio do parentesco foi 0,0092. Isso era esperado, uma vez que espera-se maior divergência entre as populações. Além disso, a população BR-106 é sabidamente a mais variável que a BR-105. O fato de estes valores serem de magnitude reduzida dificultam que o BLUP tenha um efeito preditivo muito elevado (Bernardo, 1995), principalmente entre os grupos heteróticos, abordados na presente estudo.

Na Figura 1 é apresentado um histograma ilustrando os valores de parentesco obtidos. 


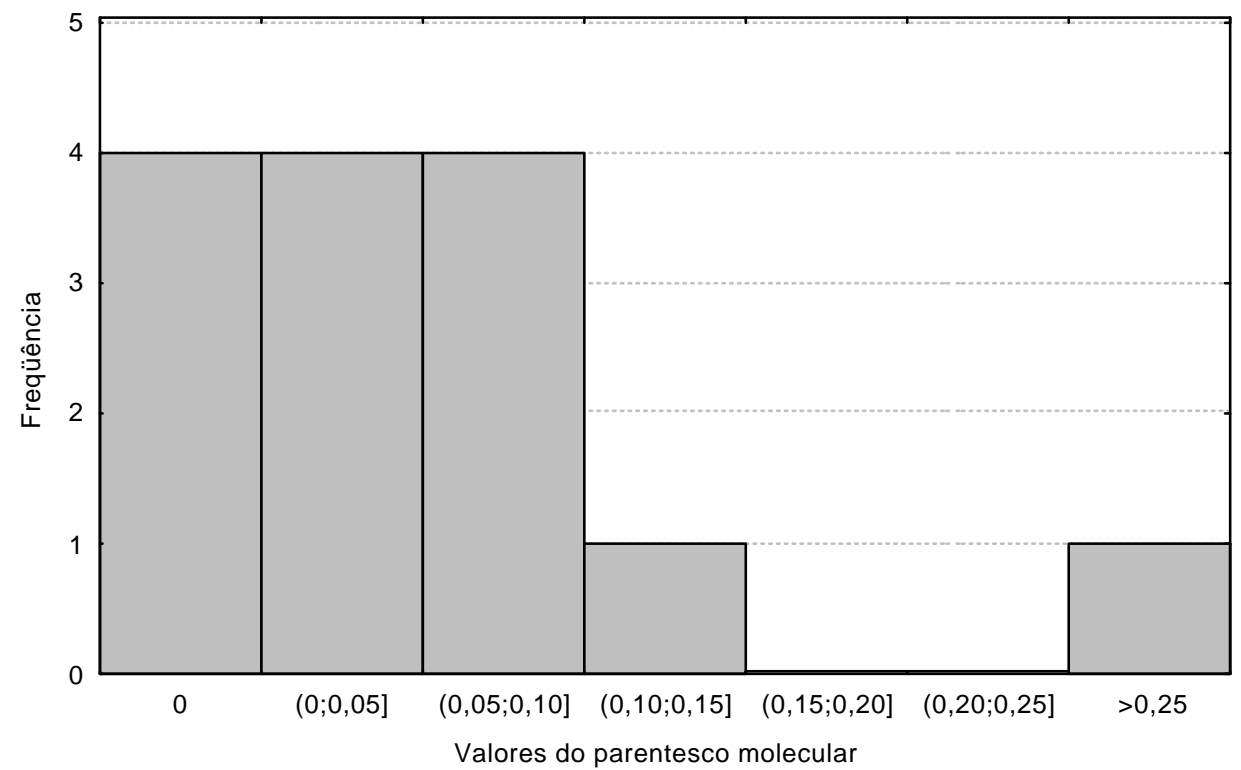

Figura 1- Histograma dos valores de parentesco, calculados através de marcador molecular $\operatorname{RFLP}\left(f_{i j^{\prime}}^{M}\right)$.

As Figuras 2 e 3 apresentam os dendrogramas construídos usando o método UPGMA, com base em $f_{i j^{\prime}}^{M}$ e no coeficiente de Jaccard. 


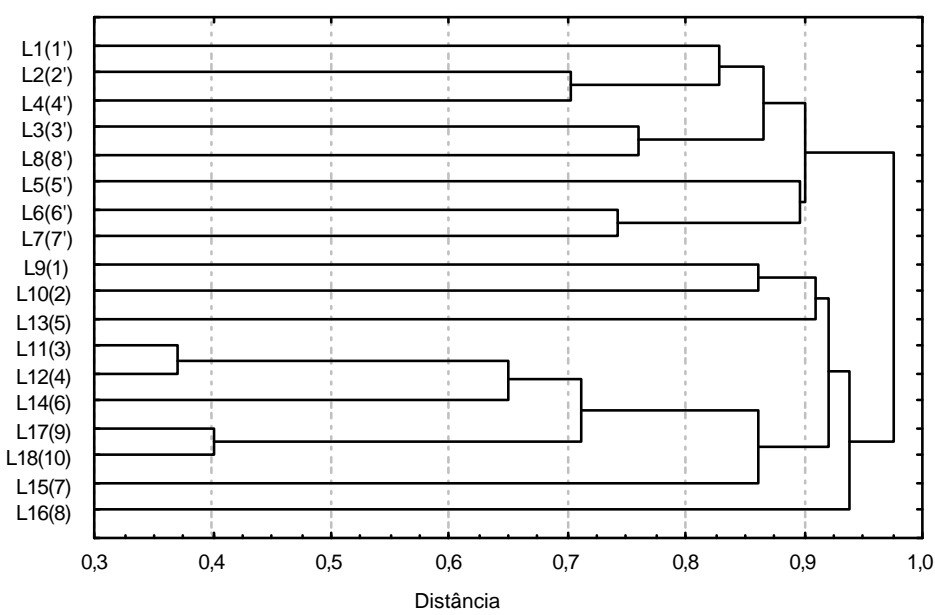

Figura 2- Dendrograma para as 18 linhagens de milho das populações BR-105 e BR-106 agrupadas segundo o método UPGMA. Medida de similaridade: coeficiente de parentesco molecular $\left(f_{i j^{\prime}}^{M}\right)$.

Na figura 2 podemos notar clara separação das 18 linhagens em dois grupos distintos, à uma aproximida distância de 0,95, ou seja, grupo1 (L1 a L8) e grupo 2 (L9 a L18), exatamente como era esperado, pois esses dois grupos representam as linhagens das populações BR-105 e BR-106 (Tabela 3), respectivamente, e cuja origem é distinta e deve realmente causar essa separação. Diversos trabalhos mostram que isso é consistente (Benchimol et al. 2000; Pinto et al. 2000; Garcia et al. 2002; Meyer, 2002).

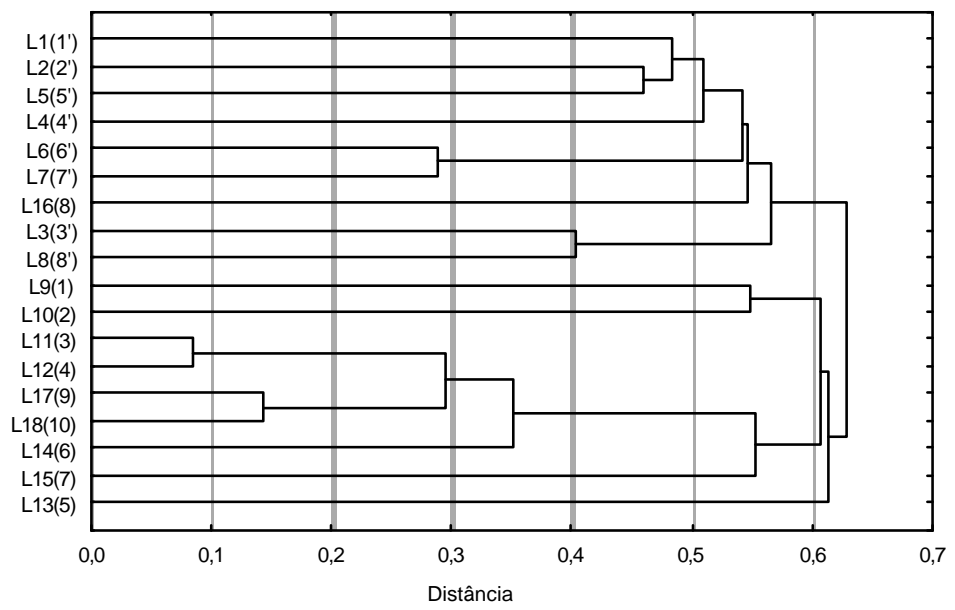

Figura 3- Dendrograma para as 18 linhagens de milho das populações BR-105 e BR-106 agrupadas segundo o método UPGMA. Medida de similaridade: coeficiente de Jaccard. 
Para o dendrograma usando coeficiente de Jaccard (Figura 3), podemos notar novamente a separação das 18 linhagens em dois grupos distintos, grupo 1 (L1 a L8, mais L16) e grupo 2 (L9 a L18, exceto L16) porém agora a uma distância de 0,62 para formação dos grupos, ou seja, menor que a anterior. Observamos que a linhagem L16 pertence a grupos distintos em cada um dos dendrogramas, e que a separação dos dois grupos foi feita com base em distâncias diferentes. O fato da linhagem L16 estar no grupo da BR-105 também tem sido verificado em outros trabalhos com essas mesmas linhagens (Barbosa et al., 2002; Meyer, 2002).

Esses dois dendrogramas foram aqui apresentados e comparados em função do coeficiente $f_{i j^{\prime}}^{M}$ ter usado as linhagens do grupo heterótico oposto para cálculo dos alelos idênticos em estado. Os resultados mostram que o uso do $f_{i j^{\prime}}^{M}$ não altera os agrupamentos estabelecidos a priori, com base na origem das populações. No entanto, os valores dos distâncias com uso do $f_{i j^{\prime}}^{M}$ foram maiores, sendo que a distância entre os dois grupos ocorreu com valor próximo de 0,62 quando se usou Jaccard, e 0,95 com $f_{i j^{\prime}}^{M}$. Nota-se assim que o coeficiente de parentesco molecular evidencia ainda mais a distância entre os grupos, o que pode ser favorável em trabalhos que desejem separar genótipos em grupos heteróticos. O fato de a linhagem L16 ter mudado sua posição nos grupos pode ser devido ao fato do coeficiente de Jaccard sabidamente apresentar viés se usado como estimativa do coeficiente de parentesco (Bernardo, 1993).

4.4 Estimativas das variâncias genéticas e ambientais

As figuras 4 a 8 apresentam a convergência das estimativas de máxima verossimilhança restrita (REML) das variâncias consideradas no modelo, em função da iteração. 


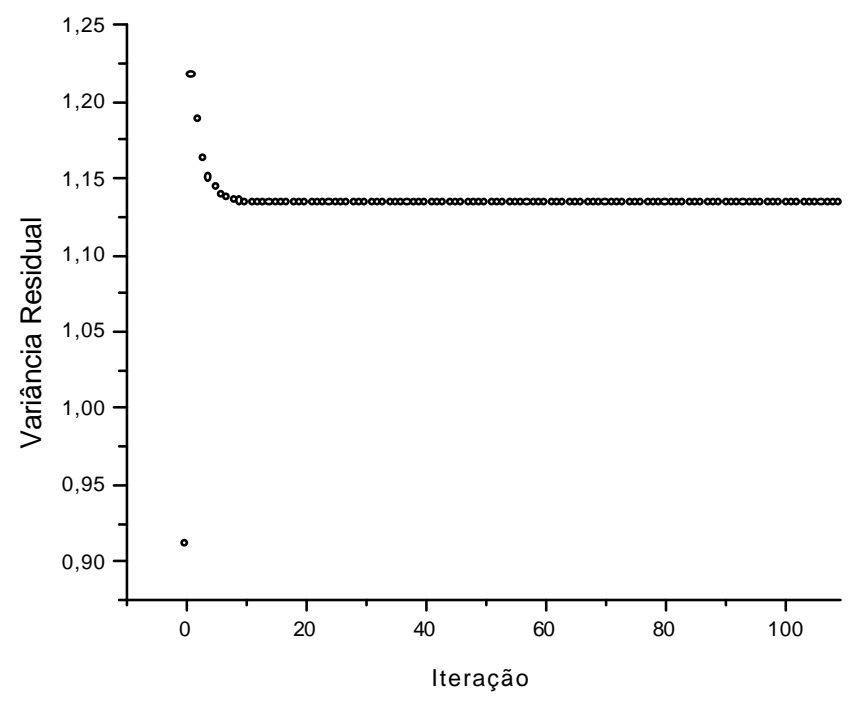

Figura 4- Valores das estimativas da variância residual em função da iteração.

A estimativa da variância residual $\left(\hat{\sigma}_{e}^{2}\right)$ (figura 4) estabilizour-se após a $10^{\mathrm{a}}$ iteração, resultando no valor $1,13433\left(t \cdot h a^{-1}\right)^{2}$. O valor inicial utilizado foi 0,911586 , $\left(t . h a^{-1}\right)^{2}$ tomado com base na estimativa da análise de variância $\left(\mathrm{QM}_{\mathrm{RES}}\right)$ considerando o modelo como fixo (descrito em material e método). 


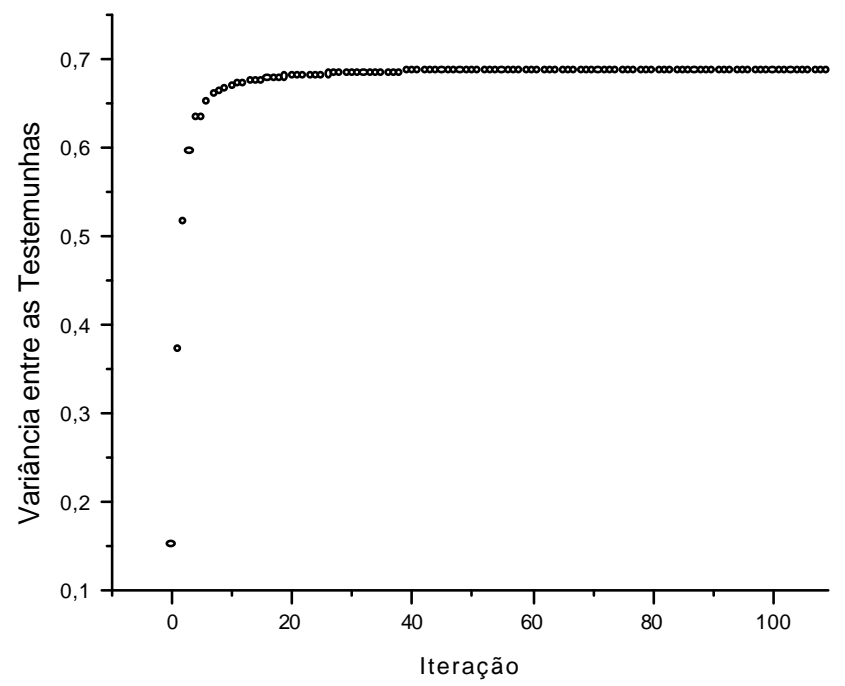

Figura 5- Valores das estimativas da variância das testemunhas em função da iteração.

Para obtenção das estimativas de $\sigma_{c}^{2}, \sigma_{A_{12}}^{2}, \sigma_{A_{21}}^{2}$ e $\sigma_{D_{(12)}}^{2}$, usou-se o valor inicial das variâncias o valor 0,151931 $\left(t \cdot h a^{-1}\right)^{2}$, com base m estimativa da variância entre os tratamentos pelo método dos momentos, conforme descrito em Material e Métodos. A estimativa da variância entre as testemunhas $\left(\hat{\boldsymbol{\sigma}}_{c}^{2}\right)$ estabilizou-se no valor 0,68835 $\left(t . h a^{-1}\right)^{2}$ após a $25^{\text {a }}$ iteração. Conforme apresentado, não foi considerado o parentesco molecular entre as testemunhas em função de não se dispor de informações de genealogias ou marcadores moleculares desses 20 genótipos. 


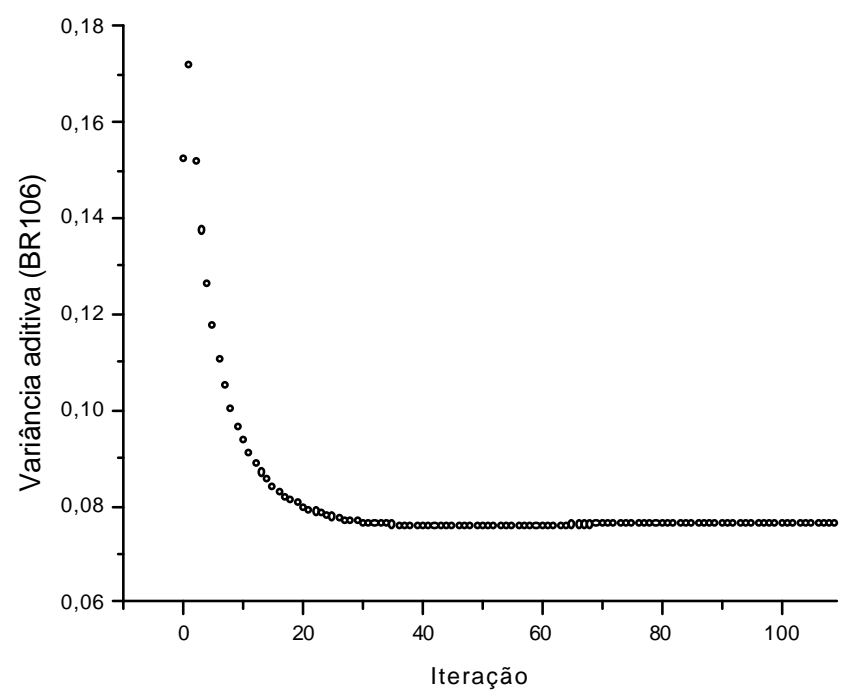

Figura 6- Valores das estimativas da variância aditiva da população BR-106 em função da iteração.

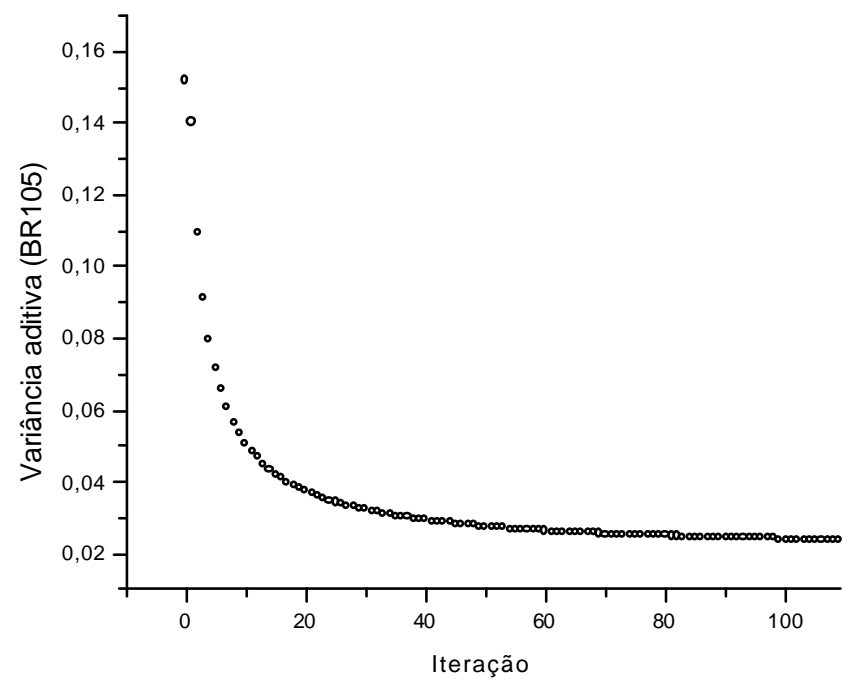

Figura 7- Valores das estimativas da variância aditiva da população BR-105 em função da iteração. 


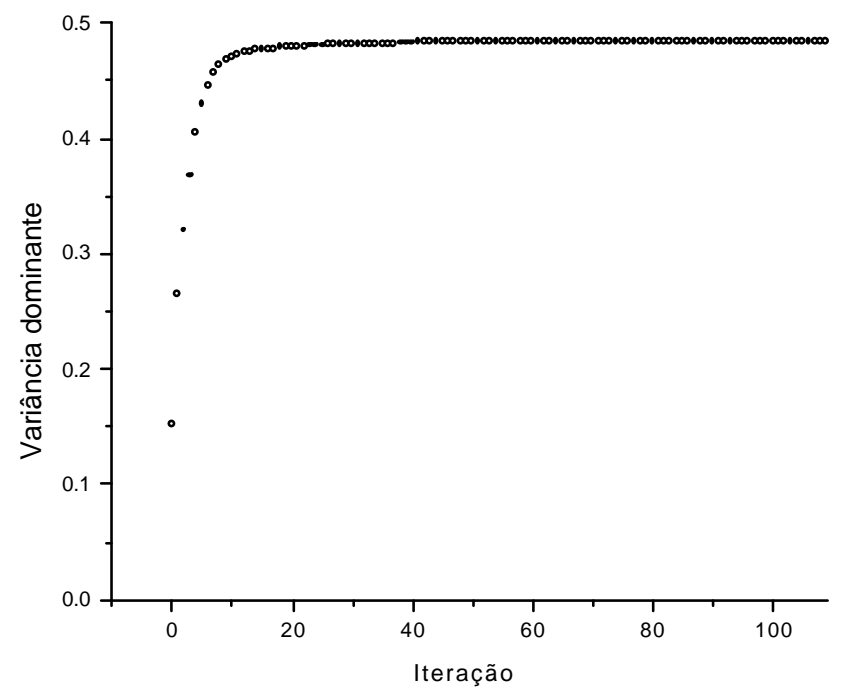

Figura 8- Valores das estimativas da variância dominante em função da iteração.

A estimativa da variância aditiva referente a capacidade geral de combinação das linhagens BR-106 $\left(\hat{\sigma}_{A_{12}}^{2}\right)$ estabilizou-se após a $40^{\mathrm{a}}$ iteração com, valor 0,0764 $\left(t . h a^{-1}\right)^{2}$.

A estimativa da variância aditiva referente a capacidade geral de combinação da população BR-105 $\left(\hat{\sigma}_{A_{21}}^{2}\right)$ BR-105 estabilizou-se após a $90^{\mathrm{a}}$ iteração, com valor de $0,02385\left(t . h a^{-1}\right)^{2}$.

A estimativa da variância dominante resultado do cruzamento das linhagens das duas populações $\left(\hat{\sigma}_{D_{(12)}}^{2}\right)$ estabilizou-se após o $50^{\circ}$ passo, com o valor 0,48427 $\left(t \cdot h a^{-1}\right)^{2}$.

Considerando-se que a estimativa REML para a variância aditiva da BR-105 foi obtida após a $90^{\mathrm{a}}$ iteração, assumiu-se que a estimativa final para todas as variâncias foi conseguida após a $110^{\mathrm{a}}$ iteração. Isso confirma o conhecido fato de que o algoritmo EM, embora didático e de fácil entendimento, em alguns casos pode demorar para convergir. No presente trabalho, contudo, não houve este problema, pois 110 iterações foram rapidamente realizadas. Os valores finais das estimativas são apresentados na Tabela 12. 
Tabela 12. Estimativas das variâncias considerando o modelo linear misto pelo método da máxima verossimilhança restrita (REML), usando processo iterativo baseado no algoritmo de maximização da esperança $(\mathrm{EM})$

\begin{tabular}{|c|c|c|c|c|c|}
\hline & $\hat{\boldsymbol{\sigma}}_{e}^{2}$ & $\hat{\boldsymbol{\sigma}}_{c}^{2}$ & $\hat{\sigma}_{A_{12}}^{2}$ & $\hat{\sigma}_{A_{21}}^{2}$ & $\hat{\sigma}_{D_{(12)}}^{2}$ \\
\hline & \multicolumn{5}{|c|}{$\left(t . h a^{-1}\right)^{2}$} \\
\hline Valores iniciais & 0,91159 & 0,15193 & 0,15193 & 0,15193 & 0,15193 \\
\hline Valores finais & 1,13433 & 0,68835 & 0,07644 & 0,02385 & 0,48427 \\
\hline $\mathrm{N}^{\circ}$ iteraçỗes para & & 25 & & & \\
\hline $\begin{array}{l}N^{\circ} \text { iterações } \\
\text { usados }\end{array}$ & 110 & 110 & 110 & 110 & 110 \\
\hline
\end{tabular}

A estimativa do coeficiente de herdabilidade, com base na média dos híbridos, foi:

$$
\hat{h}^{2}=\frac{\frac{1}{2}(0,07644)+\frac{1}{2}(0,02385)+0,48427}{\frac{1}{2}(0,07644)+\frac{1}{2}(0,02385)+0,48427+\frac{1,13433}{3(2)}}=0,7387
$$

Esse valor pode ser considerado como sendo de elevada magnitude, e assemelham-se ao apresentado por Bernardo $(1994 ; 1995)$ em situações semelhantes, em que os valores apresentados foram $\hat{h}^{2}=0,812$ e $\hat{h}^{2}=0,88$. Assim, é possível prever sucesso na seleção dos híbridos interpopulacionais superiores.

É importante ressaltar que a estimativa de $\hat{\sigma}_{A_{12}}^{2}$ (BR-106 x BR-105) foi maior que a de $\hat{\sigma}_{A_{21}}^{2}$ (BR-105 x BR-106). Isso é consistente com diversos outros trabalhos que mostraram que as linhagens da população BR-106 apresentam maior variabilidade que as da BR-105 (Pinto et al., 2001; Barbosa et al., 2002) e, portanto, devem representar maior variância da capacidade geral de combinação que para as linhagens da BR-105. Além disso, a variância dominante $\hat{\sigma}_{D(12)}^{2}$ representou $90,6 \%$ da variância genética total, o que pode ser explicado pelo fato das linhagens terem sido intensamente selecionadas para capacidade específica de combinação, o que poderia explicar essa elevada magnitude (proporcionalmente). Bernardo (1994; 1995) cita que empiricamente, Hallauer e Miranda Filho (1981) encontraram que a variância dominante constitui 
aproximadamente $40 \%$ da variância genética total para produção de grãos. Assim, o valor diferente encontrado no presente caso poderia ser explicado pela alta intensidade de seleção para capacidade específica de combinação, uma vez que as linhagens foram selecionadas com base em seu desempenho quando cruzadas com as linhagens da outra população.

\subsection{BLUP's das testemunhas}

Na Tabela 13 são apresentados os BLUP's das 20 testemunhas comercias.

Tabela 13. Melhor preditor linear não viesado (BLUP) das 20 testemunhas comerciais.

\begin{tabular}{llll}
\hline Testemunha & BLUP $\left(t \cdot h a^{-1}\right)$ & Testemunha & BLUP $\left(t . h a^{-1}\right)$ \\
\hline P3099 & 6,50058 & 8447 & 7,51257 \\
P3210 & 6,88717 & 791151 & 7,56246 \\
P3207 & 5,52238 & 8452 & 8,59372 \\
IG1 x IG2 & 7,14237 & ICI911 & 6,71294 \\
C808 & 7,16968 & XL212 & 5,76644 \\
C505 & 7,60585 & XL510 & 6,42558 \\
C701 & 7,75678 & XL520 & 6,56104 \\
C425 & 7,69030 & XL560 & 6,79949 \\
C805 & 7,62531 & C505 & 7,31120 \\
8392 & 7,64978 & C425 & 7,62829 \\
\hline
\end{tabular}

O maior valor encontrado foi $8,59372\left(t . h a^{-1}\right)$, referente à testemunha $8452 \mathrm{e}$ menor foi o 5,52382 $\left(t . h a^{-1}\right)$ referente à testemunha P3210. A amplitude de 3,07134 $\left(t \cdot h a^{-1}\right)$ e a média dos 20 híbridos igual a 7,12120 $\left(t \cdot h a^{-1}\right)$.

Na Figura 9 é apresentado um diagrama de dispersão, comparando os BLUP’s, obtidos com o modelo misto, com os BLUE's (modelo fixo) Através dele e do coeficiente de correlação $(r=0,99)$, concluímos que os BLUP's das testemunhas e seus respectivos BLUE's são altamente correlacionados. Isso poderia se explicado pelo fato 
desse efeito considerar a matriz identidade na estrutura de variâncias e covariâncias, o que não causa diferença entre as metodologias.

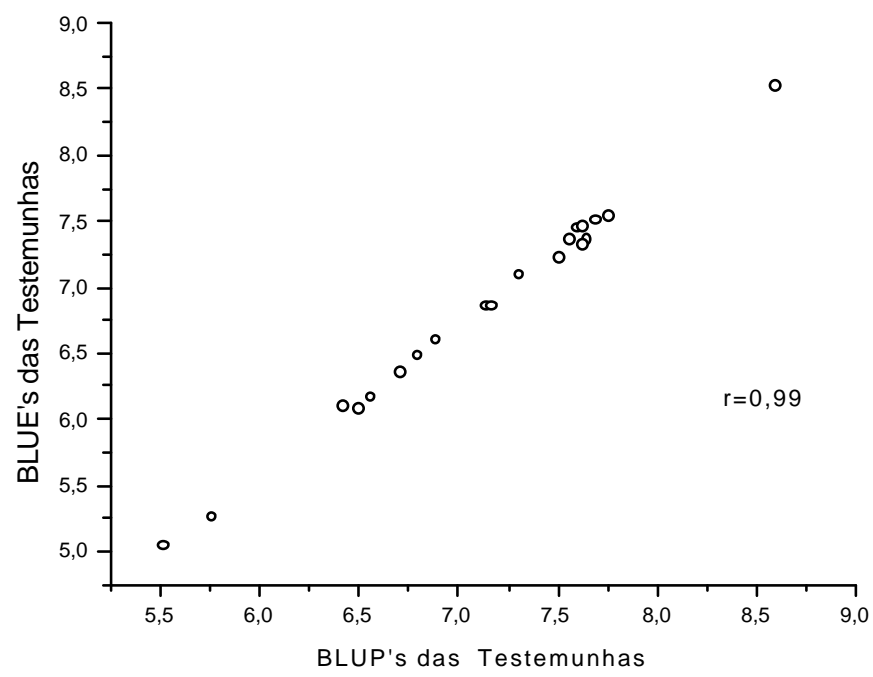

Figura 9- Diagrama de dispersão e coeficiente de correlação (r) associando os valores dos BLUE's (modelo fixo) e BLUP's (modelo misto), para as 20 testemunhas comerciais.

4.6 BLUP's dos efeitos das capacidades de combinação

Os BLUP's dos efeitos da capacidade geral de combinação das linhagens das populações BR-106 e BR-105, e das capacidades específicas de combinação são apresentados nas Tabelas 14, 15 e 16. 
Tabela 14. BLUP's da capacidade geral de combinação (CGC) para as linhagens da população BR-106

\begin{tabular}{ll}
\hline Linhagem & CGC \\
\hline L9 (1) & $-0,07620$ \\
L10 (2) & 0,26784 \\
L11 (3) & 0,21583 \\
L12 (4) & 0,25780 \\
L13 (5) & 0,13800 \\
L14 (6) & 0,18769 \\
L15 (7) & $-0,18772$ \\
L16 (8) & 0,11820 \\
L17 (9) & 0,14297 \\
L18 (10) & 0,21850 \\
\hline
\end{tabular}

O menor e o maior valor encontrado para o preditor da capacidade geral de combinação do grupo heterótico 1 (BR-106) foi -0,1877 e 0,2678, respectivamente, correspondentes as linhagens L7 e L2. Esses valores representam o comportamento médio de uma linhagem da BR-106 quando cruzada com o conjunto linhagens do outro grupo. Nota-se no entanto que os valores dos BLUP's da capacidade geral de combinação, para o modelo misto, não se correlacionam com as estimativas da CGC quando utilizamos o modelo fixo (r=-0,11) (Figura 10). 


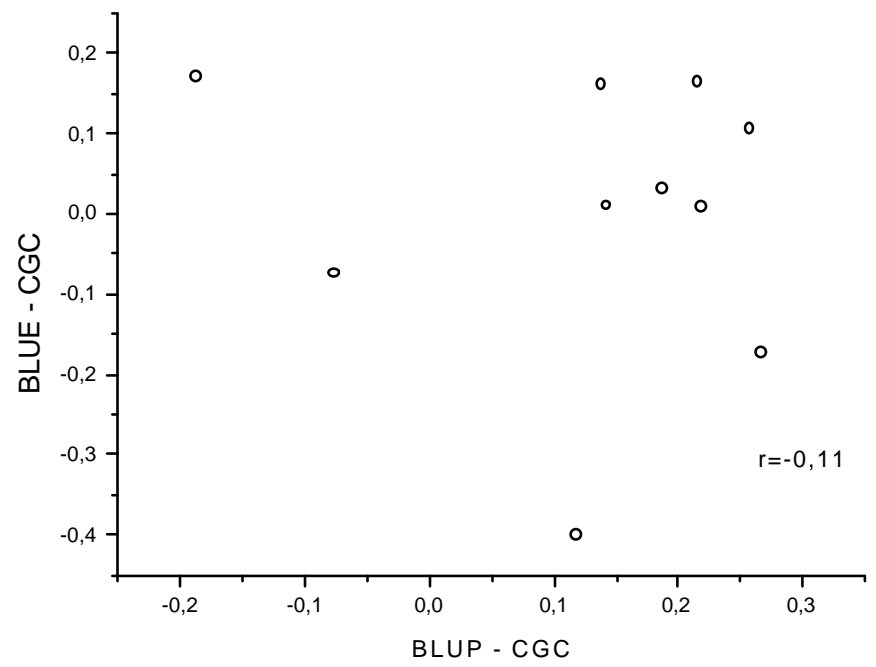

Figura 10- Diagrama de dispersão e coeficiente de correlação (r) associando os valores da capacidade geral de combinação (CGC) estimada considerando o modelo fixo e predita utilizando o modelo misto (BLUP), para as linhagens da população BR-106.

Essa baixa correlação indica que a classificação das linhagens quanto à CGC foi diferente nas duas metodologias de análise. Dessa forma, pode haver confusão por parte geneticista quando for realizar seleção. Possivelmente, as diferenças ocorreram em função da estrutura de variâncias e covariâncias incorporadas no modelo. Do ponto de vista teórico, pode-se supor que os BLUP's indicam melhor o comportamento das linhagens que os BLUE's (André, 1999). No entanto, isso deve ser considerado com ressalvas e sempre levar em conta o conhecimento do geneticista. 
Tabela 15. BLUP's da capacidade geral de combinação (CGC) para as linhagens da população BR-105

\begin{tabular}{ll}
\hline linhagem & CGC \\
\hline L1 (1') & 0,06331 \\
L2 (2') & $-0,01037$ \\
L3 (3') & $-0,08242$ \\
L4 (4') & 0,04156 \\
L5 (5') & 0,07418 \\
L6 (6') & 0,09529 \\
L7 (7') & 0,05996 \\
L8 (8') & 0,05539 \\
\hline
\end{tabular}

Considerando os BLUP's apresentados na Tabela 15, nota-se que o menor e o maior valor encontrado para a capacidade geral de combinação (CGC) do grupo 2 (BR105) foi $-0,0824$ e 0,0953, respectivamente, correspondentes as linhagens L3 e L6. De forma análoga, esses valores representam o comportamento médio de uma linhagem da BR-105 cruzada com um conjunto de linhagens da BR-106. Existe elevada correlação entre a CGC obtida considerando o modelo fixo (BLUE) e considerando o modelo misto $(\mathrm{r}=0,79)$ (Figura 11). 


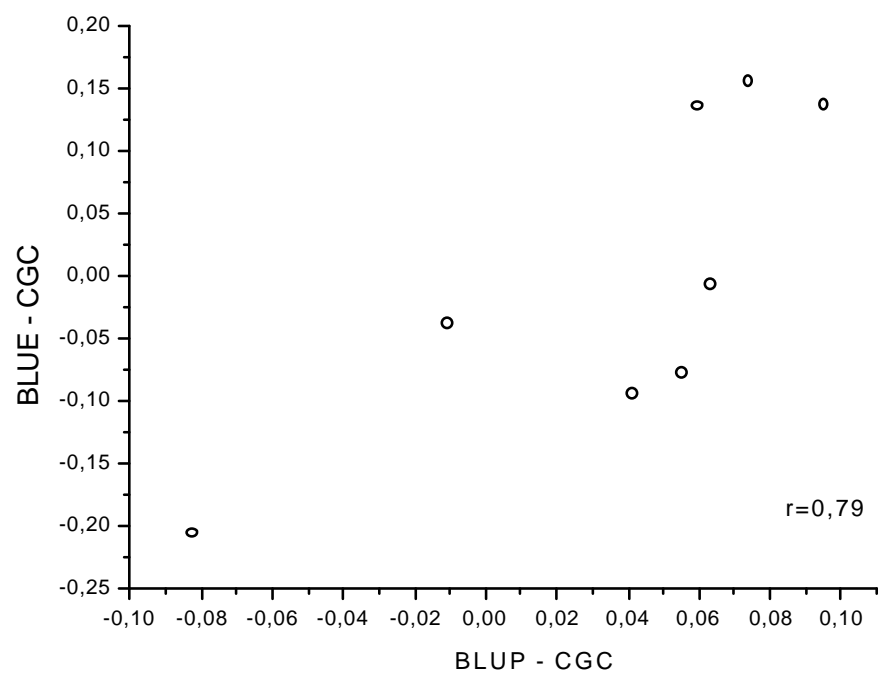

Figura 11- Diagrama de dispersão e coeficiente de correlação (r) associando os valores da capacidade geral de combinação (CGC) estimada considerando o modelo fixo (BLUE) e predita utilizando o modelo misto (BLUP), para as linhagens da população BR-105.

Essa correlação permite afirmar que, nesse caso, haveria pouca diferença sobre a classificação das linhagens usando um ou outro método de análise. Não é possível afirmar se essa correspondência deve-se a menor divergência entre as linhagens da BR105. 
Tabela 16. BLUP's da capacidade específica de combinação (CEC) paras os cruzamentos entre as linhagens das populações BR-106 e BR-105

\begin{tabular}{|c|c|c|c|c|c|c|c|}
\hline HÍBRIDO & CEC & HÍBRIDO & $\overline{\mathrm{CEC}}$ & HÍBRIDO & CEC & HÍBRIDO & $\overline{C E C}$ \\
\hline $1 \times 1$ & $-0,22892$ & $3 \times 5$ & 0,10668 & $6 \times 1$ & 0,85905 & $8 \times 5$ & 0,59790 \\
\hline $1 \times 2$ & 0,20537 & $3 \times 6$, & 0,71596 & $6 \times 2$ & 0,22816 & $8 \times 6^{\prime}$ & 0,14424 \\
\hline $1 \times 3^{\prime}$ & $-0,31442$ & $3 \times 7$ & 0,15861 & $6 \times 3$ & 0,19255 & $8 \times 7$ & 0,31582 \\
\hline $1 \times 4^{\prime}$ & $-0,34055$ & $3 \times 8$ & 0,95249 & $6 \times 4$ & 0,17376 & $8 \times 8$ & 0,01625 \\
\hline $1 \times 5$ & $-0,45292$ & $4 \times 1{ }^{\prime}$ & 0,58496 & $6 \times 5^{\prime}$ & 0,79603 & $9 \times 11^{\prime}$ & 0,33840 \\
\hline $1 \times 6^{\prime}$ & 0,30689 & $4 \times 2$ & 1,44206 & $6 \times 6$ & 0,07615 & $9 \times 2$ & $-0,16796$ \\
\hline $1 \times 7$ & $-0,17645$ & $4 \times 3$ & $-0,11755$ & $6 \times 7^{\prime}$ & 0,22233 & $9 \times 3{ }^{\prime}$ & 0,27773 \\
\hline $1 \times 8$ & 0,35569 & $4 \times 4$ & 1,01769 & $6 \times 8$ & $-0,54964$ & $9 \times 4$ & 0,18276 \\
\hline $2 \times 1$ & $-0,10097$ & $4 \times 5$ & 0,20256 & $7 \times 1{ }^{\prime}$ & 0,76420 & $9 \times 5$ & 0,24312 \\
\hline $2 \times 2^{\prime}$ & 0,82052 & $4 \times 6^{\prime}$ & 0,31007 & $7 \times 2$ & $-1,46859$ & $9 \times 6^{\prime}$ & 0,04114 \\
\hline $2 \times 3$ & 0,25313 & $4 \times 7$ & $-0,14707$ & $7 \times 3$ & $-2,18158$ & $9 \times 7$ & 0,63615 \\
\hline $2 \times 4^{\prime}$ & 0,15950 & $4 \times 8$ & 0,34345 & $7 \times 4$ & $-0,22838$ & $9 \times 8$ & $-0,13516$ \\
\hline $2 \times 5$ & 0,32983 & $5 \times 1{ }^{\prime}$ & 0,01086 & $7 \times 5$ & 0,15839 & $10 \times 1^{\prime}$ & 0,62816 \\
\hline $2 \times 6^{\prime}$ & 1,16994 & $5 \times 2$ & $-0,76007$ & $7 \times 6$ & $-0,17556$ & $10 \times 2$ & 0,00557 \\
\hline $2 \times 7$ & 0,35935 & $5 \times 3$ & $-0,44974$ & $7 \times 7$ & $-0,56770$ & $10 \times 3^{\prime}$ & 0,20487 \\
\hline $2 \times 8$ & 0,58256 & $5 \times 4$ & 0,53026 & $7 \times 8$ & 0,39488 & $10 \times 4^{\prime}$ & 0,63310 \\
\hline $3 \times 11^{\prime}$ & $-0,01629$ & $5 \times 5$ & 0,32824 & $8 \times 11^{\prime}$ & 0,11933 & $10 \times 5$ & 0,62068 \\
\hline $3 \times 2$ & 0,95282 & $5 \times 6$ & 0,32865 & $8 \times 2$ & $-0,14074$ & $10 \times 6$ & 0,40785 \\
\hline $3 \times 3$ & 0,02825 & $5 \times 7$ & 0,68534 & $8 \times 3$ & 0,18919 & $10 \times 7$ & 0,89950 \\
\hline $3 \times 4^{\prime}$ & 0,08927 & $5 \times 8$ & 0,37849 & $8 \times 4^{\prime}$ & $-0,09605$ & $10 \times 8$ & $-1,06378$ \\
\hline
\end{tabular}

Com relação aos BLUP's das capacidades específicas de combinação, os cinco menores valores foram -2,18158, -1,46859, -1,06378, $-0,76007$ e $-0,56770$, correspondendo aos híbridos 7 x 3', 7 x 2', 10 x 8', 5 x 2’' e 7 x 7', respectivamente.

Os cinco híbridos superiores para capacidade específica de combinação foram: 4 x 2', 2 × 6', 4 x 4', 3 x 2', e 3 x 8', com valores de CEC: 1,44206, 1,16994, 1,01769, 0,95282 e 0,95249, respectivamente. Esses valores representam desvios observados de uma determinada combinação híbrida, em relação ao que seria esperado somente pelas 
capacidades gerais de combinação dos respectivos genitores. Na Figura 12, nota-se que não existe correlação ( $\mathrm{r}=-0,0640)$ entre as estimativas da capacidade específica de combinação (CEC) obtidas considerando o modelo fixo (BLUE's) e as predições obtidas considerando o modelo como misto (BLUP's).

Essas discrepâncias devem ter ocorrido também em função da incorporação da estrutura de variâncias e covariâncias genéticas no modelo misto. Apesar dos BLUP's serem considerados como uma melhor aproximação das CEC's paramétricas que os BLUE's (André, 1999), esses resultados podem causar dificuldades para os geneticistas quando forem recomendar os híbridos com maior capacidade de combinação.

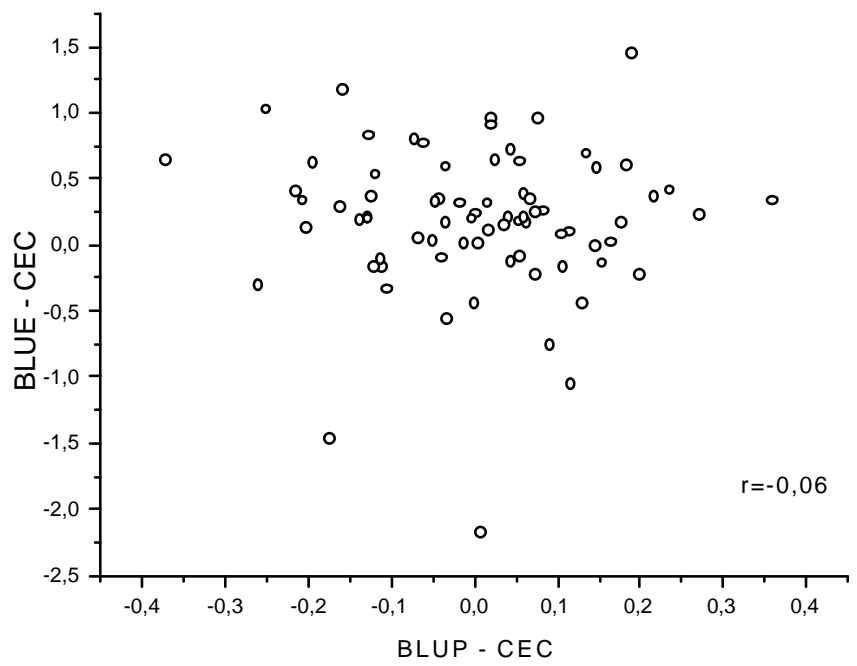

Figura 12- Diagrama de dispersão e coeficiente de correlação (r) associando os valores da capacidade específica de combinação (CEC) estimada considerando o modelo fixo (BLUE) e predita utilizando o modelo misto (BLUP).

4.7 BLUP's das produções dos híbridos interpopulacionais

Na Tabela 17 são apresentados os BLUP's dos 80 híbridos interpopulacionais avaliados, considerando o modelo misto. 
Tabela 17. BLUP's (desvios e produção de grãos) dos 80 híbridos interpopulacionais

\begin{tabular}{|c|c|c|c|c|c|c|c|c|}
\hline \multirow[b]{2}{*}{ Híbrido } & \multicolumn{2}{|c|}{ BLUP's } & \multirow[b]{2}{*}{ Híbrido } & \multicolumn{2}{|c|}{ BLUP's } & \multirow[b]{2}{*}{ Híbrido } & \multicolumn{2}{|c|}{ BLUP's } \\
\hline & Desvios & Produção & & Desvios & Produção & & Desvios & Produção \\
\hline $1 \times 1{ }^{\prime}$ & $-0,30130$ & 7,08411 & $4 \times 4{ }^{\prime}$ & 1,60307 & 8,98848 & $7 \times 7$ & $-0,83114$ & 6,55427 \\
\hline $1 \times 2{ }^{\prime}$ & 0,20535 & 7,59077 & $4 \times 5$ & 0,51010 & 7,89551 & $7 \times 8$, & 0,50643 & 7,89184 \\
\hline $1 \times 3{ }^{\prime}$ & $-0,56422$ & 6,82119 & $4 \times 6$ & 0,60870 & 7,99411 & $8 \times 11^{\prime}$ & 0,29628 & 7,68169 \\
\hline $1 \times 4^{\prime}$ & $-0,45062$ & 6,93479 & $4 \times 7$ & 0,03059 & 7,41600 & $8 \times 2$ & $-0,06261$ & 7,32280 \\
\hline $1 \times 5^{\prime}$ & $-0,56592$ & 6,81949 & $4 \times 8$ & 0,61963 & 8,00505 & $8 \times 3$, & 0,31032 & 7,69573 \\
\hline $1 \times 6^{\prime}$ & 0,39619 & 7,78160 & $5 \times 11^{\prime}$ & 0,24461 & 7,63002 & $8 \times 4^{\prime}$ & 0,01319 & 7,39860 \\
\hline $1 \times 7^{\prime}$ & $-0,24919$ & 7,13622 & $5 \times 2$ & $-0,86221$ & 6,52320 & $8 \times 5$ & 0,90365 & 8,28907 \\
\hline $1 \times 8^{\prime}$ & 0,42605 & 7,81146 & $5 \times 3$, & $-0,48989$ & 6,89552 & $8 \times 6$, & 0,37085 & 7,75626 \\
\hline $2 \times 1{ }^{\prime}$ & 0,15435 & 7,53977 & $5 \times 4$ & 0,87941 & 8,26483 & $8 \times 7$ & 0,54995 & 7,93536 \\
\hline $2 \times 2$ & 1,22375 & 8,60917 & $5 \times 5$ & 0,59580 & 7,98122 & $8 \times 8$ & 0,16590 & 7,55131 \\
\hline $2 \times 3$ & 0,43752 & 7,82294 & $5 \times 6$ & 0,57339 & 7,95880 & $9 \times 1{ }^{\prime}$ & 0,54612 & 7,93153 \\
\hline $2 \times 4^{\prime}$ & 0,41627 & 7,80168 & $5 \times 7$ & 1,01442 & 8,39983 & $9 \times 2$ & $-0,17276$ & 7,21265 \\
\hline $2 \times 5$ & 0,71093 & 8,09634 & $5 \times 8$ & 0,65449 & 8,03990 & $9 \times 3$, & 0,40627 & 7,79168 \\
\hline $2 \times 6$, & 1,73319 & 9,11861 & $6 \times 1$, & 1,24998 & 8,63540 & $9 \times 4$, & 0,30538 & 7,69079 \\
\hline $2 \times 7$ & 0,67438 & 8,05979 & $6 \times 2$ & 0,37471 & 7,76012 & $9 \times 5$, & 0,41750 & 7,80291 \\
\hline $2 \times 8^{\prime}$ & 0,96647 & 8,35189 & $6 \times 3^{\prime}$ & 0,45896 & 7,84437 & $9 \times 6$, & 0,18320 & 7,56862 \\
\hline $3 \times 11^{\prime}$ & 0,04669 & 7,43210 & $6 \times 4$ & 0,36349 & 7,74891 & $9 \times 7$ & 0,91969 & 8,30510 \\
\hline $3 \times 2$ & 1,29576 & 8,68117 & $6 \times 5$ & 1,21844 & 8,60385 & $9 \times 8$ & 0,19763 & 7,58304 \\
\hline $3 \times 3{ }^{\prime}$ & 0,16605 & 7,55146 & $6 \times 6$ & 0,30286 & 7,68827 & $10 \times 1{ }^{\prime}$ & 1,00748 & 8,39289 \\
\hline $3 \times 4$, & 0,10386 & 7,48927 & $6 \times 7$ & 0,50424 & 7,88965 & $10 \times 2$, & 0,16117 & 7,54659 \\
\hline $3 \times 5$ & 0,32574 & 7,71115 & $6 \times 8$ & $-0,52077$ & 6,86464 & $10 \times 3$, & 0,40245 & 7,78787 \\
\hline $3 \times 66^{\prime}$ & 1,19183 & 8,57724 & $7 \times 11^{\prime}$ & 0,86598 & 8,25139 & $10 \times 44^{\prime}$ & 1,03953 & 8,42494 \\
\hline $3 \times 7$ & 0,43334 & 7,81875 & $7 \times 2$ & $-1,98016$ & 5,40525 & $10 \times 5$, & 1,00977 & 8,39518 \\
\hline $3 \times 8$ & 1,50998 & 8,89539 & $7 \times 3$ & $-2,93786$ & 4,44755 & $10 \times 6$, & 0,78365 & 8,16907 \\
\hline $4 \times 11^{\prime}$ & 1,01453 & 8,39995 & $7 \times 4$ & $-0,25593$ & 7,12948 & $10 \times 7$ & 1,33273 & 8,71815 \\
\hline $4 \times 2{ }^{\prime}$ & 1,92749 & 9,31290 & $7 \times 5$ & 0,06518 & 7,45059 & $10 \times 8$, & $-1,15896$ & 6,22645 \\
\hline $4 \times 3^{\prime}$ & $-0,12455$ & 7,26086 & $7 \times 6$ & $-0,24957$ & 7,13584 & & & \\
\hline
\end{tabular}

Esses valores correspondem a soma dos efeitos aleatórios considerados no modelo. No caso, poderiam ser usados para classificar os 80 híbridos quanto à produção e indicar quais são os mais produtivos. Além disso, os BLUP's de cada híbrido avaliado formam a base para a predição de híbridos não observados, conforme será apresentado.

Para facilitar a interpretação desses valores pelos geneticistas, a cada um desses desvios foi acrescida a média geral ( $\mu$ do modelo), apenas para que os valores sejam expressos em $t \cdot h a^{-1}$, unidade comumente usada na prática (Tabela17).

Observando os valores dos BLUP's da produção, notamos que os cinco híbridos mais produtivos são 4 × 2', 2 x 6', 4 x 4', 3 x 8'e 10 x 7', o que concorda com a classificação obtida usando o modelo fixo (BLUE). No caso dos híbridos inferiores, os 
cinco piores classificados foram 7 × 3', 7 × 2', 10 × 8', 5 × 2' e 7 × 7', que foram iguais aos obtidos com o modelo fixo (item 4.2).

Essas coincidências são mais facilmente observadas na Figura 13, que mostra que a correlação entre os resultados usando modelo fixo ou misto foi muito alta $(r=0,99)$. Dessa forma, é possível concluir que, embora os valores da CGC das linhagens da população BR-106 e da CEC tenham baixa correlação entre as duas metodologias, a classificação dos híbridos mais produtivos sofre poucas alterações e não causa dificuldade na seleção.

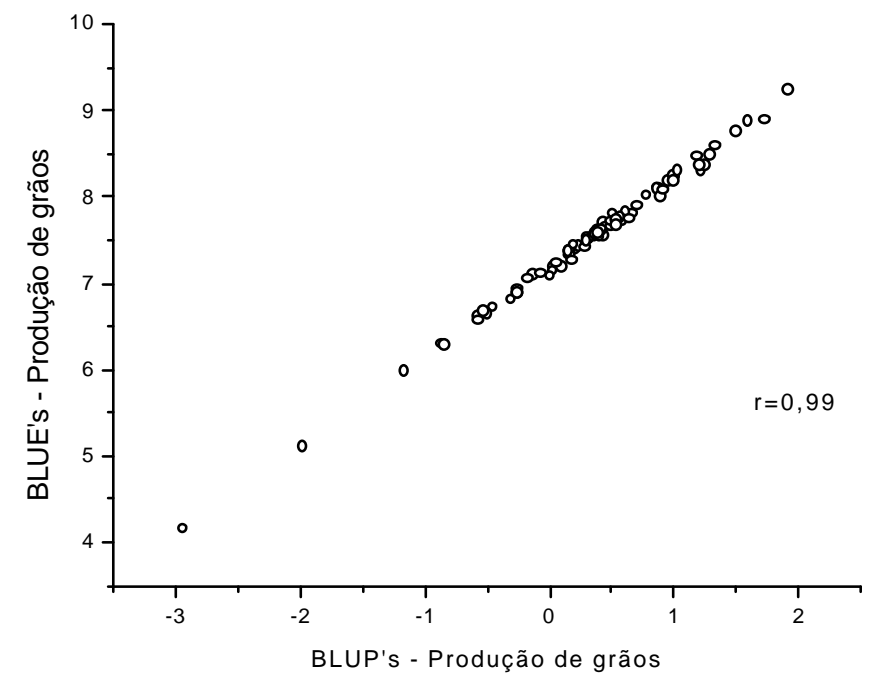

Figura 13.- Diagrama de dispersão e coeficiente de correlação (r) associando os valores do peso de grãos (PG) observado considerando o modelo aleatório (BLUP) e o peso de grãos a partir do modelo fixo (BLUE).

4.8 Predição de híbridos não observados

Conforme apresentado em material e métodos, foi simulada a retirada de cada um dos 80 híbridos do conjunto, sendo sua predição realizada a partir dos 79 remanescentes. Para tanto, usou-se a estrutura de variâncias e covariâncias genéticas 
com base no marcador molecular RFLP. Dessa forma, o procedimento foi repetido 80 vezes, e os resultados são apresentados na Tabela 18, para o BLUP da produção de grãos (acrescida da média) e para a capacidade específica de combinação.

Tabela 18. Valores preditos (BLUP's) a partir dos híbridos observados dos pesos de grãos $\left(y_{M F}\right)$ e da capacidade específica de combinação $\left(y_{D M}\right)$.

\begin{tabular}{|c|c|c|c|c|c|c|c|c|}
\hline Híbrido & $y_{M F}$ & $y_{D M}$ & Híbrido & $y_{M F}$ & $y_{D M}$ & Híbrido & $y_{M F}$ & $y_{D M}$ \\
\hline $1 \times 1{ }^{\prime}$ & 7,44610 & 0,04408 & $4 \times 4$ & 7,79622 & 0,17963 & $7 \times 7$ & 7,35141 & 0,03386 \\
\hline $1 \times 2$ & 7,12097 & $-0,15243$ & $4 \times 5$, & 8,00388 & 0,27930 & $7 \times 8$ & 6,46053 & $-0,68792$ \\
\hline $1 \times 3$, & 7,34770 & 0,08396 & $4 \times 6$ & 8,22414 & 0,47283 & $8 \times 11^{\prime}$ & 7,70975 & 0,14049 \\
\hline $1 \times 4$ & 7,36838 & $-0,01325$ & $4 \times 7$ & 8,02058 & 0,27894 & $8 \times 2{ }^{\prime}$ & 7,48539 & $-0,01692$ \\
\hline $1 \times 5$ & 7,50931 & 0,06996 & $4 \times 8$ & 8,16453 & 0,45607 & $8 \times 3^{\prime}$ & 7,19851 & $-0,18696$ \\
\hline $1 \times 6$ & 7,37123 & $-0,00483$ & $5 \times 11^{\prime}$ & 7,43076 & $-0,13951$ & $8 \times 4^{\prime}$ & 7,69160 & 0,12507 \\
\hline $1 \times 7$ & 7,47522 & 0,07955 & $5 \times 2$ & 7,78132 & 0,19894 & $8 \times 5$ & 7,57780 & 0,05891 \\
\hline $1 \times 8$ & 7,26500 & $-0,05801$ & $5 \times 3{ }^{\prime}$ & 7,45093 & $-0,02955$ & $8 \times 66^{\prime}$ & 7,67890 & 0,08549 \\
\hline $2 \times 11^{\prime}$ & 7,99842 & 0,24537 & $5 \times 4$ & 7,28119 & $-0,21279$ & $8 \times 7$ & 7,59651 & 0,05998 \\
\hline $2 \times 2$ & 7,82259 & 0,22080 & $5 \times 5$ & 7,63364 & 0,06460 & $8 \times 8^{\prime}$ & 7,69616 & 0,12588 \\
\hline $2 \times 3$ & 7,82882 & 0,25759 & $5 \times 6$ & 7,8913 & 0,27734 & $9 \times 11^{\prime}$ & 7,92506 & 0,33380 \\
\hline $2 \times 4$ & 8,10249 & 0,38684 & $5 \times 7$ & 7,60577 & 0,08526 & $9 \times 2{ }^{\prime}$ & 7,77467 & 0,23318 \\
\hline $2 \times 5$ & 7,85487 & 0,14656 & $5 \times 8$ & 7,54014 & $-0,00012$ & $9 \times 3{ }^{\prime}$ & 7,49926 & 0,06972 \\
\hline $2 \times 6$ & 7,95575 & 0,28553 & $6 \times 11^{\prime}$ & 7,9078 & 0,32015 & $9 \times 4^{\prime}$ & 7,95619 & 0,37112 \\
\hline $2 \times 7$ & 8,13601 & 0,41698 & $6 \times 2$ & 7,90408 & 0,33546 & $9 \times 5$ & 7,99816 & 0,38268 \\
\hline $2 \times 8$ & 7,99033 & 0,30851 & $6 \times 33^{\prime}$ & 7,04623 & $-0,39961$ & $9 \times 6$, & 7,98651 & 0,33967 \\
\hline $3 \times 11^{\prime}$ & 8,35635 & 0,63324 & $6 \times 4$ & 7,94389 & 0,31809 & $9 \times 7$ & 7,94717 & 0,38154 \\
\hline $3 \times 2$ & 8,14380 & 0,57402 & $6 \times 5$ & 7,75282 & 0,16226 & $9 \times 8$, & 6,98700 & $-0,56008$ \\
\hline $3 \times 3$ & 7,53350 & 0,01563 & $6 \times 6$ & 7,97016 & 0,28617 & $10 \times 1$ ' & 7,95513 & 0,31697 \\
\hline $3 \times 4$ & 8,48224 & 0,78568 & $6 \times 7$ & 7,71379 & 0,09195 & $10 \times 2$ & 7,76147 & 0,15895 \\
\hline $3 \times 5$ & 8,01941 & 0,32453 & $6 \times 8$ & 7,96289 & 0,26646 & $10 \times 3^{\prime}$ & 7,52329 & 0,01665 \\
\hline $3 \times 6$ & 7,89479 & 0,23415 & $7 \times 1{ }^{\prime}$ & 6,90385 & $-0,25142$ & $10 \times 4^{\prime}$ & 7,79759 & 0,18783 \\
\hline $3 \times 7$ & 7,82315 & 0,16167 & $7 \times 2$ & 7,07292 & $-0,19983$ & $10 \times 5$ & 7,95508 & 0,30608 \\
\hline $3 \times 8$ & 7,68599 & 0,10022 & $7 \times 3^{\prime}$ & 7,19705 & $-0,10294$ & $10 \times 6^{\prime}$ & 7,89964 & 0,21536 \\
\hline $4 \times 1$ & 7,92694 & 0,25188 & $7 \times 4$ & 6,46167 & $-0,73205$ & $10 \times 7^{\prime}$ & 8,03083 & 0,41057 \\
\hline $4 \times 2$ & 8,36494 & 0,77206 & $7 \times 5$ & 7,32689 & 0,06468 & $10 \times 8$ & 7,84559 & 0,08695 \\
\hline $4 \times 3$ & 8,02370 & 0,41990 & $7 \times 6$ & 7,03040 & $-0,25558$ & & & \\
\hline
\end{tabular}


Como todos os híbridos foram observados, esses valores podem ser comparados aos efetivamente realizados, permitindo que o procedimento seja avaliado.

A correlação entre os valores preditos a partir do conjunto e os valores observados, para produção de grãos e para capacidade específica de combinação, são apresentados nas Figuras 14 e 15.

Na Figura 14 podemos observar que há moderada correlação entre os valores dos BLUP's da produção de grãos e os valores preditos a partir dos híbridos observados $(\mathrm{r}=0,35)$, o que indica que essa metodologia tem capacidade em predizer a estimativa de valores não observados, porém com alguma imprecisão. A interpretação é análoga para a Figura 15, com moderado valor da correlação entre as CEC observadas e as preditas $(\mathrm{r}=0,30)$.

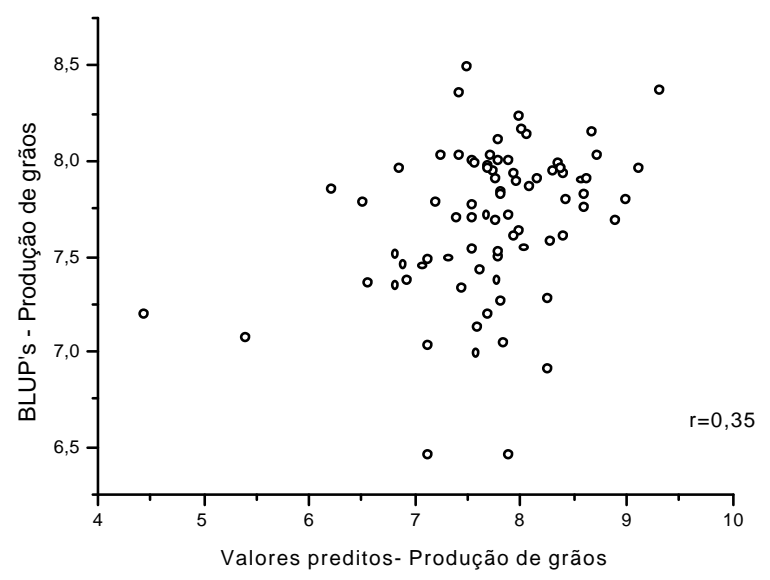

Figura 14- Diagrama de dispersão e coeficiente de correlação (r) associando os valores preditos pelos BLUP's para produção de grãos e valores efetivamente observados. 


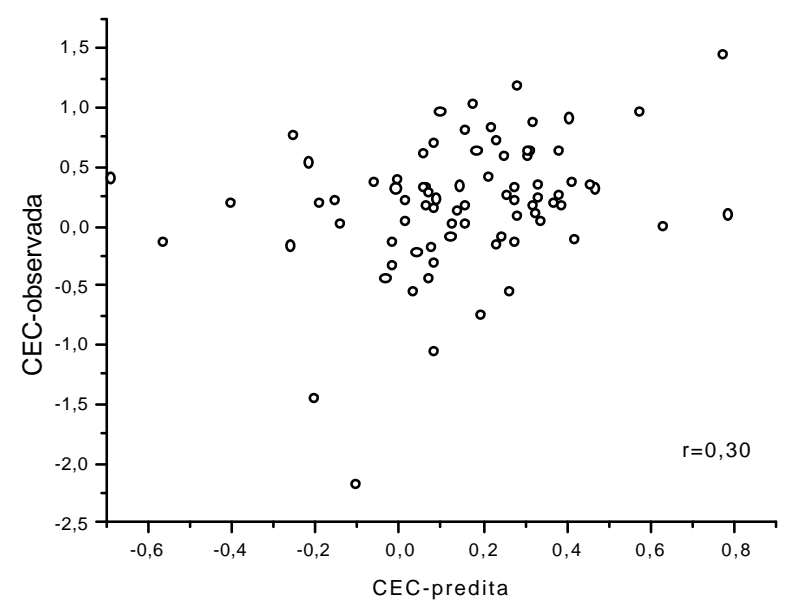

Figura 15- Diagrama de dispersão e coeficiente de correlação (r) associando os valores da capacidade específica de combinação (CEC) observada e predita utilizando o modelo misto.

Quando se calcula a correlação entre os valores preditos e os observados sem acrescentar as médias aos BLUP's (Figura 16), encontra-se uma correlação de magnitude moderada $(\mathrm{r}=0,35)$, que é a mesma encontrada na da Figura 15 , já que os valores preditos dos BLUP's apenas foram acrescidos de uma constante, reiterando que há alguma possibilidade de efetuar predição de híbridos não observados, porém com alguma imprecisão.

Quando se calcula a correlação entre os valores preditos com as médias obtidas com o modelo fixo (BLUE's) (Figura 17), nota-se também uma correlação positiva e de magnitude moderada $(\mathrm{r}=0,35)$. Nota-se então que há uma certa capacidade preditiva, embora sujeita a certas imprecisões. Isso fica ainda mais evidente quando nota-se que, dos 80 valores preditos, 54 deles $(67,5 \%)$ encontram-se dentro do intervalo de confiança (95\%) das médias do modelo fixo. Uma vez que as médias verdadeiras encontram-se dentro desses intervalos, é possível que a predição das médias tenha algum valor prático, embora necessitando de alguma cautela nas interpretações. 


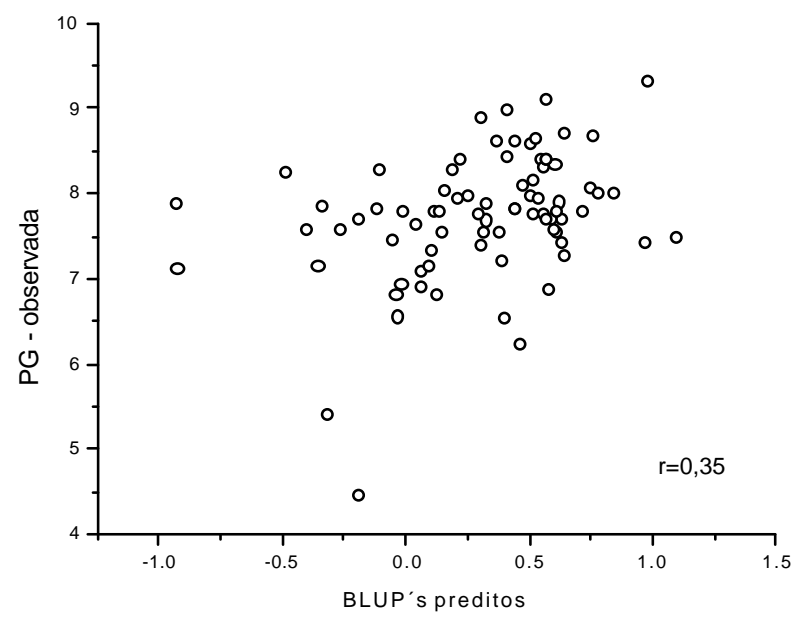

Figura 16- Diagrama de dispersão e coeficiente de correlação (r) associando os valores do peso de grãos (PG) preditos (BLUP’s) com o peso de grãos observado.

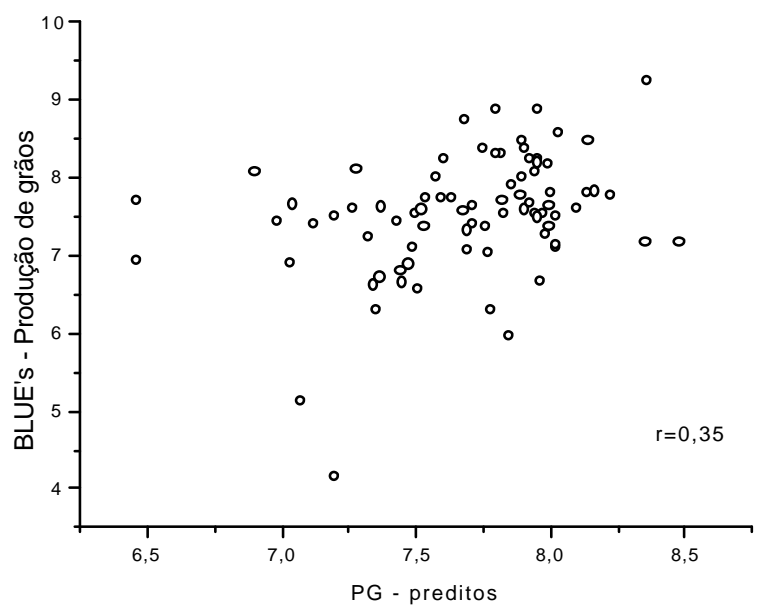

Figura 17- Diagrama de dispersão e coeficiente de correlação (r) associando os valores do peso de grãos obtido através do modelo fixo (BLUE's) e peso de grãos (PG) preditos. 
Da mesma forma que considerando os BLUP's das CEC's observadas e preditas, não foi encontrada correlação entre os valores preditos e os BLUE's (Figura 18), indicando o baixo valor preditivo desse método para a CEC.

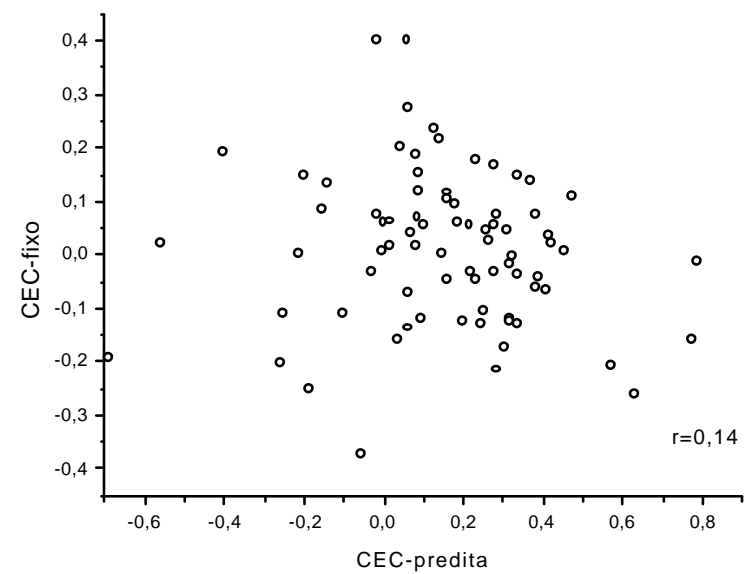

Figura 18- Diagrama de dispersão e coeficiente de correlação (r) associando os valores da capacidade específica de combinação (CEC) estimada considerando o modelo fixo e predita utilizando o modelo misto. 


\section{CONCLUSÕES}

a) $\mathrm{Na}$ comparação entre as análises dialélicas obtidas considerando o modelo fixo e o modelo misto, embora os valores da capacidade geral de combinação das linhagens da população BR-106 e da capacidade específica de combinação tenham baixa correlação entre as duas metodologias, a classificação dos híbridos mais produtivos sofre poucas alterações e não causa dificuldade na seleção.

b) Na eficiência do melhor preditor linear não viesado (BLUP) para predição de cruzamentos não realizados entre linhagens de milho, utilizando informações de marcadores moleculares para a estimação da matriz de parentesco, notou-se moderada correlação entre os valores dos BLUP's da produção de grãos e os valores preditos a partir dos híbridos observados ( $\mathrm{r}=0,35)$, o que indica que essa metodologia tem capacidade em predizer a estimativa de valores não observados, porém com alguma imprecisão. A interpretação é análoga entre as capacidades específicas de combinação observadas e as preditas ( $\mathrm{r}=0,30)$, com moderado valor da correlação. 


\section{REFERÊNCIAS BIBLIOGRÁFICAS}

ANDRÉ, C. M. G. Avaliação da melhor predição linear não tendenciosa (BLUP) associada ao uso de marcadores moleculares na análise dialélica. Lavras, 1999. 101p. Dissertação (Mestrado) - Universidade Federal de Lavras.

BARBOSA, A.M.M.; GERALDI, I.O.; BENCHIMOL, L.L.; GARCIA, A.A.F.; SOUZA JÚNIOR, C.L.; SOUZA, A.P. Relationship of intra and interpopulatio tropical maize single cross hybrib performance and genetic distances computed from AFLP and SSP markers. Euphytica (no prelo). 2002.

BENCHIMOL, L.L.; SOUZA JÚNIOR., C.L.; GARCIA, A.A.F.; KONO, P.M.S.;MANGOLIN, C.A.; BARBOSA, A.M.M.; COELHO, A.S.G.; SOUSA, A.P. Genetic diversity in tropical maize inbred lines: heterotic group assigment and hybrid performance determined by RFLP markers. Plant Breeding, v.119, p.491-496, 2000

BERNARDO, R. Estimation of coefficient of coancestry using molecular markers in maize. Theoretical and Applied Genetics v. 85:p. 1055-1062, 1993.

BERNARDO, R. Prediction of maize single-cross performance using RFLPs and information from related hybrids. Crop Science, v.34, n.1, p.20-25, jan.-fev., 1994.

BERNARDO, R. Genetic models for predicting maize performance in unbalanced yield trial data. Crop Science , v.35, n.1 , p.141-147, jan.-fev., 1995.

BERNARDO, R. Best linear unbiased prediction of maize single-cross performance. Crop Science , v.36, n.1 , p.50-56, jan.-fev., 1996a.

BERNARDO, R. Best linear unbiased prediction of maize single-cross performance given erroneus inbred relatioships. Crop Science, v.36, n.4 , p.862-866, aug.-sep., 1996b. 
BERNARDO, R. Best linear unbiased prediction of the performance of crosses between untested maize inbreds. Crop Science ,. v.36, n.4 , p.872-876, aug.-sep., 1996c.

BUENO FILHO, J. S. de S. Modelos mistos na predição de valores genéticos aditivos em testes de progênies florestais. Piracicaba, 1997. 118p. Tese (Doutorado)- Escola Superior de Agricultura “Luiz de Queiroz”, Universidade de São Paulo.

BUSSAB, W. DE ; MIAZAKI, E.S.; ANDRADE, D.F. Introdução à análise de agrupamentos. São Paulo: Associação Brasileira de Estatística, 1990. 105p.

COX , T.S.; KIANG, Y.T.; GORMAN, M.B.; RODGERS, D.M. Relationship between coefficient of parentage and genetic similarity índices in the soybean.. Crop Science v.25, p.529-532, 1985.

CRUZ, C. D.; REGAZZI, A. J. Modelos biométricos aplicados ao melhoramento genético. Viçosa, MG: UFV, Imprensa Universitária, 390p. 1994.

DUDLEY, J.W.; SAGHAI MAROOF, M.; RUFENER, G.K. Molecular markers and grouping of parents in maize breeding programs. Crop Science, v.31, n.2, p.718$723,1991$.

FERREIRA, M.E.; GRATTAPAGLIA, D. Introdução ao uso de marcadores moleculares em análise genética. Brasília: EMBRAPA, 1996. 220p.

GARCIA, A.A.F.; BENCHIMOL, L.L.; BARBOSA, A.M.M.; GERALDI, I.O.; SOUZA JÚNIOR, C.L.; SOUZA, A.P. de. A comparison of RAPDs, RFLPs, AFLPs, and SSRs for the estimation of genetic variation in tropical maize inbread lines. Euphytica (submetido). 2002.

GARDNER, C. O.; EBERHART, S. A. Analysis and interpretation of the variety cross diallel related population. Biometrics, v.22, n.3, p.439-452. 1966.

GRIFFING, B. Concept of general and specific combining ability in relation to diallel crossing sistems. Australian Journal of Biological Sciences, v.9, p.463-493. 1956.

HALLAUER, A.R.; MIRANDA FILHO, J.B. Quantitative genetics in maize breeding, local: Iowa State University Press, 468p., 1981.

HARTLEY, H.; RAO, J.N.K. Maximum-likelihood estimation for the mixed analysis of variance model. Biometrika, v.54, n.1, p.93-108, 1967. 
HAYMAN, B. I. The analysis of variance of diallel tables. Biometrics, v.10, n.2, p.235-244. 1954a.

HAYMAN, B. I. The theory and analysis of diallel crosses. Genetics, v.39, n.6, p.789809. 1954b.

HENDERSON, C. R. Estimation of variance and covariance components. Biometrics, v.17, n.1, p.226-252, jan.-mar., 1953.

HENDERSON, C. R. General flexibility of linear models for sire evaluation. Journal of Dairy Sciences, v.57, n.8, p.963-972, aug., 1974.

HENDERSON, C. R. Best linear unbiased estimation and prediction under a selection model. Biometrics, v.31, n.2, p.423-447, apr.-jun., 1975.

HENDERSON, C. R. Aplications of linear models in animal breeding. Ontario, University of Guelph, 462p. 1984

HENDERSON, C. R. Best Linear unbiased prediction of nonadditive genetic merits in noninbred populations. Journal of Animals Sciences v.60: p.111-117, 1985.

HENDERSON, C. R. Recent developments in variance and covariance estimation. Journal of Animals Sciences, v.63, p.208-216, 1986.

HENDERSON, C. R.; KEMPTHORNE, O.; SEARLE, S. R.; VON KROSIG, C. M. Estimation of enviorinmental and genetic trends from records subjecting to culling. Biometrics, v.15, n.1, p.192-218. 1959.

JEYARUBAN, M. G.; GIBSON, J. P.; GOWE, R. S. Comparision of index selection and best linear unbiased prediction for simulated layer poultry data. Poultry Science, v.74, n.7, p.1566-1576. 1995.

JOHNSON, R.A.; WICHERN, D.W. Applied multivariate statistical analysis. New Jersey: Prentice-Hall, 1988. 607p.

LANZA, L.L.B.; C.L. de SOUZA JÚNIOR.; L.M. OTTOBONI; M.L.C. VIEIRA; A.P. de SOUZA. Genetic distance of inbred lines and prediction of maize single-cross performace using RAPD markers. Theoretical and Applied Genetics, v.94, p.10231030, 1997.

LYNCH, M. Estimation of relatedness by DNA fingerpriting. Molecular Biology and Evolution, v.5 p.584-599. 1988. 
LIU, B.H. Statistical genomics: linkage, mapping and QTL analysis. Boca Raton, CRC Press, 1998. 611p.

LOPES, P. S.; MARTINS, E. N.; SILVA, M. A.; RAGGI, L. A. Métodos de resolução de sistemas de equações lineares. Viçosa, MG: UFV, Imprensa Uiversitária, 1993. $55 \mathrm{p}$.

MARTINS, E. N. Desenvolvimento de uma estratégia computacional para seleção de coelhos, usando a melhor predição linear não-viesada. Viçosa, 1995. 117p. Tese (Doutorado) - Universidade Federal de Viçosa.

MELCHINGER, A.E.; MESSMER, M.M.; LEE, M.; WOODMAN, W.L.; LAMKEY, K.R. Diversity and relationships among U.S. maize inbreds revealed by restriction fragment lenght polymorfisms. Crop Science, v.31, n.2, p.669-678, 1991.

MEYER, A.S. Comparação de coeficientes de similaridade usados em análises de agrupamento com dados de marcadores moleculares dominantes. Piracicaba, 2002. 106p. Dissertação (Mestrado) - Escola Superior de Agricultura "Luiz de Queiroz", Universidade de São Paulo.

PANTER, D. M.; ALLEN, F. L. Using best linear unbiased predictions to enhance breeding for yield in soybean: I Choosing Parents. Crop Science, v.35, n.2, p.397405, mar.-apr., 1995a.

PANTER, D. M.; ALLEN, F. L. Using best linear unbiased predictions to enhance breeding for yield in soybean: II Selection of superior crosses from a limited number of yield trials. Crop Science, v.35, n.2, p.405-410, mar.-apr., 1995 b.

PATTERSON, H.D.; THOMPSON, R. Recovery of inter-block information when block sizes are unequal. Biometrika, v.58,n.3 p.545-554, 1971.

PINTO, R.M.C. Comparações de marcadores moleculares e cruzamentos dialélicos na alocação de linhagens de milho em grupos heteróticos. Piracicaba, 2000. 147p. Tese (Doutorado) - Escola Superior de Agricultura "Luiz de Queiroz", Universidede de São Paulo.

PINTO, R.M.C.; GARCIA, A.A.F. Alocação de linhagens de milho derivadas das populações BR - 105 e BR - 106 em grupos heteróticos. Scientia Agricola, v.58, n.3, p.541-548, 2001. 
RAO,C.R. Estimation of heteroscedastic variances in linear models. Journal of American Statistical Association, v.65, n.1, p.161-172, 1970.

RAO, C.R. Estimation of variance and covariance components. Journal of Multivariate Analysis, v.1, n.1, p.257-275, 1971a.

RAO, C.R. Minimum variance quadratic unbiased estimation of variance components. J. Mult. Anal. , v.1, n.2, p.445-456, 1971 b.

SAS INSTITUTE SAS IML software: Usage and Reference, Version 6, Cary, 1989. $501 \mathrm{p}$.

SAS INSTITUTE. Statistical analysis system: release 6.08, ( software). Cary, 1992. $620 \mathrm{p}$.

SEARLE, S.; CASELA, G.; McCULLOCH, C. E. Variance components. Local: John Willey, 1992. 501p.

SNEATH, P.H.A.; SOKAL, R.R. Numeric taxonomy: the principles and practice of numerical classification. San Francisco: W.H. Freeman, 1973. 573p.

SORENSEN, D. A., KENNEDY, B. W. Estimation of response to selection using leastsquare and mixed model methodology. Journal of Animals Science, v.58, n.4, p.1097-1106, apr., 1984.

SOUZA JUNIOR, C.L.de. Componentes da variância genética e suas implicações no melhoramento vegetal. Piracicaba: FEALQ, 1989, 134p..

STAT SOFT STATISTICA. Quick Reference. Tulsa, 1999. 231p.

VAN VLECK, L. D. Variance of prediction error with mixed model equations when relationships are ignored. Theoretical and Applied Genetics v.85, p.545-549. 1993a.

VAN VLECK, L. D. Selection index na introduction to mixed model methods for genetic improvement of animals: the green book. Boca Raton: CRC Press 1993b. 481p. 
VERNEQUE, R. da S. Procedimentos numéricos e estimação de componentes de covariância em análise multivariada pelo método da máxima verossimilhança restrita - modelos mistos aplicados ao melhoramento animal. Piracicaba, 1994. 157p. Tese (Doutorado) - Escola Superior de Agricultura "Luiz de Queiroz", Universidade de São Paulo.

VENCOVSKY, R.; BARRIGA, P. Genética biométrica no fitomelhoramento. Ribeirão Preto: Sociedade Brasileira de genética. 1992. 486p.

WHITE, T.L.; HODGE, G.R. Predicting breeding values with applications in Forest tree improvement. , Dordrecht, Netherlands: Kluwer Academic, 1989. 367p.

WOOD, C. M.; CHRISTIAN, L. L.; ROTHSFIELD, M. F. Use of animal model in situations of limited subclass numbers and high degrees of relationships. Journal of Animals Sciences. v.69, n.6, p. 1420-1427, jun., 1991. 